This PDF is a selection from an out-of-print volume from the National Bureau of Economic Research

Volume Title: NBER Macroeconomics Annual 1986, Volume 1

Volume Author/Editor: Stanley Fischer, editor

Volume Publisher: MIT Press

Volume ISBN: 0-262-06105-8

Volume URL: http://www.nber.org/books/fisc86-1

Publication Date: 1986

Chapter Title: Why Is Japan's Saving Rate So Apparently High?

Chapter Author: Fumio Hayashi

Chapter URL: http://www.nber.org/chapters/c4247

Chapter pages in book: (p. $147-234)$ 
Fumio Hayashi

OSAKA UNIVERSITY, JAPAN

\section{Why Is Japan's Saving Rate So Apparently High?}

\section{Introduction}

The huge U.S. trade deficit with Japan, which totaled $\$ 50$ billion in 1985 and accounts for a thumping one-third of the total U.S. trade deficit, has worried policy makers and economists alike for some time. The widening trade gap has cost jobs in the United States, particularly in the manufacturing sector, providing ample ammunition for protectionists. The identity in the national income accounts states that the excess of saving over investment equals the trade surplus. The blame for Japan's large trade surplus with the United States must therefore fall on Japan's high saving or her slumping investment. The widespread sentiment that the Japanese save too much was even echoed in a 1985 speech by the U.S. Secretary of State. 'The sentiment has some empirical grounds. In 1984 the most widely mentioned saving rate-the rate of personal savingwas 16 percent for Japan, a full 10 percentage points higher than that in the United States.

The purpose of this article is to explore possible factors that contribute to Japan's high saving rate. That Japan's saving rate is high by international standards has been recognized in Japan for more than two decades, yet the reason for it is poorly understood: I quote the last sentence of a recent survey in the Japanese literature. "In any event . . . Japan's high personal saving rate remains a mystery to be resolved." 2 It is not that empirical investigations have been hampered by a scarcity of data. Although consistent time series in the Japanese national income accounts do not start until 1965, a large amount of micro data on house-

1. George Shultz's speech at Princeton University attracted widespread attention in the Japanese press.

2. Kurosaka and Hamada (1984). 
holds is available from various surveys that have been conducted regularly by the Japanese government. Perhaps the issue of Japan's high saving rate has not attracted enough of the empirical attention it deserves.

I will begin with very down-to-earth facts about aggregate saving in Japan and the United States. Those are contained in section 2, which tries to see if the perception of high savings in Japan has any empirical basis. It will be argued that some conceptual differences between U.S. and Japanese national accounting explain a substantial portion of the observed differences in the saving rates. Section 3 summarizes the explanations that have been offered in the literature. (I will examine them further in later sections.) The first theory of saving, to be taken up in section 4 , is the life-cycle hypothesis. After rejecting the life-cycle explanations, I turn in section 5 to micro data on households analyzed by age group to locate possible deviations from the life-cycle hypothesis of the actual Japanese saving behavior. It turns out that the cross-section age profile of saving in Japan appears to defy any simple life-cycle explanation, including an explanation based on the high housing-related saving by younger generations. Continuing the theme at the end of section 5 that bequests might be an important factor, section 6 digresses somewhat to calculate the aggregate flow of intergenerational transfers that can be inferred from the cross-section saving profiles. Other aspects of household behavior, including the impact of social security, relevant to assessing the importance of bequests will be analyzed in section 7 . Section 8 then takes up a separate issue, tax incentives for saving. The Japanese tax system does seem to be geared to promote saving. Taxes, however, are probably not the main factor behind the high saving rate, I argue, because saving does not appear to be responsive to interest rates.

\section{Facts about Japan's Aggregate Saving Rates}

\subsection{WHICH SAVING RATE?}

When comparing saving behavior between the two countries, we must first decide which saving rate to use. The choice of the saving rate has several dimensions. The first is the boundary of the relevant sector. Should we look at the household sector, the private sector, or the nation as a whole? The focus on personal (household) saving is unwarranted if undistributed profits (corporate saving) are fully reflected in the capital gains in stock prices that are recognized by households as part of income, or if corporations are just an accounting device for individuals to 
receive corporate tax treatment on their income. ${ }^{3}$ We should then look at private saving (the sum of personal and corporate saving). But even private saving is inappropriate if the private sector can see through the government veil and internalize the government budget constraint. The Ricardian Equivalence Thorem states that a government budget deficit is recognized by the private sector as a tax of the same amount because the public debt is just a signal of future increased taxes. The relevant notion of saving then is national saving (the sum of private and government saving). The question of the relevant boundary is one of the basic issues in economics yet to be resolved, and in this article we will not commit ourselves to any one particular saving rate. We should, however, bear in mind that the substance of the corporate sector in the Japanese National Accounts is somewhat different from corporate business in the U.S. National Income and Product Accounts. At one end of the corporate sector in the Japanese national accounts there are numerous token corporations that are essentially a disguised form of the household sector. At the other end lie most government enterprises (including the central bank as well as institutions that are not corporations in the legal sense).'

The second dimension in the choice of the saving rate is the definition of income. Should we include in income, and hence in saving, revaluation (capital gains/losses) of assets? Perhaps fully anticipated revaluation should be included, but that is difficult to identify. If revaluation is recognized as part of income, private saving is a more meaningful saving concept than personal saving.

The third dimension is the scope of assets, which is where the treatment of consumer durables is relevant. In principle, any commodity that is durable should be regarded as an object of saving. But measurement of the durability of commodities in general is a difficult task. ${ }^{5}$ The impor-

3. The top combined national and local personal tax rate is currently 88 percent in Japan. (However, we are told, there is a footnote in the personal tax code that reduces the top marginal rate to 75 percent.) People in high-income tax brackets can spread their income over their spouses and relatives by setting up a token corporation. By paying them high wages and by taking advantage of the more generous tax deductibility provisions in the corporate tax codes, they can understate corporate income and thus avoid double taxation at the corporate and personal levels. In 1983 there were about 1.8 million corporations in Japan. The largest 1.2 percent paid close to 70 percent of the total corporation tax. About 60 percent of all corporations reported negative taxable income.

4. The Japanese national accounts also divide the nation into private and public sectors. Government enterprises are included in the public sector. In retrospect, the focus on private sector might have been more appropriate. Fortunately, as we shall see later, the difference between the national and the private saving rates is small compared to the difference of the personal rate from the private and the national saving rates.

5. A good example is dental services. It is classified as services in the national accounts but 
tance of consumer durables will be touched upon when we compare the personal saving rate between the two countries in figure 2 . Depending on the stand one takes in each of the three dimensions, there can be multitudes of saving rates. Only a subset of the possible saving rates will be discussed in the text. The data appendix to this paper provides information necessary for calculating not only the saving rates discussed in the text but also several others that the reader might care to entertain.

\subsection{DATA COMPARABILITY}

Even after the choice of the saving rate is made, there is a measurement problem that makes international comparison tricky. There are (at least) four major conceptual differences between the United States and Japan in the compilation of national accounts.

1. A very surprising fact about the Japanese national income accounts is that depreciation is valued at historical costs. ${ }^{6}$ This means that personal saving is overstated during and after the inflationary period of the 1970s.? Remeinber that personal disposable income is a net concept-it excludes depreciation of household assets. Since personal saving is defined as personal disposable income minus consumption, it is net of depreciation. Corporate saving is severely overstated for the same reason. There must, however, be an official estimate of replacement-cost depreciation floating around within the Economic Planning Agency, the statistical mill of the Japanese national accounts data, since the stock of assets is valued at replacement costs in the capital accounts (balance sheets and stock-flow reconciliations) of the Japanese national accounts. Although the official estimate is neither published nor released, we can recover it fairly accurately from the numbers published in the Annual Reports on National Accounts. Detailed descriptions of our calculation procedure and our estimate of capital consumption adjustments (the excess of depreciation at replacement costs over depreciation at historical costs) are given in the data appendix. The basic idea is to separate out the revaluation component from the reconciliation accounts and identify the residual as capital consumption adjustments. The calculation can be done only for the post- 1969 period because the capital accounts start in 1970. Since investment goods prices were more or less stable until the

in essence it is a purchase of a durable good of good teeth. Hayashi (1985a) reports using Japanese data that food is almost the only commodity that exhibits no durability. Recreational expenditures are found to be more durable than consumer durables.

6. Inventory valuation adjustments are incorporated in the Japanese national accounting.

7. Investment goods prices more than doubled in the $1970 \mathrm{~s}$. 
first oil crisis of 1973-74, the capital consumption adjustment is not significant for that period. However, the size of the adjustment to private depreciable assets has increased rapidly since then, reaching as much as 30 percent of reported private saving in several recent years. (See table A2.)

2. Unlike most other countries (including Japan), the U.S. National Income and Product Accounts compiled by the Bureau of Economic Analysis (BEA) treat all types of government expenditure as consumption and fail to credit the government for the value of its tangible assets. The BEA definition of government saving is therefore the government's budget surplus, while government saving in the Japanese national accounts includes in addition the net increase in government tangible assets. This conceptual difference also means that even GNP and NNP are not directly comparable because the BEA definition does not include output service flows from government tangible assets.

To make matters even more complicated, the Japanese national accounts do not depreciate government depreciable assets except buildings. Thus reported depreciation of government assets is very substantially understated: it is valued at historical costs and it covers only buildings. In the data appendix we constructed time series on the stock of govermment depreciable assets by the perpetual inventory method and the associated depreciation at replacement costs, so that the saving rate series for which government assets are included as components of assets can be constructed for Japan. We decided not to construct such saving rate series for the United States. When we compare the Japanese to the U.S. data, we will recalculate the Japanese saving rates according to the BEA convention.

Readily available data sources on U.S. government capital accounts are Ruggles and Ruggles (1982) and Eisner (1985). ${ }^{8}$ The definition of government assets in Ruggles and Ruggles appears comparable to that in the Japanese national accounts, but the data do not extend beyond 1980 . The ratio to NNP of net government capital formation for the United States was roughly around 1 percent in the 1970s. Eisner's data encompass a much broader spectrum of assets and are thus not directly comparable. According to our estimate of government assets, the ratio to NNP of net government capital formation is about 3-5 percent (see table A5). Thus the exclusion of government capital alone makes a 2-4 percent difference to the BEA definition of the national saving rate. However, it is not clear that all government capital formation should be counted as saving. Government investment projects in Japan, often politically motivated

8. The estimates of government capital in Boskin, Robinson, and Roberts (1985) are for the federal government only. 
and not necessarily justifiable on economic grounds, may be viewed by the private sector as wasteful and incapable of yielding any useful service flows. It could even be argued that government capital is inherently unobservable, in which case it would be difficult to estimate the usefui (as viewed by the private sector) asset lives for municipal buildings, highways, dams, and tunnels.

3. The Japanese national accounts do not adjust after-tax income for "capital transfers" (wealth taxes and lump-sum transfers), so in the capital transactions (saving/investment) accounts the sum of saving, depreciation, and capital transfers equals the sum of investment in tangible and financial assets plus a statistical discrepancy. In what follows we include transfers as part of saving, which is consistent with the U.S. practice. For the household sector, capital transfers are negative because they are mainly bequest and gift taxes. In 1984 these are about 5 percent of reported personal saving. Almost all of the reduction of personal saving is transferred to corporate saving, making little difference to national saving.

4. (very minor) In the U.S. national accounts personal consumption and saving do not add up to personal disposable income because interest paid by households to business and to foreigners is included in personal disposable income. In what follows that interest component will be subtracted from U.S. personal disposable income."

All the saving rates to be presented are adjusted as described above. The data source for Japan is the 1986 Annual Report on National Accounts (which incorporates the latest benchmark revision). For the U.S. National Income and Product Accounts data we use the 1985 Economic Report of the President (which does not incorporate the January 1986 benchmark revision). It is supplemented by the Balance Sheets for the U.S. Economy, 1945-84 (compiled by the Board of Govemors of the Federal Reserve System) for balance sheet information, without addressing the question of compatibility between the two sets of U.S. data.

\subsection{A LOOK AT AGGREGATE SAVING RATES}

The most widely cited evidence in support of the notion that the Japanese like to save far more than Americans do is Japan's exceptionally high personal saving rate (the ratio of personal saving to personal disposable income). Is it still higher than the U.S. personal saving rate after the needed adjustments? Figure 1 shows the adjusted personal saving rate for Japan and the United States. Japan's personal saving rate in 1984 was

9. If the principal is reduced as a consumer repays loans, that reduction in principal is part of saving. 


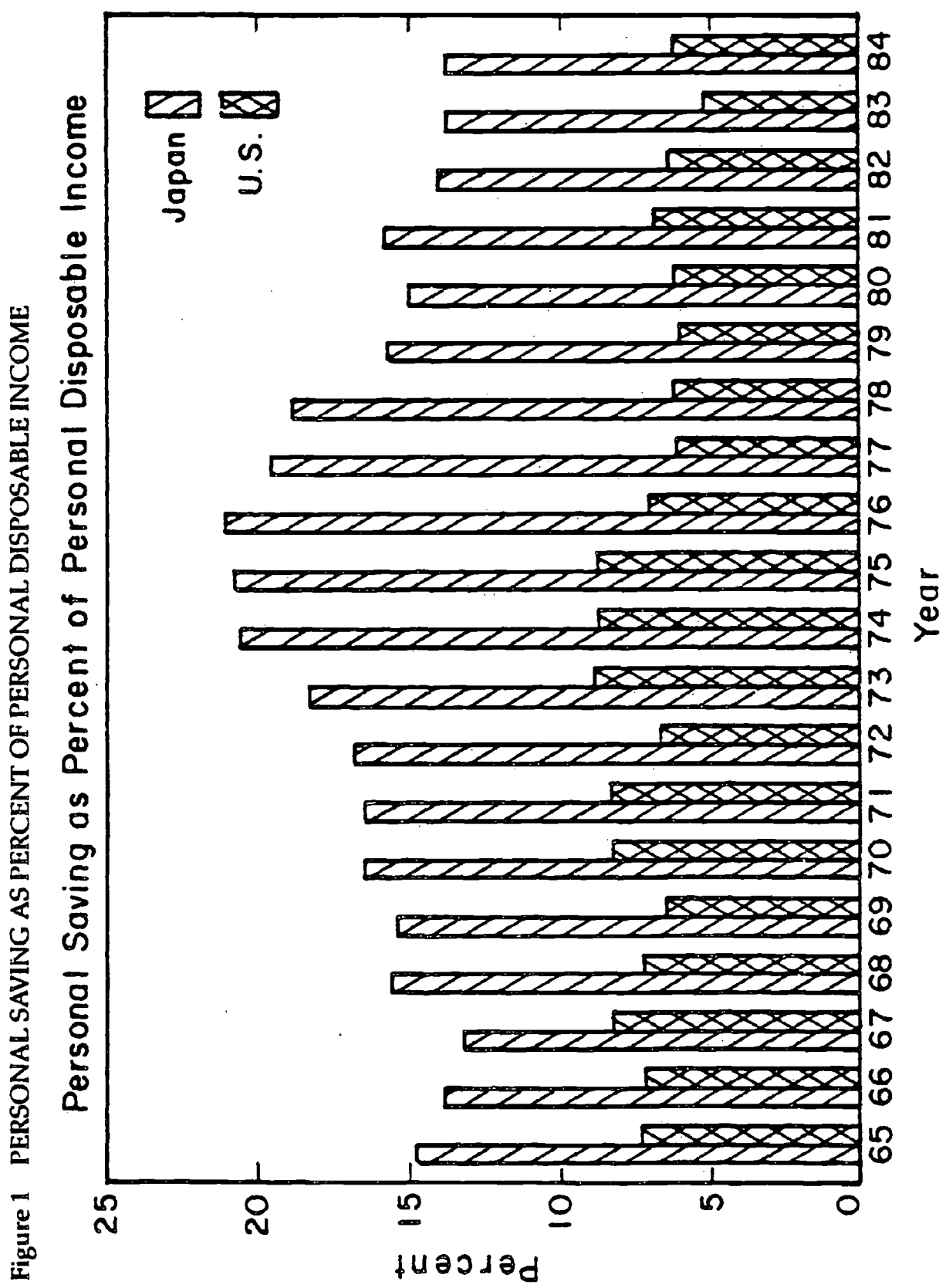




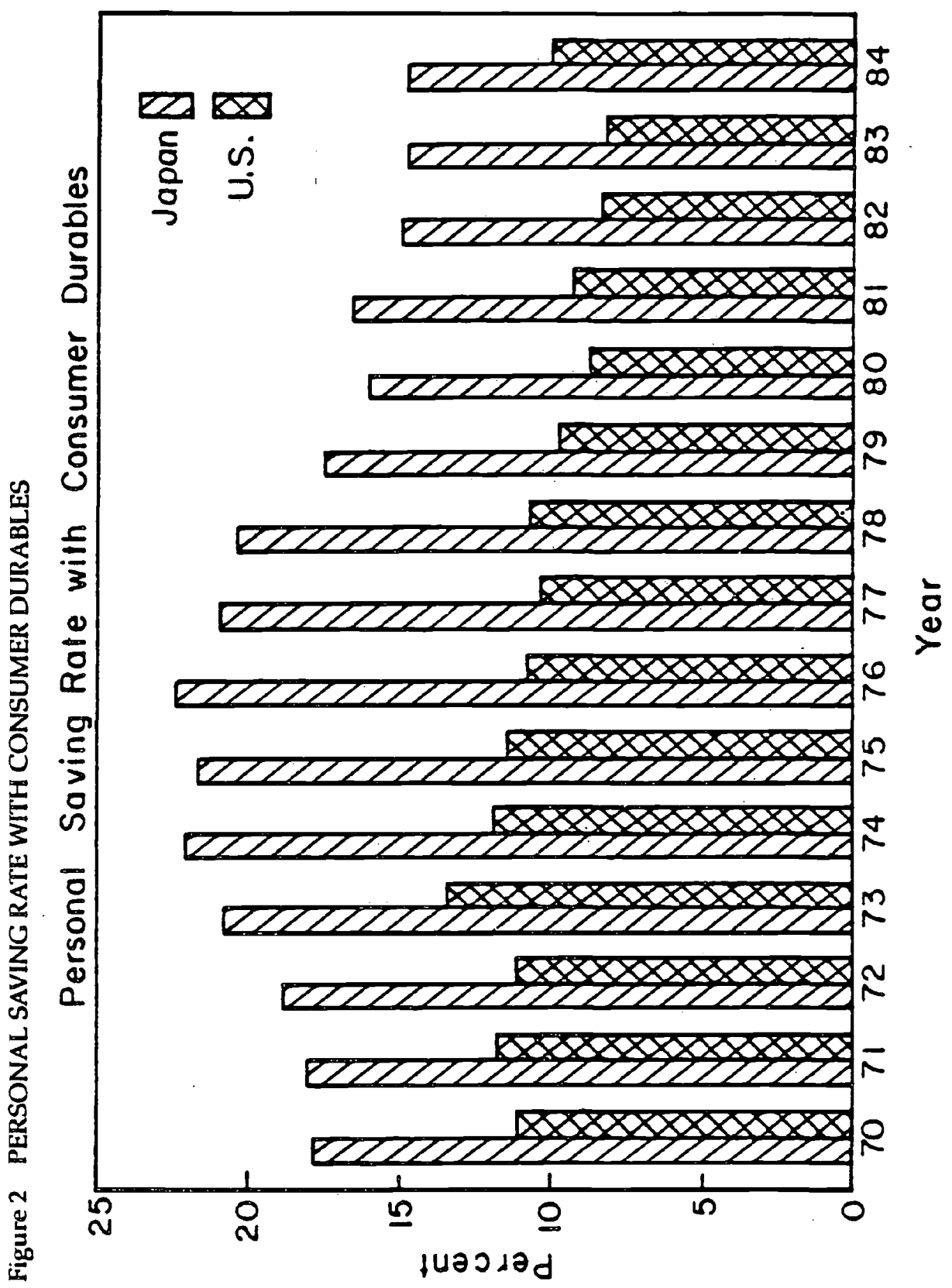


13.7 percent, about 2.5 percent lower than the personal saving rate reported in the national accounts and about 7 percent higher than the U.S. rate. The difference between the adjusted and the reported rate is mainly due to the capital consumption adjustments. The adjusted personal saving rate still exhibits the same basic pattern: it surges after the first oil crisis of 1973-74 to a peak in 1976 of 21.1 percent. The U.S. personal saving rate is stationary and has been fluctuating around 6 percent. It is clear that even after the needed adjustments Japan's personal saving rate is substantially higher.

Figure 2 shows the effect of including consumer durables as assets. Personal consumption thus excludes expenditures on durables but includes gross service flows from consumer durables. Personal disposable income now includes net service flows from consumer durables. A depreciation rate for consumer durables of 19 percent and a constant real rate of 4 percent are used for imputation. (See the data appendix for a detailed description of the imputation process.) It is well known in the United States that inclusion of consumer durables raises the personal saving rate by a few percent. That is not the case for Japan-the personal saving rate is little affected, thus narrowing the gap between the two countries for 1984 to about 4 percent.

Figure 3 (and column (1) of table 1) displays the private saving rate (the ratio of private saving to NNP, where Japan's NNP is calculated according to the BEA convention of not including net service flows from government assets). It does not include consumer durables. The U.S. rate is more or less stationary. For Japan the behavior of the private saving rate is very different from that of the personal rate. It declines during and after the first oil crisis and has a declining trend since 1970. This is brought about by the sharp drop in corporate saving depicted in figure 4 which shows the ratios of personal, corporate, and government saving to NNP for Japan. (The NNP here includes service flows from government capital.) The corporate saving rate declined by 9 percent points from 1973 to 1974 in the face of stagnant earnings, increased dividend payments, and increased depreciation at replacement costs.

The BEA definition of the national saving rate, which excludes government net capital formation from national saving, is compared in figure 5 for the two countries. It reveals a surprising fact about Japan-though one that is already apparent from a look at Japan's private saving rate in figure 3-that the national saving rate has declined quite sharply since 1970. In the late 1970 s there was only a small difference between the national saving rates in the two countries. If one takes the view that private, not national, saving is the relevant saving concept, a good part of the de- 


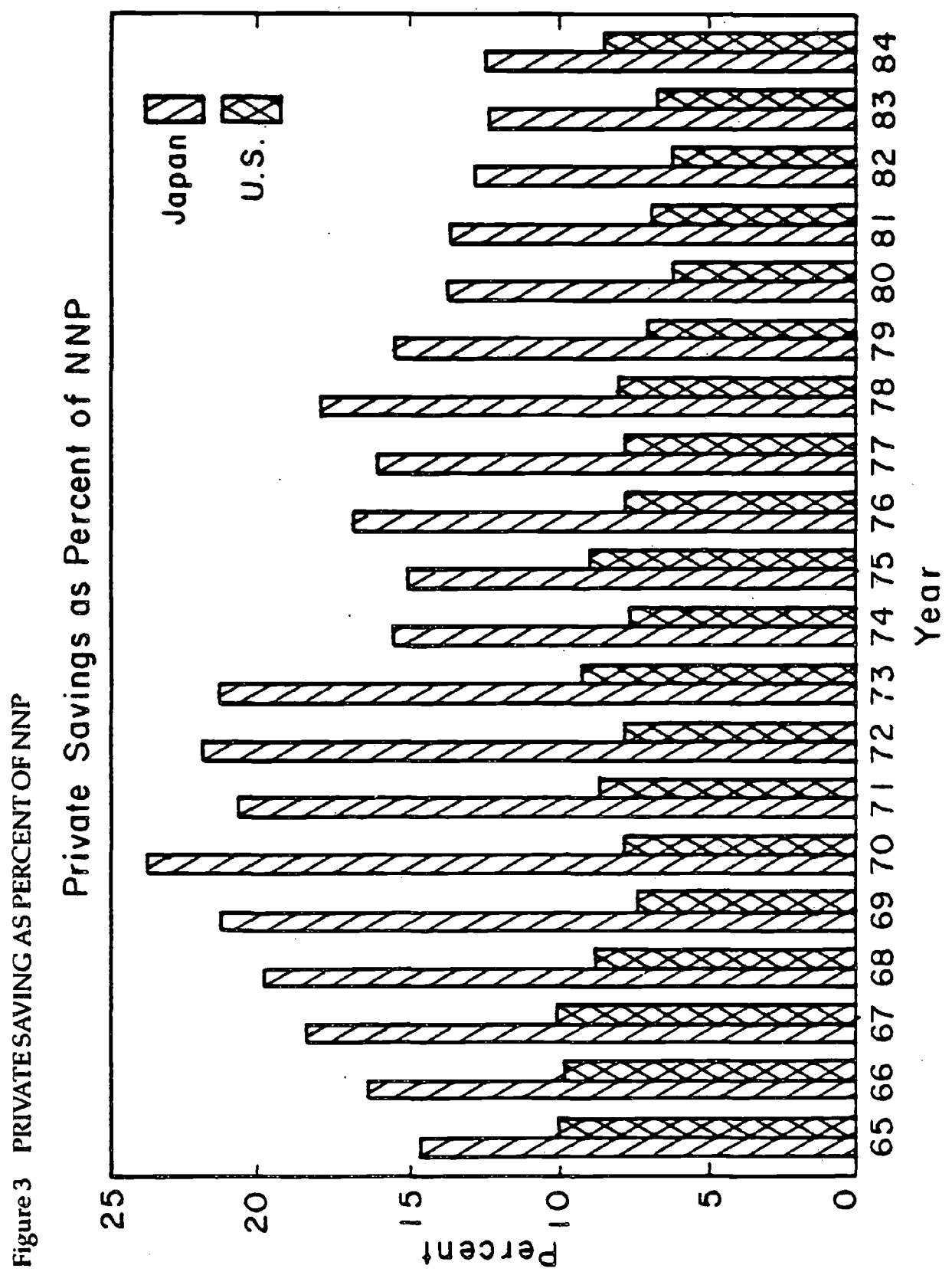




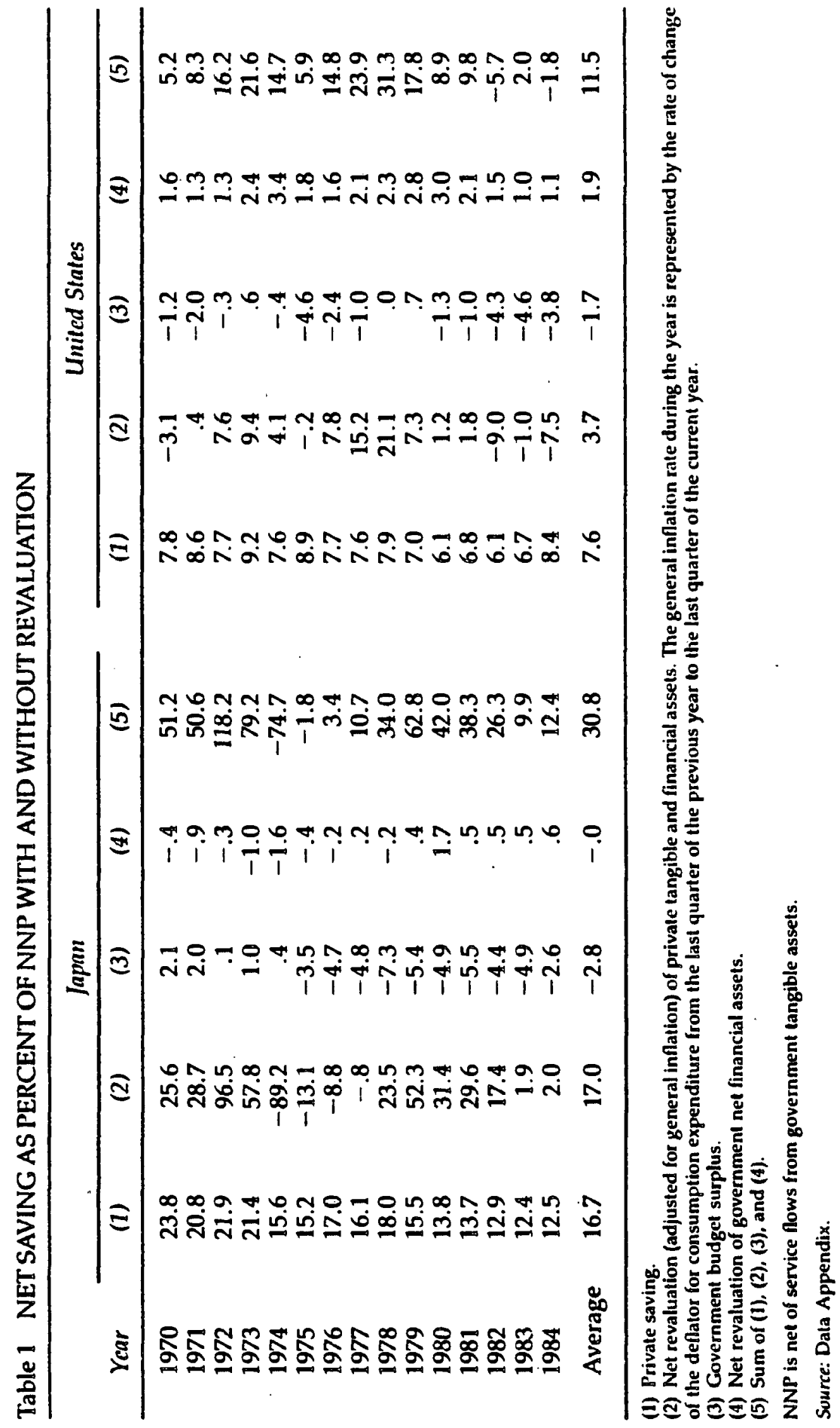




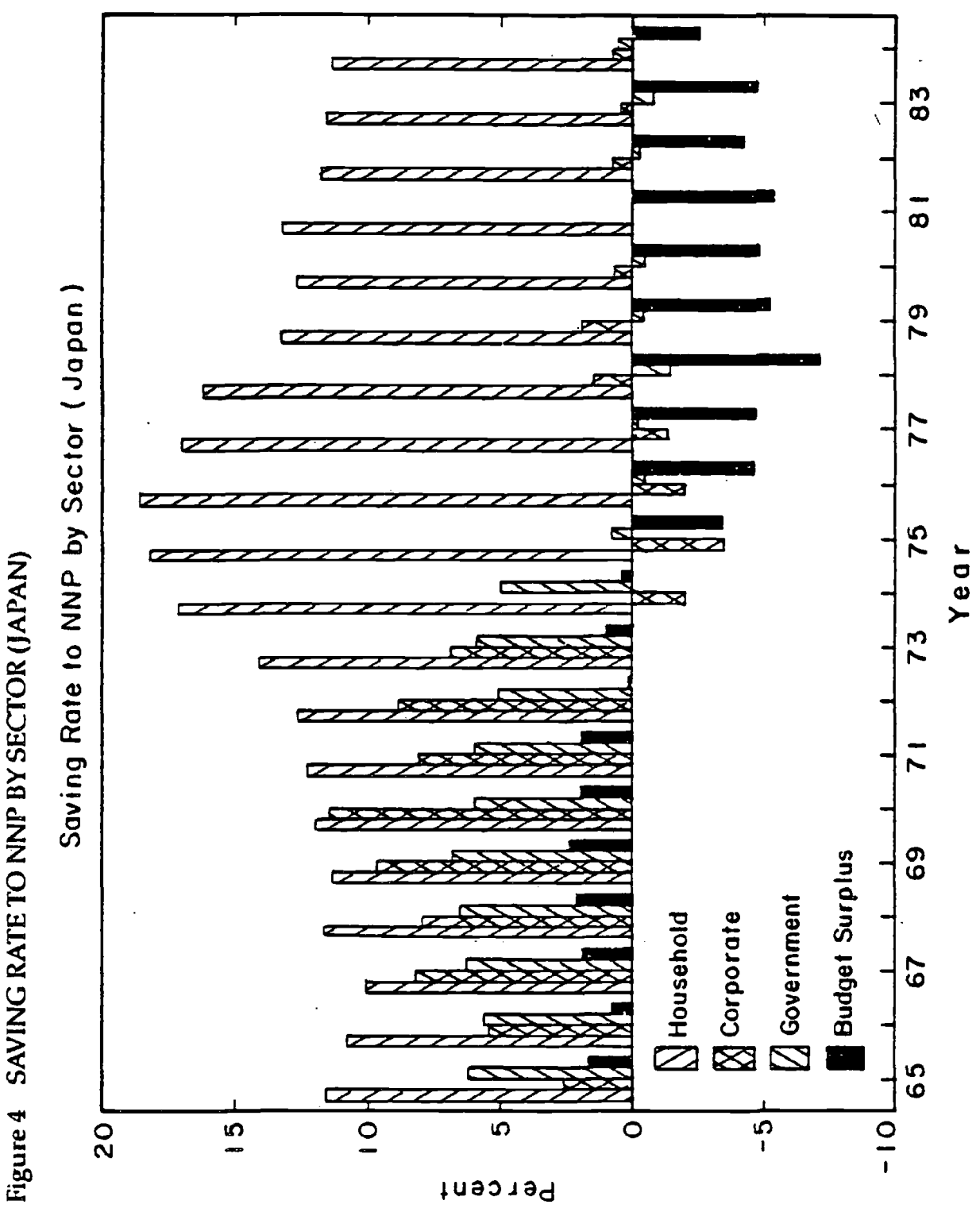




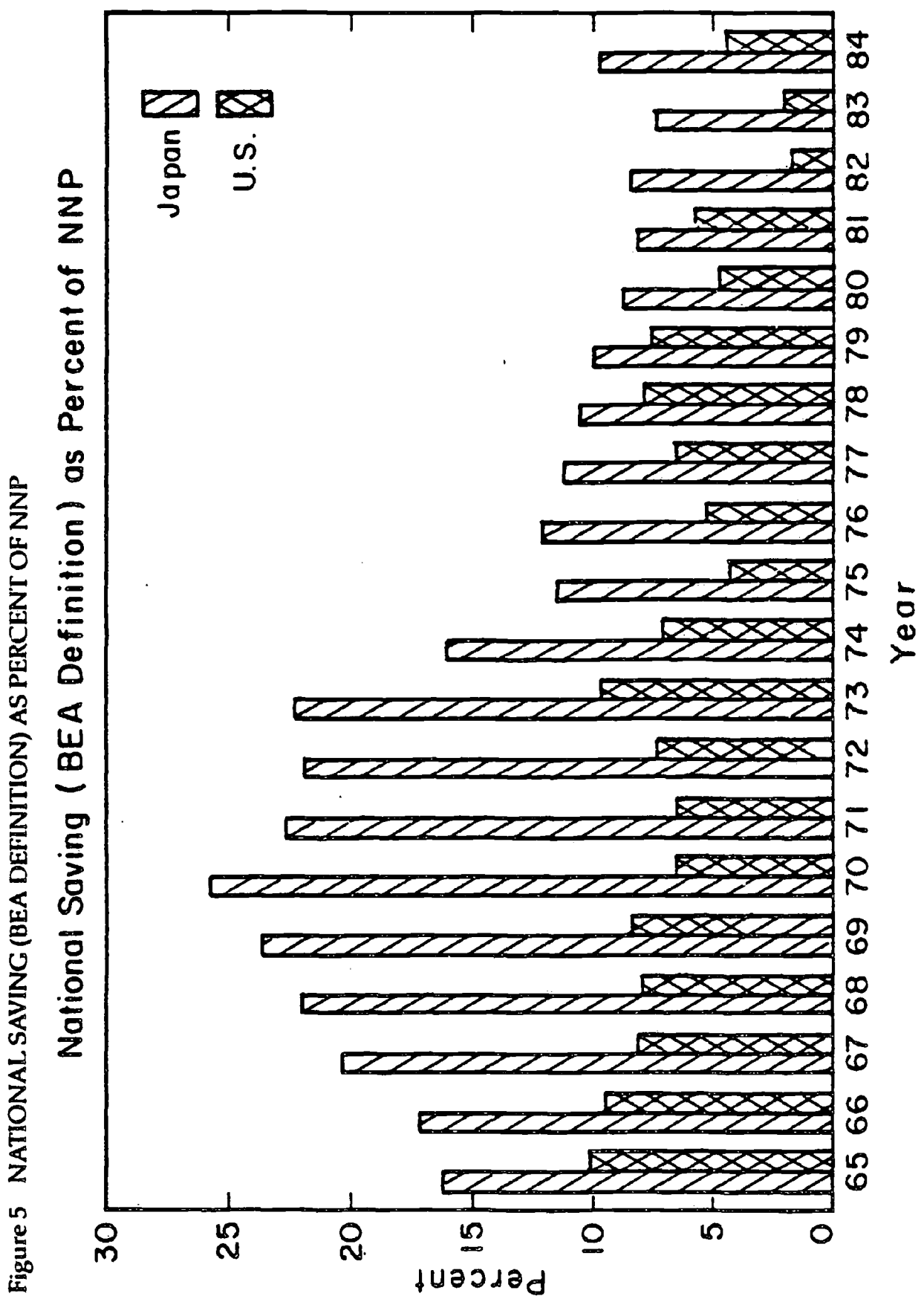


cline in Japan's national saving rate after 1974 is attributable to the large budget deficit shown in figure 4 . Government saving, the sum of the budget surplus and net government capital formation, has also been negative since 1976, while reported government saving (not shown) has been positive for all years.

The saving rates displayed thus far do not allow for revaluation or capital gains/losses. This leads to an understatement of saving by net debtors in an inflationary environment. Column (2) in table 1 reports net revaluations-that is, changes in nominal values minus changes in value attributable to changes in the general price level-on private (tangible and financial) assets as a percent of NNP for Japan and the United States. ${ }^{10}$ (To make the Japanese data comparable to the U.S. data, I use the BEA convention here.) The huge capital gains and losses for Japan come principally from the value of land, which is over 75 percent of the value of total private assets. Column (3) in table 1 reports the size of the budget surplus (government saving under the BEA definition). Net revaluation of government net financial assets is in column (4). It shows the wellknown fact that the U.S. government has gained substantially as a net debtor. Since the ratio of net government financial liabilities to NNP was low in Japan in the inflationary period of the 1970s (the ratio was minus 6 percent in 1974) and since the inflation rate has been low in the 1980 s when the ratio is rapidly rising (it was 30 percent in 1984), net revaluation for the Japanese government has been small. The total national saving rate inclusive of revaluation is reported in column (5). The number for Japan may be overstated, as it is strongly dependent on the estimate of land value in the national accounts. The value of land in the private sector (excluding government enterprises) at the end of 1984, according to the Japanese national accounts, is 858 trillion yen. It is substantially higher than the market value of the U.S. private land of $\$ 3.3$ trillion reported in the Federal Reserve's Balance Sheets.

\subsection{MEASUREMENT OF DEPRECIATION}

Coming back to the saving rates without revaluation, the impact of capital consumption adjustments for Japan is most dramatically shown in figure 6 where the ratio of national saving to NNP (with government

10. The household and corporate sectors are already consolidated in table 1, because the data on the market value of equity in the Japanese national accounts seem wholly unreliable. The value of Tobin's $q$ (the ratio of the value of tangible assets at replacement cost to the market value of net financial liabilities) for the corporate sector at the end of 1984 is 0.38 (see table A4). The reported market value of net financial liabilities is less than the reported value of inventory. This low estimate is due to the fact that stocks that are not publicly traded are valued in the Japanese national accounts at their "par" value (a mere 50 yen). By consolidating the household and corporate balance sheets, the prob- 


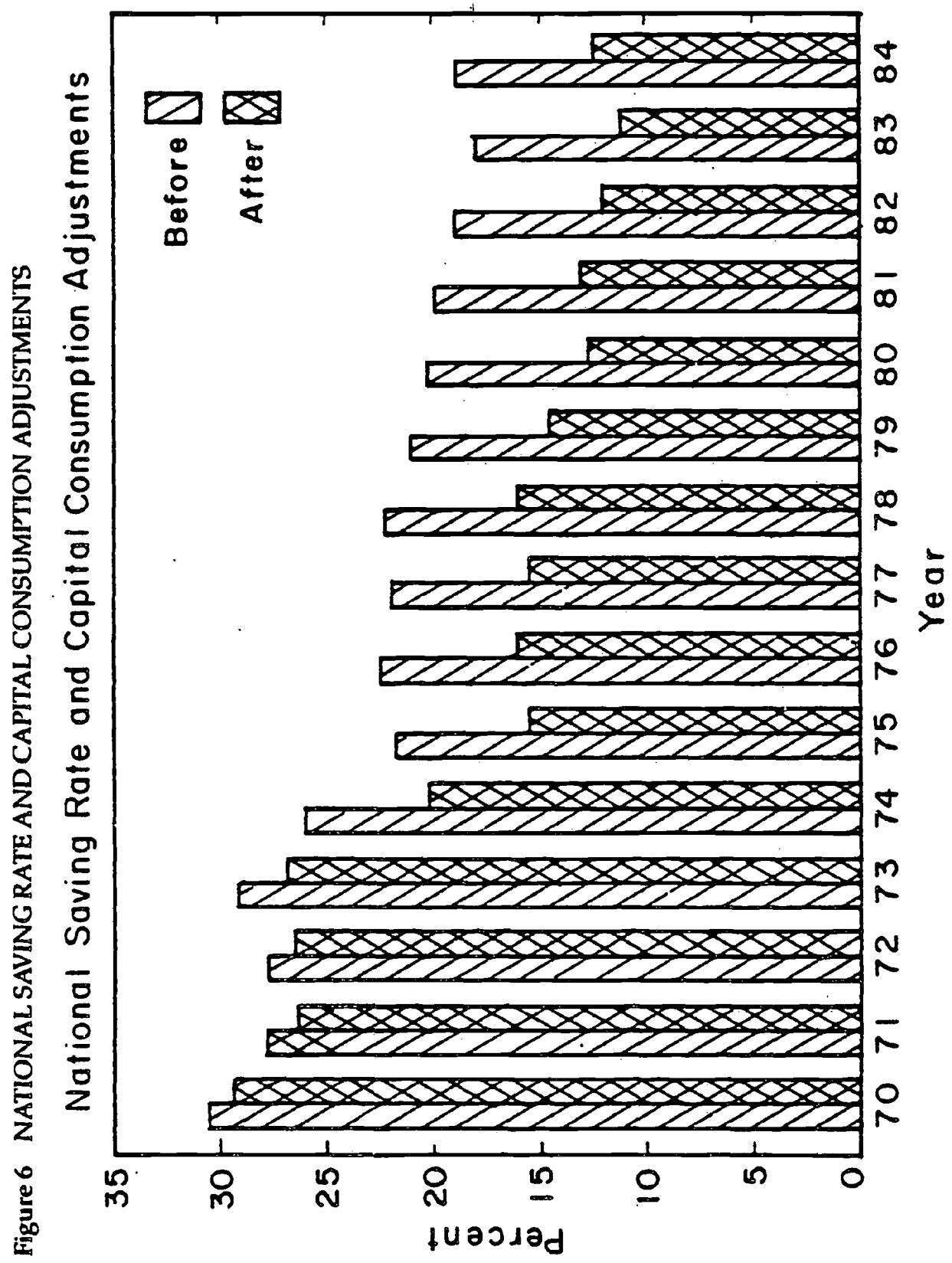


capital) is shown with and without capital consumption adjustments. In 1984 the difference was over 6 percentage points, about 60 percent of which came from capital consumption adjustments on private assets. Its sheer size makes us wonder if our capital consumption adjustments may have been carried too far. The capital accounts in the Japanese national accounts provide estimates of the value of the nation's depreciable assets for five asset types: housing, nonresidential buildings, other structures, transportation equipment, and machinery and other equipment. (The decomposition of depreciable assets by type is available only for the nation as a whole.) The implicit rate of physical depreciation can be calculated for each year and for each asset type as a ratio of depreciation to the year-beginning value of the asset. If the reported value of depreciation is used, the implicit depreciation rate shows a marked downward trend for each of the five asset types, a clear indication that depreciation at historical costs is inappropriate. The overall (asset-weighted) depreciation rate

Table 2 IMPLICIT PHYSICAL DEPRECIATION RATES

\begin{tabular}{lccccccc}
\hline Year & $(1)$ & $(2)$ & $(3)$ & $(4)$ & $(5)$ & $(6)$ & $(7)$ \\
\hline 1970 & 9.8 & 6.8 & 7.8 & 54.6 & 22.8 & 12.5 & 13.9 \\
& $(20.6)$ & $(24.9)$ & $(29.8)$ & $(4.2)$ & $(20.6)$ & & \\
& {$[39.5]$} & {$[40.0]$} & {$[36.5]$} & {$[69.4]$} & {$[64.6]$} & & \\
1975 & 8.8 & 6.4 & 6.3 & 31.2 & 20.5 & 7.3 & 11.0 \\
& $(23.5)$ & $(22.7)$ & $(30.0)$ & $(4.7)$ & $(19.1)$ & & \\
& {$[70.1]$} & {$[70.3]$} & {$[67.4]$} & {$[91.0]$} & {$[93.7]$} & & \\
1980 & 9.1 & 6.8 & 6.3 & 31.8 & 21.9 & 6.5 & 10.6 \\
& $(26.1)$ & $(21.9)$ & $(34.6)$ & $(3.4)$ & $(14.0)$ & & \\
& {$[95.7]$} & {$[94.0]$} & {$[93.3]$} & {$[96.6]$} & {$[95.7]$} & & \\
1984 & 8.5 & 6.4 & 5.7 & 30.6 & 21.4 & 6.6 & 9.9 \\
& $(23.5)$ & $(22.7)$ & $(37.1)$ & $(3.0)$ & $(13.6)$ & & \\
& {$[103.0]$} & {$[106.3]$} & {$[107.3]$} & {$[99.0]$} & {$[95.5]$} & & \\
Average & 9.0 & 6.5 & 6.6 & 33.5 & 21.6 & & \\
\hline
\end{tabular}

The first row for each year is the depreciation rate, the second row in parentheses is the value share in the nation's stock of depreciable assets, and the third row in brackets is the deflator for the asset at the begirning of the year. Depreciation rates and shares are in percents. Columns (1)-(5) represent the five asset types: (1) housing, (2) nonresidential buildings, (3) other structures, (4) transportation equipments, and (5) machines and other equipment. The depreciation rates reported in these five columns are net of our capital consumption adjustments. Column (6) shows the overall depreciation rate as reported in the Japanese national accounts. Column $(7)$ is the overall depreciation at replacement costs and govemment depreciable assets.

Source. Columns (1)-(6) from the 1985 Annual Report on National Accounts (with our capital consumption adjustment procedure applied to columns (1)-(5)). Column ( 7 ) from the Data Appendix. 
is reported for selected years in column (6) of table 2 . It clearly shows the impact of the 1973-74 inflation.

If our procedure for capital consumption adjustments, briefly described above, is applied to the five asset types to obtain depreciation at replacement cost, we obtain the implicit depreciation rates reported in columns (1)-(5) of table 2 along with the asset shares in parentheses and asset price indexes in brackets. The depreciation rate for other structures still shows a downward trend, but it may be attributable to the practice in the Japanese national accounts of not depreciating government assets other than buildings, which also distorts the asset shares in table 2 in favor of structures. (The depreciation for transportation equipment shows a steep downward trend for the first three or four years after 1970 . We suspect that the 1970 value of the stock of transportation equipment is understated.) The average depreciation rates in the last rows of columns (1)-(5) do not seem totally out of line with, for example, the average implicit BEA rates reported in Hulten and Wykoff (1981, table 2). ${ }^{11}$ Column ( 7 ) reports the overall depreciation rate implied by our capital consumption adjustment procedure and implicit in all the saving rates displayed so far. It is not strictly the asset-weighted average of columns (1) -(5) because it is based on our estimate of government capital where the depreciation rate is constrained to be 6.5 percent. It still shows a clear but mild downward trend. This downward trend, which is not apparent in asset-specific depreciation rates in columns (1)-(5), is attributable to the shift in asset value shares in favor of longer-lived assets. This shift in turn is due mainly to the large-scale change in relative asset prices that has continued since at least 1970, shown in brackets. It appears that our capital consumption adjustments are of reasonable magnitude.

We conclude that Japan's aggregate saving rate-however defined-is indeed higher than the comparable U.S. saving rate, but not by as much as is commonly thought. Not only is the level different, but the pattern over time of Japan's saving rate with large peaks and well-defined trends is in sharp contrast to the stationary U.S. pattern. We now turn to the question of how one might explain the difference.

lem of a correct valuation of equity can be avoided. This amounts to valuing corporate capital at replacement cost rather than at the market value observed in the financial markets.

11. The average depreciation rates obtained in table 2 are close to the asset life reported in the 1970 National Wealth Suroey. Almost all the available estimates of the capital stock in Japan are based on this periodic official sampling survey of the net capital stock of the nation. The survey has not been conducted since 1970 . 


\section{A Catalogue of Explanations}

That Japan's personal saving rate is one of the highest in the world was recognized in Japan as early as 1960 . A concise survey of the early literature can be found in Komiya (1966). The most recent and most exhaustive survey is Horioka (1985b) which lists over thirty possible factors that might contribute to Japan's high personal saving rate. A striking feature of the Japanese literature is its lack of a neoclassical perspective: the personal saving rate as a fraction of personal disposable income is the center of attention. Also, no attention has been given to the measurement of depreciation which, as we have seen, is very important. This section is a catalogue of explanations of Japan's high saving rate that have been offered in the literature and still enjoy some currency. They will be examined later.

High Income Growth An association of the income growth rate and the saving rate is consistent with several alternative hypotheses of saving. Both the life-cycle hypothesis (with finite lives) and the permanent income hypothesis (with infinite horizon) imply that a temporary rise in the growth rate raises the saving rate. For a permanent increase in the growth rate, the permanent income hypothesis would predict a lower saving rate (if the real interest rate is unchanged). In the life-cycle hypothesis, the initial impact of a permanent increase in the growth rate on the saving rate is probably to lower it, but the long-run impact is a higher saving rate, because older and dissaving generations are, in the long run, outweighed by younger and wealthier generations. The habit persistence hypothesis predicts a positive response of the saving rate to either a permanent or a temporary increase in productivity growth. For Japan the relation between the growth rate and the saving rate is far from clear-cut. Figure 7 contains the graph of the GNP growth rate and the personal saving rate. They tend to move in opposite directions, especially during and shortly after the first oil crisis. This is inconsistent with the habit persistence hypothesis. Comparing figure 7 with figures 3,5 , and 6 , we see that the private and the national saving rates are more closely related to GNP growth than the personal rate.

The correlation of the saving rate with the growth rate is actually difficult to interpret because there can be a reverse causation running from saving to growth through capital accumulation. However, the clear prediction by the life-cycle hypothesis that a secularly high growth rate should be associated with a high saving rate could explain Japan's higher saving rate. This will be examined in the next section where we perform a saving rate simulation based on the life-cycle hypothesis. 


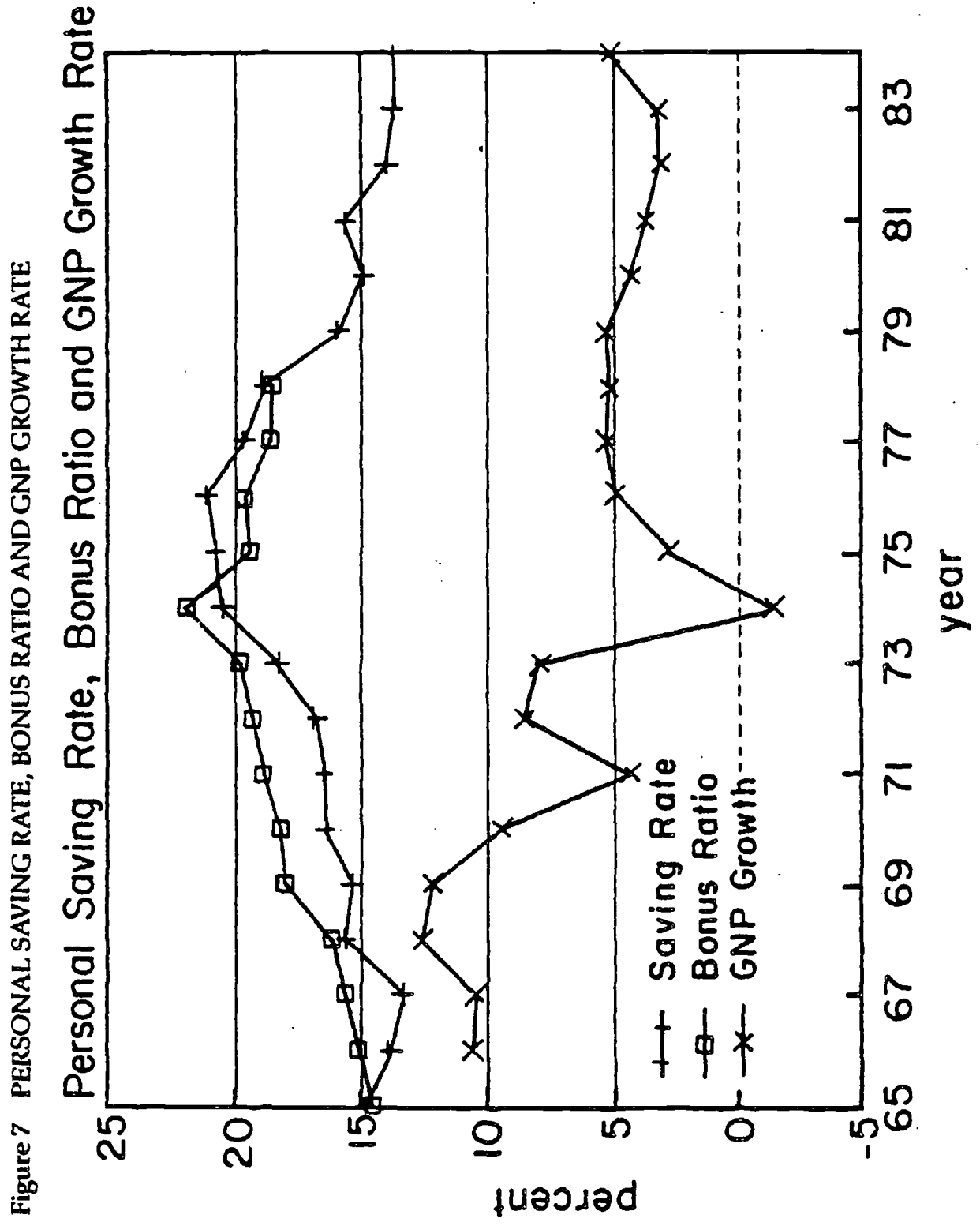


Demographics The proportion of the aged has historically been small in Japan. Also, the life expectancy of the Japanese is now the longest in the world. According to the life-cycle hypothesis, these demographic factors should raise the aggregate saving rate. This, too, will be taken up in the next section.

Underdeoeloped Social Security System The reasoning is that because Japan's social security system is underdeveloped people have strong needs to provide for old age by themselves. Japan's social security system has expanded rapidly since 1973. If the household sector is the relevant boundary, this explanation is inconsistent with the data because the personal saving rate actually increased after 1973 . The decline in the private saving rate could be explained by the enlarged social security system. The role of social security will be taken up in section 7 .

Bonus System In postwar Japan, workers receive large lump-sum payments twice a year. The bonus system originated in large firms and has spread to smaller ones. The amount depends on the profitability of the firm and the industry, although less so in recent years. The evidence that appears to support this bonus hypothesis is that the ratio of bonuses to regular employee compensation is closely related to the personal saving rate, as shown in figure 7 . (The data on the bonus ratio is from Ishikawa and Ueda (1984)). The bonus hypothesis was advanced very early and gained popularity when both the bonus ratio and the personal saving rate rose after 1973 and then slowly started to decline. This fact can, however, be explained straightforwardly by a neoclassical perspective that households can see through the corporate veil. Bonuses are a transfer of corporate saving to personal saving. If it is private saving that matters, the bonus ratio should raise personal saving. The bonus hypothesis cannot be an explanation of a high private saving rate. ${ }^{12}$

Tax Incentives The Japanese tax system encourages saving because income from capital is very lightly taxed at the personal level. This issue will be examined in section 8 .

High Housing/Land Prices As Horioka (1985a) reports: "The annual Public Opinion Survey on Saving . . . has consistently found that the five most important motives for household saving in Japan are those relating to illness/unexpected disaster, education and marriage, old age, land/

12. Those who receive bonuses and those who own the company's stock are often different. The neoclassical reasoning is that they are linked with operative bequest and gift motives. 
housing purchases, and peace of mind. Moreover, a comparison of the Japanese findings and those of a similar U.S. survey shows that the biggest differences are that the motives relating to education and marriage and land/housing purchases are far more important in Japan, while the old age motive is far more important in the United States." As documenied in Hayashi, Ito and Slemrod (1985, incomplete), the Japanese had to accumulate probably as much as 40 percent of the purchase price of a house while borrowing the remaining fraction from government loans (subsidized and therefore rationed) and from private financial institutions. The high down-payment ratio and the nondeductibility of interest expense for mortgage borrowing may contribute to high savings by younger generations. Like the first three explanations above, this explanation has life-cycle considerations in mind. Some evidence will be presented in section 5 to gauge the relevance of high housing prices.

Bequests This is probably the least popular explanation in Japan. There is a casual discussion in Shinohara (1983) to the effect that perhaps the Japanese may like to leave large bequests. Horioka (1984), after rejecting the standard life-cycle hypothesis on the basis of household survey data and various opinion surveys, also notes at the end the importance of bequests and their connection to the prevalence of the extended family in Japan. To anticipate, my conclusion is that bequests are probably the most important factor.

Cultural Factors If all else fails, there is a cultural explanation. The Japanese are simply different. They are more risk-averse and more patient. If this is true, the long-run implication is that Japan will absorb all the wealth in the world. I refuse to comment on this explanation. Horioka (1985b), after examining various studies that address the cultural issue, concludes that the available evidence is mixed.

\section{Explanation by the Life-cycle Hypothesis}

The life-cycle hypothesis of saving (Modigliani and Brumberg (1954), Ando and Modigliani (1963)) asserts that people's saving behavior is strongly dependent on their age. Aggregate saving can be explained by such demographic factors as age distribution and life expectancy, and such economic factors as the age profile of earnings. The hypothesis is attractive because it generates very specific empirical predictions about aggregate saving if data are available on demographics, the age profile of earnings, and asset holdings. This section performs a standard "steadystate" simulation of aggregate saving under the life-cycle hypothesis. 
The steady-state assumption allows us to impute rather than observe the age profile of asset holdings. The profile of asset holdings by the age of a person (rather than by the age of a head of household) is difficult to observe for the case of Japan because of the prevalence of the extended family.

Before getting into the actual simulation, however, a precise definition of the life-cycle hypothesis is in order. Its essential feature, eloquently expounded by Modigliani (1980), is that people are selfish and do not plan to leave bequests. It is this feature which, coupled with the singlepeaked age-earnings profile, leads to the prediction that people save to prepare for their retirement. An equally important, but often implicit, assumption is that people can purchase annuities and life insurance at actuarially fair prices. This means (see Barro and Friedman (1977)) there is only one constraint, the lifetime budget constraint, faced by the consumer:

$$
\begin{aligned}
& \sum_{i=0}^{\infty} q(t, v, i)(1+r)^{-i} c(t+i, v+i) \\
& =\sum_{i=0}^{\infty} q(t, v, i)(1+r)^{-i} w(t+i, v+i)+A(t, v),
\end{aligned}
$$

where $c(t, v), w(t, v)$ and $A(t, v)$ are, respectively, consumption, earnings and initial assets of a consumer aged $v$ at time $t . q(t, v, i)$ is the probability at time $t$ that the consumer of age $v$ survives into period $t+i . r$ is the real rate of retum. This version will be referred to as the strict life-cycle model.

In the absence of complete annuity markets, perfect insurance, as represented by equation (1), against living "too long" is not available. Involuntary bequests are the price to be paid to self-insure against longevity risk. But, as Kotlikoff and Spivak (1981) point out, longevity risk can be partially insured against if selfish parents "purchase," in exchange for bequests, a promise by children to provide assistance in old age. This class of models may be called the selfish life-cycle model with imperfect insurance.

Other models of saving include the strategic bequest model recently proposed by Burnheim, Shleifer, and Summers (1985) and the model of dynastic altruism of Barro (1974) and Becker (1981). In the latter model parents care about the welfare of their children and thus behave as if their planning horizon is infinite. In the former model, parents are not necessarily altruistic toward their children but use bequests to influence their children's action. I do not here intend to confront all these models with the Japanese data in a formal fashion. Since most of the explana- 
tions surveyed in the previous section have the strict life-cycle model in mind, the first order of business is to test it on Japanese data by a simulation technique.

If the strict life-cycle model is applicable to Japan, it should for realistic values of relevant parameter values generate the aggregate saving rate and the wealth-income ratio as observed in Japan. If we take seriously the numbers in the capital accounts of the Japanese national accounts, the ratio of national wealth (including. land) to (capital consumptionadjusted) NNP was about 4 in 1970 and about 6 in 1980 (see figure 8, where the inverse of the wealth-NNP ratio is plotted). The inputs to the simulation are: (i) the actual age-earnings profile $(w(t, v))$, (ii) the actual age distribution of the population, (iii) survival probabilities ( $q$ ), and (iv) a constant annual real rate of return of 4 percent. ${ }^{13}$ There are two parameters: the longitudinal consumption growth rate $(h)$ implicit in the ageconsumption profile and the secular productivity growth rate $(g)$. Thus the longitudinal consumption profile is assumed to be

$c(t+i, v+i)=c(t, v)(1+h)^{i}$,

and the prospective earnings profile is

$w(t+i, v+i)=w(t, v)(1+g)^{i}$.

The potential lifespan is represented by seven ten-year periods. The first period corresponds to ages $20-29$ and the last to $80-89$. Under the steady-state assumption that earnings and assets of a consumer of given age $v$ grow at a constant rate $g$ over time, we can calculate for each combination of $h$ and $g$ the aggregate saving rate and wealth-NNP ratio. ${ }^{14}$

13. The age-earnings profile is constructed as follows. Earnings by age are taken from the Basic Survey of Wage Structure (the Ministry of Labor). They are multiplied by the labor force participation rate taken from the Labor Ministry's Labor Force Survey. The earnings for 50-59-year-olds are then multiplied by a factor of 1.18 to accommodate the retirement payments. This factor is calculated from the age-earnings profile displayed in Table 3-24 of the 1985 White Paper on Japanese Economy (Economic Planning Agency). The survival probability for a cohort in year $t$ in a ten-year age group is calculated as the ratio of the number of the cohort in year $t+10$ to year $t$. For 1980, the survival probability is assumed to be the same as in 1970, except for cohorts over 60 . For the 60-69-year-olds it is set at $(1-0.01483) * 10$, where the number 0.01483 is the death probability for 60-69-year-olds reported in a Ministry of Health and Welfare publication. Similarly for the 70-79-year-olds the survival probability is set at (1 0.046045 )"*10.

14. Our "steady-state" simulation is a mere replication of the analysis in the second half of Tobin's (1967) paper but using japanese data on the age-earnings profile and the age distribution. To be more concrete, equations (1)-(3) are sufficient to give the prospective consumption and asset holdings profile $(c(t+i, v+i)$ and $A(t+i, v+i)$ for all $i)$ 
Table 3 displays the actual age profile of earnings for 1970 and 1980 with the sum normalized to unity, along with the U.S. earnings profile. ${ }^{15}$ For lack of data, earnings for those aged 70 and over are set at zero. The share of earnings for ages 20-29 has declined in Japan, mainly due to a decline in the labor force participation rate brought about by the increase in college enrollment. Eamings in Japan peak in the 50-59 age group because of lump-sum retirement payments. It may be argued that the high earnings by those aged 50-59 do not reflect productivity; rather the earnings are a return from implicit saving whose amount equals the excess of true productivity over actual earnings at younger ages. Without the retirement payment adjustment, earnings for groups $40-49$ and 5059 are nearly the same, but the steady-state calculations do not change

for those aged $v=0$ in period $t$ because for $v=0$ we have $A(t, 0)=0$ under the selfish life-cycle hypothesis. The steady-state assumption implies that assets held by $v$-year-olds in period $t+i$ are $(1+8)^{* *} i$ times as large as assets held by $v$-yearolds in period $t$. That is, $A(t+i, v) *\left((1+g)^{* *}(-i)\right)=A(t, v)$. This allows us to calculate prospective consumption and asset holdings profile for those who are $\nabla$ years old in period $t$ because their initial assets $A(t, v)$ can be set at $A(t+v, v) \cdot((1+$ $g)^{* *}(-v)$ ). The simulation is partial equilibrium in nature, because what is generated is the supply of saving, that is not guaranteed to equal changes in the capital stock. Also note that the aggregate output growth rate depends on the age distribution as well as on the productivity growth rate $g$. Our simulation does not take taxes and transfers into account. Proportional income taxes will not affect the saving and wealth-income ratios. We also do not consider social security, because assumptions about future expected benefits are inevitably arbitrary. If social security is actuarially fair, then it is clear that the size of the social security system does not affect our steady-state calculations of the national saving rate.

15. The U.S. earnings profile is taken from the 1972-73 Consumer Expenditure Survey. It would have been preferable to obtain it from labor market data.

Table 3 AGE DISTRIBUTION OF EARNINGS AND POPULATION

\begin{tabular}{lcccccccc}
\hline & \multicolumn{7}{c}{ Earnings } \\
\cline { 2 - 8 } & $20-29$ & $30-39$ & $40-49$ & $50-59$ & $60-69$ & $70-79$. & $80-89$ \\
\hline Japan, 1970 & 0.12 & 0.22 & 0.26 & 0.28 & 0.13 & 0.0 & 0.0 \\
$\begin{array}{l}\text { Japan, 1980 } \\
\text { United States, } \\
\text { 1972-73 }\end{array}$ & 0.09 & 0.22 & 0.28 & 0.29 & 0.13 & 0.0 & 0.0 \\
& 0.17 & 0.24 & 0.26 & 0.22 & 0.11 & 0.0 & 0.0 \\
& \multicolumn{7}{c}{ Population (Fraction of total population) } \\
\cline { 2 - 9 } & $20-29$ & $30-39$ & $40-49$ & $50-59$ & $60-69$ & $70-79$ & $80-89$ \\
\hline Japan, 1970 & 0.19 & 0.16 & 0.11 & 0.09 & 0.06 & 0.03 & 0.01 \\
Japan, 1980 & 0.14 & 0.17 & 0.14 & 0.11 & 0.07 & 0.04 & 0.01 \\
\hline
\end{tabular}

See footnote 13 for the source of the Japanese data. The U.S. earnings profile is obtained from the Consumer Expenditure Survey, 1972-73. Bureau of Labor Statistics Bulletins 1992 and 1997. Table 3. 
Table 4 STEADY-STATE SIMULATION RESULTS

Panel A. Japanese Earnings Profile, Japanese Age Distribution of Population

\begin{tabular}{|c|c|c|c|c|c|c|}
\hline \multirow{3}{*}{$\begin{array}{l}\quad 1970 \\
\text { Annual } \\
\text { consumption } \\
\text { growth }(h)\end{array}$} & \multicolumn{3}{|c|}{ Saving rate $(\%)$} & \multicolumn{3}{|c|}{ Wealth-income ratio } \\
\hline & \multicolumn{3}{|c|}{ Annual productivity growth } & \multicolumn{3}{|c|}{ Annual productivity growth } \\
\hline & $0 \%$ & $5 \%$ & $10 \%$ & $0 \%$ & $5 \%$ & $10 \%$ \\
\hline $\begin{array}{r}=0 \% \\
5 \% \\
10 \%\end{array}$ & $\begin{array}{r}3 \\
32 \\
52\end{array}$ & $\begin{array}{r}-81 \\
28 \\
66\end{array}$ & $\begin{array}{r}-680 \\
-87 \\
53\end{array}$ & $\begin{array}{r}-0.5 \\
6.6 \\
10.0\end{array}$ & $\begin{array}{r}-7.8 \\
1.2 \\
5.0\end{array}$ & $\begin{array}{r}-30.4 \\
-4.1 \\
1.9\end{array}$ \\
\hline 1980 & \multicolumn{3}{|c|}{ Saving rate $(\%)$} & \multicolumn{3}{|c|}{ Wealth-income ratio } \\
\hline \multirow{2}{*}{$\begin{array}{l}\text { Annual } \\
\text { consumption } \\
\text { growth }(h)\end{array}$} & \multicolumn{3}{|c|}{ Annual productivity growth } & \multicolumn{3}{|c|}{ Annual productivity growth } \\
\hline & $0 \%$ & $5 \%$ & $10 \%$ & $0 \%$ & $5 \%$ & $10 \%$ \\
\hline $\begin{array}{r}h=0 \% \\
5 \% \\
10 \%\end{array}$ & $\begin{array}{r}8 \\
33 \\
52\end{array}$ & $\begin{array}{r}-64 \\
27 \\
68\end{array}$ & $\begin{array}{r}-596 \\
57 \\
60\end{array}$ & $\begin{array}{r}-0.9 \\
7.0 \\
10.5\end{array}$ & $\begin{array}{r}-8.9 \\
1.5 \\
5.5\end{array}$ & $\begin{array}{r}-35.1 \\
-3.9 \\
2.3\end{array}$ \\
\hline
\end{tabular}

Panel B. U.S. Eomings Profile, Japanese Age Distribution of Population

\begin{tabular}{|c|c|c|c|c|c|c|}
\hline \multirow{3}{*}{$\begin{array}{l}\quad 1970 \\
\text { Annual } \\
\text { consumption } \\
\text { growth }(h)\end{array}$} & \multicolumn{3}{|c|}{ Saving rate $(\%)$} & \multicolumn{3}{|c|}{ Wealth-income ratio } \\
\hline & \multicolumn{3}{|c|}{ Annual productivity growth } & \multicolumn{3}{|c|}{ Annual productivity growth } \\
\hline & $0 \%$ & $5 \%$ & $10 \%$ & $0 \%$ & $5 \%$ & $10 \%$ \\
\hline $\begin{array}{r}h=0 \% \\
5 \% \\
10 \%\end{array}$ & $\begin{array}{r}7 \\
34 \\
54\end{array}$ & $\begin{array}{r}-50 \\
30 \\
70\end{array}$ & $\begin{array}{c}-400 \\
-47 \\
61\end{array}$ & $\begin{array}{r}1.1 \\
7.5 \\
10.6\end{array}$ & $\begin{array}{r}-5.0 \\
2.2 \\
5.4\end{array}$ & $\begin{array}{r}-17.9 \\
-2.3 \\
2.3\end{array}$ \\
\hline 1980 & \multicolumn{3}{|c|}{ Saving rate $(\%)$} & \multicolumn{3}{|c|}{ Wealth-income ratio } \\
\hline \multirow{2}{*}{$\begin{array}{l}\text { Annual } \\
\text { consumption } \\
\text { growth }(h)\end{array}$} & \multicolumn{3}{|c|}{ Annual productivity growth } & \multicolumn{3}{|c|}{ Annual productivity growth } \\
\hline & $0 \%$ & $5 \%$ & $10 \%$. & $0 \%$ & $5 \%$ & $10 \%$ \\
\hline $\begin{array}{r}h=0 \% \\
5 \% \\
10 \%\end{array}$ & $\begin{array}{l}10 \\
34 \\
53\end{array}$ & $\begin{array}{r}-35 \\
36 \\
72\end{array}$ & $\begin{array}{r}-330 \\
-23 \\
67\end{array}$ & $\begin{array}{r}1.6 \\
8.5 \\
11.6\end{array}$ & $\begin{array}{r}-5.2 \\
2.2 \\
6.1\end{array}$ & $\begin{array}{r}-19.7 \\
-1.9 \\
2.8\end{array}$ \\
\hline
\end{tabular}

In Panel B, the actual 1970 Japanese age distribution of population is used for 1970, and the actual 1980 Japanese age distribution of population is used for 1980 . 
significantly. ${ }^{16}$ Table 3 also shows the actual age distribution of the population over the seven age groups. The postwar baby boom generation is now approaching the prime earning ages. There are now more 40-59year-olds, which should increase the aggregate saving rate.

The steady-state values of the aggregate saving rate and wealth-income ratio expressed at annual rates are shown in table 4 . The table suggests several conclusions: Consumption must rise very rapidly through life for the selfish life-cycle model to be consistent with the observed values of the aggregate saving and wealth-income ratios, because the Japanese age-eamings profile is much steeper. To isolate the effect of the earnings profile, Panel B of table 4 displays the simulation result which uses the 1972-73 U.S. earnings profile for both the 1970 and 1980 simulations, but still uses the same actual Japanese age distribution of population. Comparing the saving rates in Panel B with those in Panel A for the same year for each combination of the consumption growth rate and the productivity growth rate, we can see that with the age structure fixed the difference in the eamings profile between the United States and Japan should make the U.S. saving rate higher. Looking at Panel B for 1970 and 1980 and thus holding the age profile of earnings fixed, we see that the Japanese demographics also work against the life-cycle hypothesis: it predicts a rising aggregate Japanese saving rate.

Another surprising conclusion is that the saving rate generally declines with the productivity growth rate under the Japanese age-earnings profile and demographics. This has a clear and simple explanation. Since earnings are highly skewed toward older ages, quite contrary to the usual textbook picture of hump saving, saving is done primarily by older generations. As the secular productivity growth rate goes up, aggregate saving becomes dominated by a younger and wealthier generation whose saving rate is lower than the saving rate for older generations. It is still true that the very old are dissaving, but their weight in the actual age distribution is tiny.

Since a primary source of the failure of the life-cycle model to mimic the observed saving and wealth-income ratios is dissaving by younger generations, the introduction of liquidity constraints may alter the conclusion. The result (not shown) of a simulation in which consumption is constrained not to exceed the sum of income and initial assets indicates that the saving and wealth-income ratios are now higher because the negative saving by the young is constrained from below, but that the de-

16. This is because what is crucial in the simulation turns out to be the steepness of the Japanese age-earnings profile. See Hashimoto and Raisian (1985) for a full documentation on the effect of tenure on earnings in Japan and the United States. 
mographics still works clearly against the model and the inverse relation of the aggregate saving rate with the productivity growth rate remains.

\section{Evidence from Household Survey Data \\ 5.1. HOUSEHOLD SURVEYS}

The failure of the steady-state life-cycle simulation to mimic the aggregate saving rate and wealth-income ratio means that the actual Japanese age profiles of consumption and asset holdings differ greatly from the life-cycle predictions. We now examine them in order to locate possible deviations of the Japanese saving behavior from the life-cycle models. To this end, survey data on households grouped by age of head of household are essential. Several household surveys in tabulated form are publicly available in Japan. The Family Income and Expenditure Survey (FIES) is a monthly diary survey of about 8,000 households. It has no information on assets and imputed rents and no information on income for households other than the so-called worker household (namely, households whose head is on a payroll). The Family Saving Survey annually collects data on balances and changes in financial assets and liabilities and pretax annual income. It has no information on expenditures and physical assets. The sample size is less than six thousand, insufficient to give reliable tabulations by age. These two surveys do not cover one-person households. The National Survey of Family Income and Expenditure (hereafter National Survey), conducted every five years since 1959, is a very large sample (over 50,000) and covers most types of households (the exceptions are agriculture and fishing). It obtains information through biweekly collection of diaries on expenditures on various items, imputed rent, income, taxes, and financial assets. The shortcoming of this survey is that it covers only three months (September, October, and November) and that except for the pretax income for the twelve-month period ending in November no information is available on monthly income and taxes for nonworker households, which are about 30 percent of the sample. The 1974 and 1979 tapes on individual households have been extensively analyzed by Ando (1985). Our present study uses only the published tabulations in the National Survey Reports.

Table 5A displays some cross-section information for the United States, taken from the 1972-73 Consumer Expenditure Survey. Table 5B contains similar information for Japan taken from the 1974 National Survey Report. One-person households are counted as a half household in the tabulation for Japan. Since average monthly income and taxes are not available for nonworker households, we show disposable income, consumption expenditure and the saving rate separately for worker households. In- 


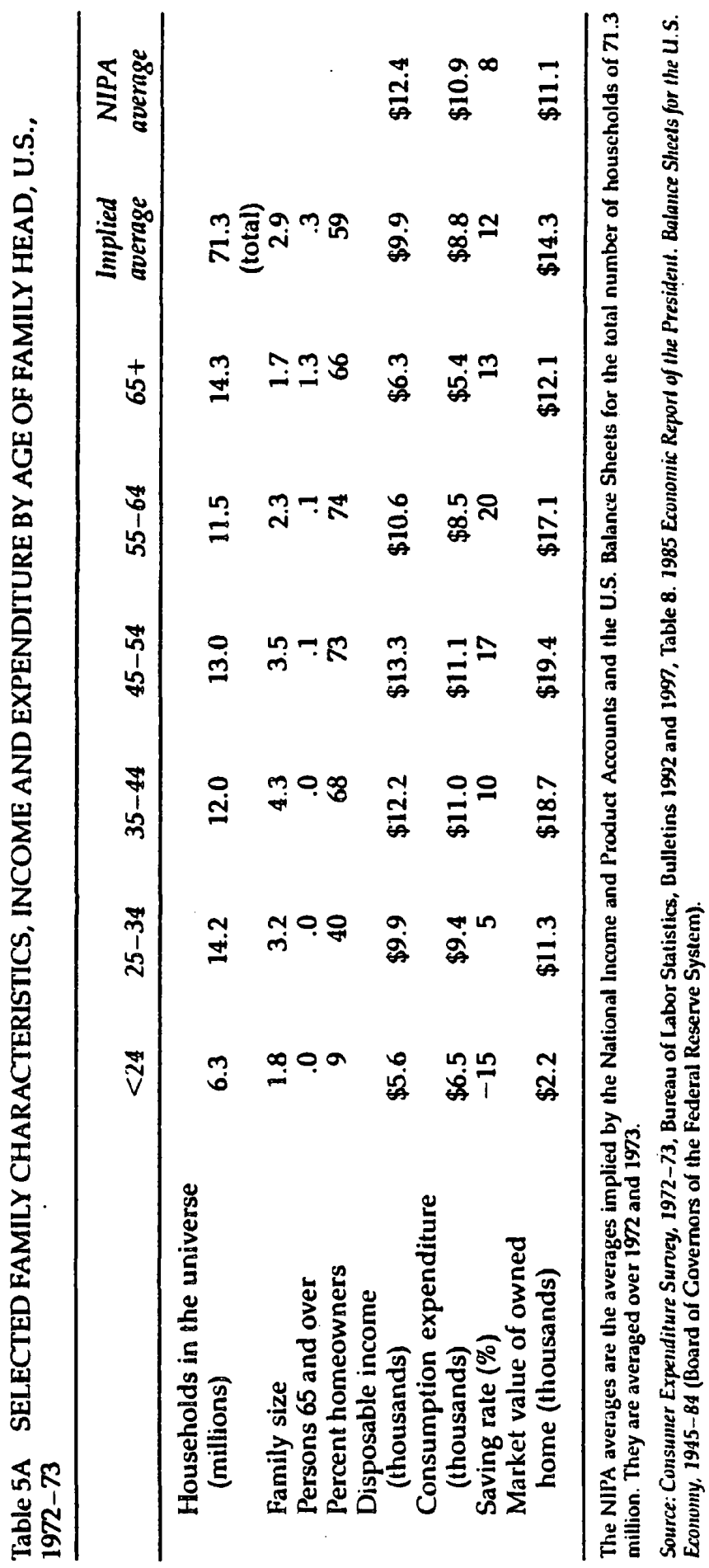




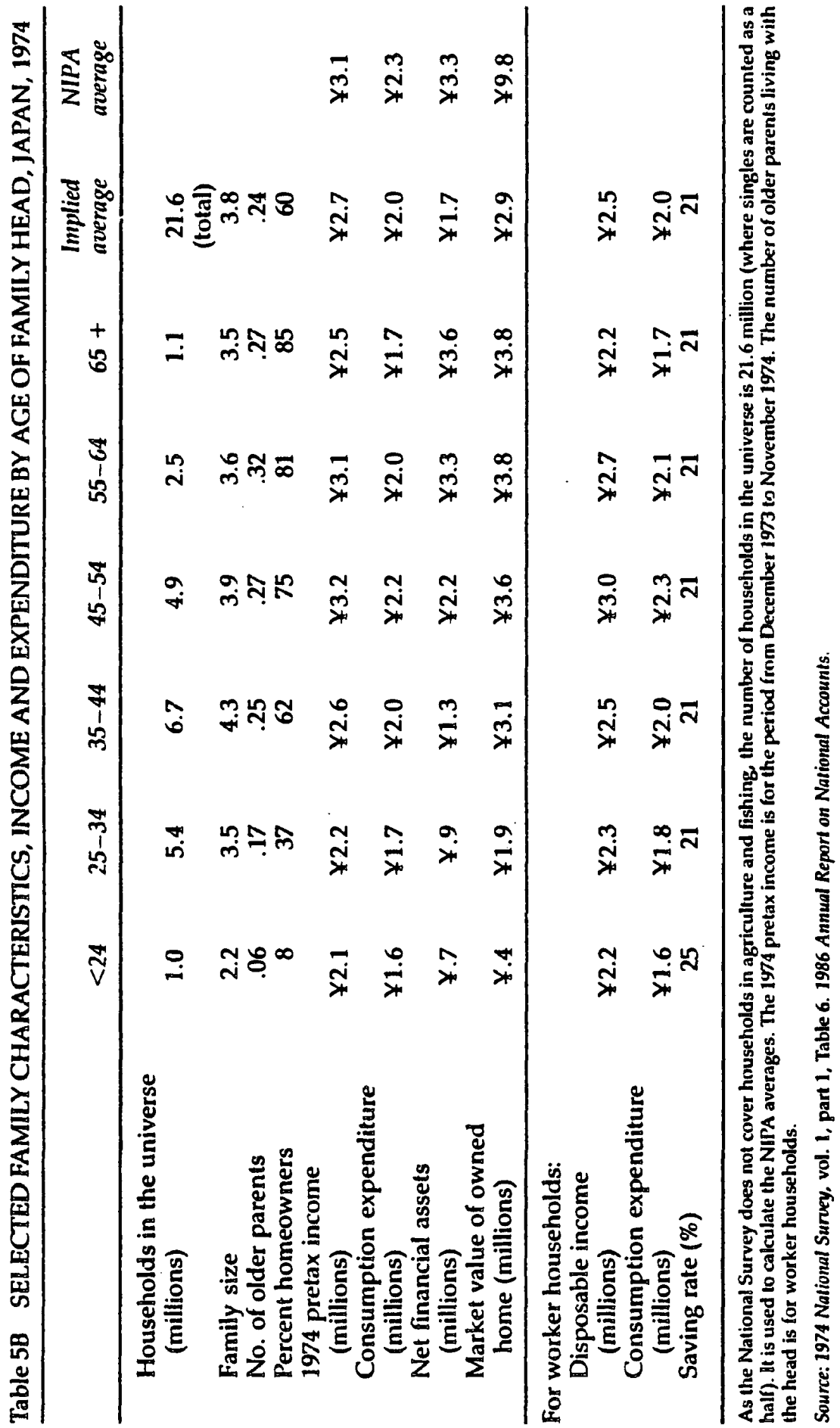


come and expenditure variables are at annual rates. ${ }^{17}$ The value of owned homes (which includes the value of land) is obtained from data on imputed rent assuming that the annual real rate of retum is 4 percent and the depreciation rate 1 percent. The definition of disposable income and consumption expenditure is brought closer to the national income definition by using the following formulas:

$$
\begin{aligned}
\text { consumption expenditure }= & \text { total consumption expenditure } \\
+ & \text { income in kind (including imputed } \\
& \text { rent), }(4)
\end{aligned}
$$
disposable income $=$ total income (including social security benefits and pensions)
+ income in kind (including imputed rent)
- depreciation on owned home ( 20 percent of imputed rent)
- interest part of loan repayments (6 percent times financial liabilities outstanding).

Unless otherwise stated, this is the definition of disposable income and consumption that we employ throughout the article. Although the remaining conceptual differences make the comparison with the national accounts data more or less meaningless (see Ando (1985) for detailed discussion) it appears from the last two columns of table 5B that the $\mathrm{Na}$ tional Survey severely underreports asset values.

From the viewpoint that the private sector or the nation is the relevant boundary, the definition of income should include anticipated capital gains on stocks. We should bear in mind that the saving rate displayed in the tabulations is the personal saving rate, exclusive of revaluations. We know from table 1 that there were large capital losses on private assets in 1974 and large capital gains in 1979. To the extent that some components of revaluation were anticipated, the saving rate for 1974 in table $5 B$ is overstated.

Several differences between the United States and Japan are clearly noticeable from tables $5 \mathrm{~A}$ and $5 \mathrm{~B}$. First, the share in the total universe of households headed by persons 65 and over is very small in Japan. Second, the average number of old people living with younger households is much higher. Third, home-ownership does not decline after the house-

17. Monthly figures averaged over the three-month period of September through November are converted to annual rates by using the seasonality factors reported in the Annual Reports of the Family Income and Expenditure Suroey. 
hold head retires. These are just different aspects of the same important fact about Japan, emphasized in Ando (1985), that elderly parents often invite one of their children (usually the eldest son) and his family to move into their house or, less frequently, the parents move into the younger household. According to the Basic Surveys for Welfare Administration, over 80 percent in 1960 and 67 percent in 1983 of persons 65 or over lived with their children. For persons 80 years or over, the proportion was 90 percent in 1983. Thus data such as those given in table 5B organized by age of head of household give only a mixture of the saving behavior by the young and the old. This certainly makes the interpretation of the data less straightforward. We will come back to this issue of household merging shortly.

\subsection{HIGH HOUSING/LAND PRICES?}

The fourth difference is that the saving rate does not depend very much on age. ${ }^{18}$ This could be explained by the saving behavior of the elderly living with younger families, but, as we will see (in table 9, Panel A), the pattern is clearly observed for nuclear families as well. This is why the life-cycle models fail to explain the Japanese saving rate. Fifth, unlike the United States, there is no indication of dissaving by very young households. This can be explained by a combination of liquidity constraints, the extremely high Japanese housing prices, and the high downpayment required to purchase a house.

This brings us to the explanation mentioned in section 3 that the Japanese saving rate is high because the Japanese have to save a great deal to purchase a house whose price is several times their annual income. The National Survey Reports since 1974 have separate tabulations for the three largest metropolitan areas. We can therefore calculate the saving rate separately for urban and rural areas. Since housing prices are much higher in urban areas, the saving rate must be higher as well. We can actually get more information from the National Survey Reports because since 1979 the tabulations are further broken down to three household types: homeowners; renters without a plan to purchase a house within the next five years; and renters with such a plan.

Table 6 displays the saving rate by region and household type for 1979 and 1984. (As disposable income is not available for nonworker house-

18. This pattern shows up consistently in almost any household survey in Japan for every year. We must, however, be careful about the saving rate for the old. The saving rate is for worker households, which automatically excludes retirees. But table 5B indicates that, for all households whose head is 65 or over, average annual income is 2.5 million yen and average expenditure 1.7 million yen. For those households the average tax rate would be at most 15 percent. Thus their personal saving rate must be over 20 percent. 
holds, the saving rate is calculated for worker households only.) As predicted by the housing price hypothesis, the saving rate for renters with purchase plans is several percent over that for other types of households in 1979. However, the saving rate for those who plan to purchase a house in urban areas is about the same as that in rural areas, which suggests that the elasticity of substitution between housing and other forms of consumption may be close to unity. It is not the price of houses per se that is driving the saving rate up. More important are the unavailability of housing loans and the tendency of the Japanese to own, rather than rent, houses despite no tax advantages on mortgage payments. Another piece of evidence in the table unfavorable to the housing-price hypothesis is that the saving rate averaged over household types is, if anything, higher for rural areas, where houses are much cheaper. This underscores the general principle that a high saving rate for the young population by itself does not translate into a high aggregate saving rate. If for some reason or other the young are forced to save more than they otherwise would, the life-cycle hypothesis implies that the involuntary saving will be spent in the later stages of life and thus reduce the saving rate for older generations. The high housing price does not seem to have any relevance in very recent years, because the table shows that for 1984 saving rates are not at all affected by the intent to purchase a house.

\subsection{ASSET HOLDINGS BY THE AGED}

The prevalence of children living with parents creates two problems that must be borne in mind in analyzing lapanese household survey data. First, as already mentioned, tabulation by age of the household head does not fully reveal the life cycle of a typical person, because of

Table 6 SAVING RATES BY AGE, TYPE AND REGION, WORKER HOUSEHOLDS

\begin{tabular}{lcccccc}
\hline & \multicolumn{2}{c}{1979} & & \multicolumn{2}{c}{1984} \\
\cline { 2 - 3 } \cline { 5 - 6 } \cline { 5 - 6 } & Urban & Rural & & Urban & Rural \\
\hline $\begin{array}{l}\text { 1. Homeowners } \\
\text { 2. Renters without }\end{array}$ & 18 & 19 & & 18 & 20 \\
$\begin{array}{l}\text { purchase plans } \\
\text { 3. Renters with }\end{array}$ & 19 & 19 & & 18 & 20 \\
$\begin{array}{l}\text { Purchase plans } \\
\text { Average }\end{array}$ & 25 & 24 & & 19 & 21 \\
\hline
\end{tabular}

Source: 1979 National Survey Report, vol. 1, part 1, Table 26, and vol. 1, part 2, Table 18. 1984 National Survey Report. 
the presence of the elderly. in the extended family. Second, since the household survey defines the head of a household to be the main income earner, there is a sample selection bias, in that heads of extended families in older age groups are high-income people whose earnings are greater than the earnings of their adult offspring in their prime earning ages.

This sample selection bias is particularly relevant when we examine the issue of asset decumulation by the aged, a popular test of the selfish life-cycle models. Table 7 combines two of the tabulations given in Ando's (1985) study. The table is arranged to make it easy to trace over the fiveyear period of 1974-79 the asset holdings by cohorts defined by five-year age groups. The tabulation is for two-or-more-person households whose head was over 56 in 1974, so both nuclear and extended families are included. Assets here consist of financial assets (excluding the present value of social security benefits), the market value of any owned home (whose main component, of course, is the value of land), and consumer durables. They are stated in 1979 prices. The mean asset holdings do not decline as cohorts age. The essential aspect of the life-cycle models does not seem to hold. This, however, is a premature conclusion, for three reasons. The first is probably familiar to American researchers, while the other two are specific to the prevalence of the extended family. First,

Table 7 AGE PROFILE OF ASSET HOLDINGS BY OLDER TWO-OR-MOREPERSON HOUSEHOLDS, 1974 AND 1979

\begin{tabular}{lcccc}
\hline & \multicolumn{4}{c}{ Age of head in 1974} \\
\cline { 2 - 5 } 1974 & $56-60$ & $61-65$ & $66-70$ & $71-75$ \\
\hline Sample size & 1572 & 1418 & 927 & 553 \\
Mean & 1946 & 1936 & 1815 & 1813 \\
First quantile & 1185 & 1153 & 1095 & 1107 \\
Second quantile (median) & 1760 & 1755 & 1662 & 1660 \\
Third quantile & 2455 & 2456 & 2293 & 2323 \\
\hline & \multicolumn{4}{c}{ Age of head in 1979} \\
& $61-65$ & $66-70$ & $71-75$ & $76-80$ \\
\hline 1979 & 1623 & 1187 & 615 & 245 \\
\hline Sample size & 1971 & 1839 & 1865 & 1847 \\
Mean & 1160 & 1038 & 1080 & 965 \\
First quantile & 1785 & 1565 & 1636 & 1515 \\
Second quantile (median) & 2512 & 2351 & 2398 & 2291 \\
Third quantile & & & & \\
\hline
\end{tabular}

In ten thousands of 1979 yen.

Source: Ando (1985). 
poor people at the lower end of the 1974 asset distribution are more likely to die and thus disappear from the asset distribution for 1979. Second, of old nuclear families, poor ones may be more likely to disappear as they are merged into younger households. Third, by the very design of the survey, older household heads of extended families are the ones who still dominate their sons in terms of income. This is the sample selection bias mentioned above.

For these reasons the lower end in the 1974 asset distributions becomes tapered as time goes on. However, it should still be the case that if the old are decumulating, the upper ends of the asset distribution shift to the left. For those who were $56-60$ years old in 1974, there is no attrition in the first place because the sample sizes for 1974 and 1979 are about the same. Thus simply comparing the mean is enough to conclude that there is no asset decumulation. For the 61-65-year-olds in 1974, there is a slight reduction in the sample size (from 1,418 to 1,187), and the whole upper end seems to have shifted to the left between 1974 and 1979. But the shift is very small-averaging across quartiles less than 10 percent over five years. For the 66-70-year-olds the sample size declines by a third over the five-year period. If assets were neither accumulated nor decumulated, the 1979 second quantile should be somewhere between the 1974 second and third quantiles. But in the table the 1979 second quantile is actually less than the 1974 quantile, indicating that asset decumulation may have occurred. We get the same conclusion for the 71-75-year-olds. Thus, there is some evidence of slight asset decumulation by the old. We hasten to add, however, that the conclusion is based on the assumption of no attrition for the upper end of the asset distribution. Also, the sample size for the very old may not be large enough to deem the quantile estimates reliable.

\subsection{IMPORTANCE OF BEQUESTS}

Thus, the evidence on old persons maintaining independent households with or without their children is not very favorable to the selfish lifecycle models. Does the same conclusion apply to the elderly living with younger generations - the majority of the older population in Japan? Ando (1985) claims that there is strong evidence that they decumulate assets. He drew this conclusion from an equation explaining asset holdings for preretirement households. The equation shows a positive effect on household assets of the presence of the elderly in the household. This by itself is not surprising because when older parents retire they bring previously accumulated assets to younger households. What is significant is that the positive effect rapidly declines as the age of the older per- 
son increases. However, it seems that Ando's conclusion is premature because it ignores the role of bequests.

The saving behavior of the elderly living with younger generations can be inferred from a comparison of the nuclear family with the extended family. Table 8 displays the age profile of pretax income, expenditure, and financial asset holdings for 1979 and 1984. Because the tabulation in the 1979 and 1984 National Survey Reports by family type (nuclear and extended) do not show income in kind and imputed rent by age, consumption expenditure and income in the table are not adjusted for it. The market value of owned homes cannot be estimated, either. Taxes also are not shown because the National Surveys have no data on taxes for nonworker households. The profiles for nuclear families are in Panel A, and the profiles for extended families (households with adults of more than one generation) are in Panel B. One-person households are counted as half a nuclear household. ${ }^{19}$ If entries in Panel A are subtracted from the corresponding entries in Panel B, we obtain Panel C. It therefore contains the difference in income, expenditure, and assets brought about by the presence of older parents. Consistent with Ando's conclusion, financial assets attributable to the elderly start to decline as we move to the right across age groups in Panel C. ${ }^{20}$ This pattern of asset decumulation by the elderly, however, is inconsistent with the low expenditure relative to income shown in Panel C. Although table 8 shows pretax income, similar tabulations (not shown) based on disposable income for worker households indicate that the average tax rate is somewhere between 13 percent and 17 percent depending on age and family type and is somewhat higher for nuclear families. Thus if the pretax income is multiplied by 0.85 it serves as a lower bound for the difference in personal disposable income (though not adjusted for income in kind). Comparison of this estimate of disposable income and consumption expenditure

19. At the time of writing, the 1984 National Survey Report was not yet published, but I was given access to the 1984 tabulations in computer printout form. The tabulation for 1984 in table 8 does not take single-person households into account. It would make little difference to the results.

20. The difference in financial assets for the 20-29 age group in Panel $C$ is small for the sample selection bias I have mentioned. Because the survey defines the household head to be the main income earner, older persons in a young extended family where the household head is the son tend to be low-income people, unable to earn more than 20-29-year-olds do. Their contribution to household assets is therefore small. Because table 8 is a cross-sectional tabulation of assets, we must also be aware of the cohort effect due to economic growth that asset holdings by 0 -year-olds in year $t+i$ are $(1+g)^{*} i$ times as large as asset holdings by $v$-year-olds in year $t$, where $g$ is the long. term growth rate. The cross-sectional decline in asset holdings reported in Panel $C$ of the table is too steep to be accounted for by the growth factor, however. 


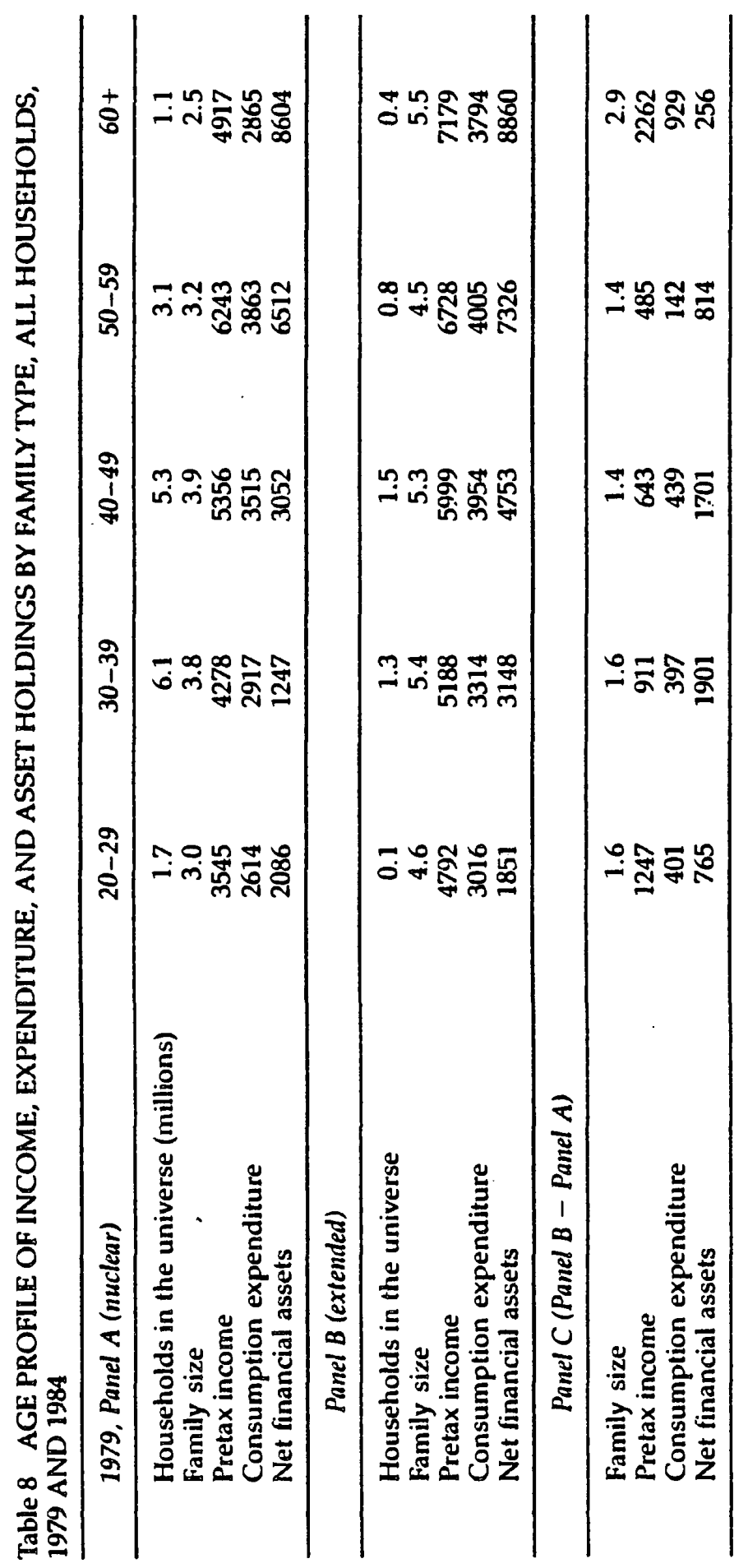




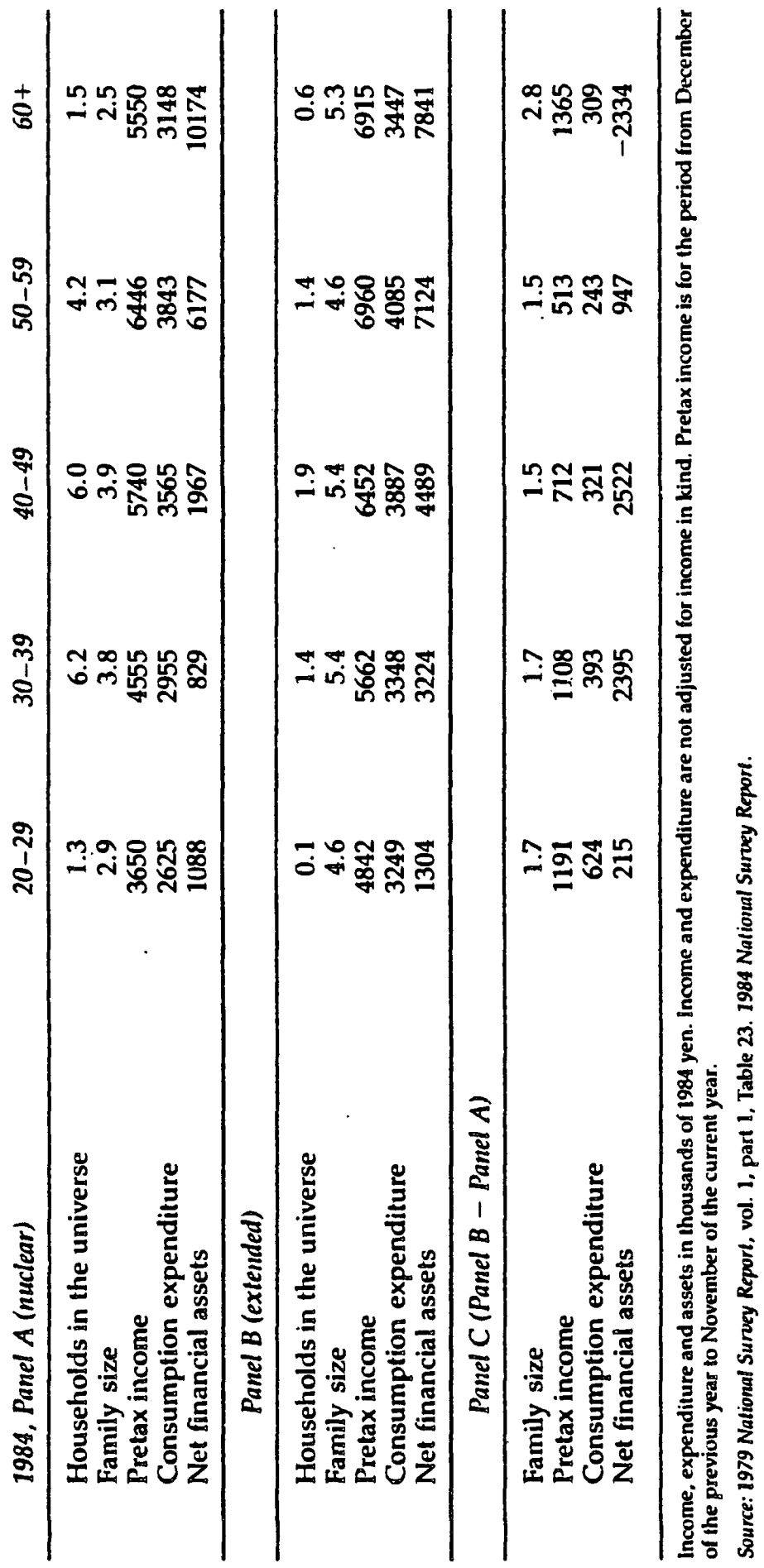


in Panel $C$ indicates that the elderly in younger extended households are accumulating. Put differently, then, how is it that nuclear families are accumulating assets so rapidly without the help of parents?

Our answer is that nuclear families do receive help from their parents-in the form of bequests. As we move to the right across age groups in Panel C, both parents and children (heads of household) get older. More and more parents die as they get older. If parents in an extended family leave bequests, the extended family turns into a nuclear family with additional assets. Furthermore, as the head of a nuclear family gets older, more and more parents who maintain independent households die and leave bequests, not to extended families, but to the nuclear family. In short, for middle-aged and older families, being an extended family is more like a signal of not yet having received bequests. The next section formalizes this argument to arrive at the flow of intergenerational transfers.

\section{Calculation of Intergenerational Transfers}

The sharp contrast between positive saving and declining assets shown in Panel C suggests a substantial amount of intergenerational transfers. We digress in this section to evaluate the quantitative importance of bequests. Since saving and asset holdings by age in 1979 are given in table 8 , we can calculate asset holdings by age in 1984 that would have been obtained through saving accumulated over the five-year period 1979-84 in addition to the 1979 asset were it not for intergenerational transfers. (This calculation becomes rather complicated because within each age group there are inflows and outflows of households between the nuclear and extended families.) The difference between the actual and predicted 1984 asset holdings is then attributable to transfers. Aggregating transfers over age groups of recipients, we arrive at an estimate of the aggregate flow of transfers over the 1979-84 period. Clearly, this procedure captures only intergenerational rather than intragenerational. transfers. It is the former that we are most interested in. And the captured flow of transfers would include bequests as well as gifts inter oivos.

This simple idea cannot be implemented for the 1979-84 period, though. For one thing, table 8 presents data by ten-year age groups, whereas we need tabulations organized by five-year groups. Second, the table gives no information on real assets. The value of owned homes is by far the most important household wealth in Japan. Fortunately, the 1969 and 1974 National Survey Reports do give such needed information, 
albeit only for worker households. ${ }^{21}$ The age profiles of disposable income, consumption expenditures, and the sum of financial assets and the market value of owned homes are displayed in table 9 for 1969 and 1974. As in table 7, the tabulation for the second year in table 9 is shifted to the left by five years for tracking cohorts. For example, the saving rate for a typical nuclear family whose head was 25 to 29 years old in 1969 is 17 percent. Moving down vertically in the same column across panels, we see that five years later its saving rate is 21 percent. To eliminate the sample selection bias that parents (who are also the household heads) in older extended families are rich while parents (who are not the household heads) in younger extended families are relatively poor, extended families in the 55-59 group are put into the 25-29 group, the 60-64 group into the 30-34 group, and the 65-and-over group into the 35-39 group. This is why data for 1974 for cohorts in the 50-54 age group in 1969 get lost and are not shown in table 9. This means that we cannot calculate transfers going to the households in the 1969 50-54 group.

A somewhat detailed description of the calculation of the flow of intergenerational transfers is as follows. Households are classified into three categories:

(a) young nuclear, whose head was under 55 in 1969 (and under 60 in 1974),

(b) young extended, whose younger generation was under 55 in 1969 (and hence under 60 in 1974),

(c) old independent, whose head was 55 or over in 1969 (and 60 or over in 1974, or may have disappeared due to death or household merging by 1974).

As one-person households are counted as a half of (a), all households except for single-parent households (whose number is small and which are ignored in our calculation) fall into one of the three categories. Households in (a) and (b) are further classified by five-year age groups according to the age in 1969. Thus table 9 contains the income, consumption and asset information for $(a)$ and $(b)$. Let $W(i, j, t)$ and $S(i, j, t)$ be the average total wealth and saving (at 1974 prices) of households of type $i$

21. The tabulations by age and family type (nuclear and extended) in the 1969 and 1974 National Survey Reports have no separate listing of imputed rent, although income in kind is listed. The tabulation by age alone does list imputed rent, which shows a more or less stable proportion to food expenditure across age. This proportion is used to separate out imputed rent from income in kind. Disposable income and consumption expenditure are then calculated by the formulas (4) and (5) in section 5 . 


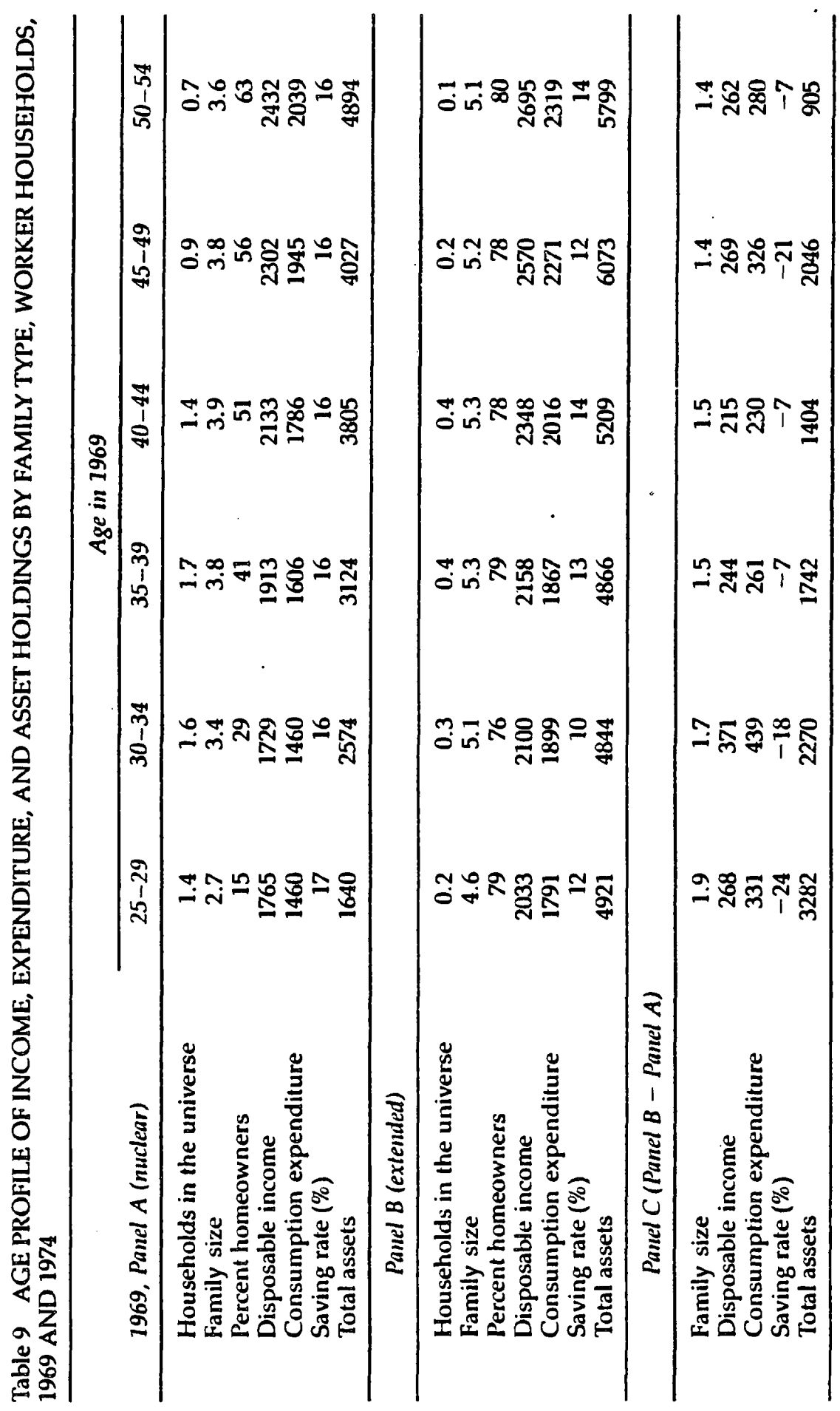




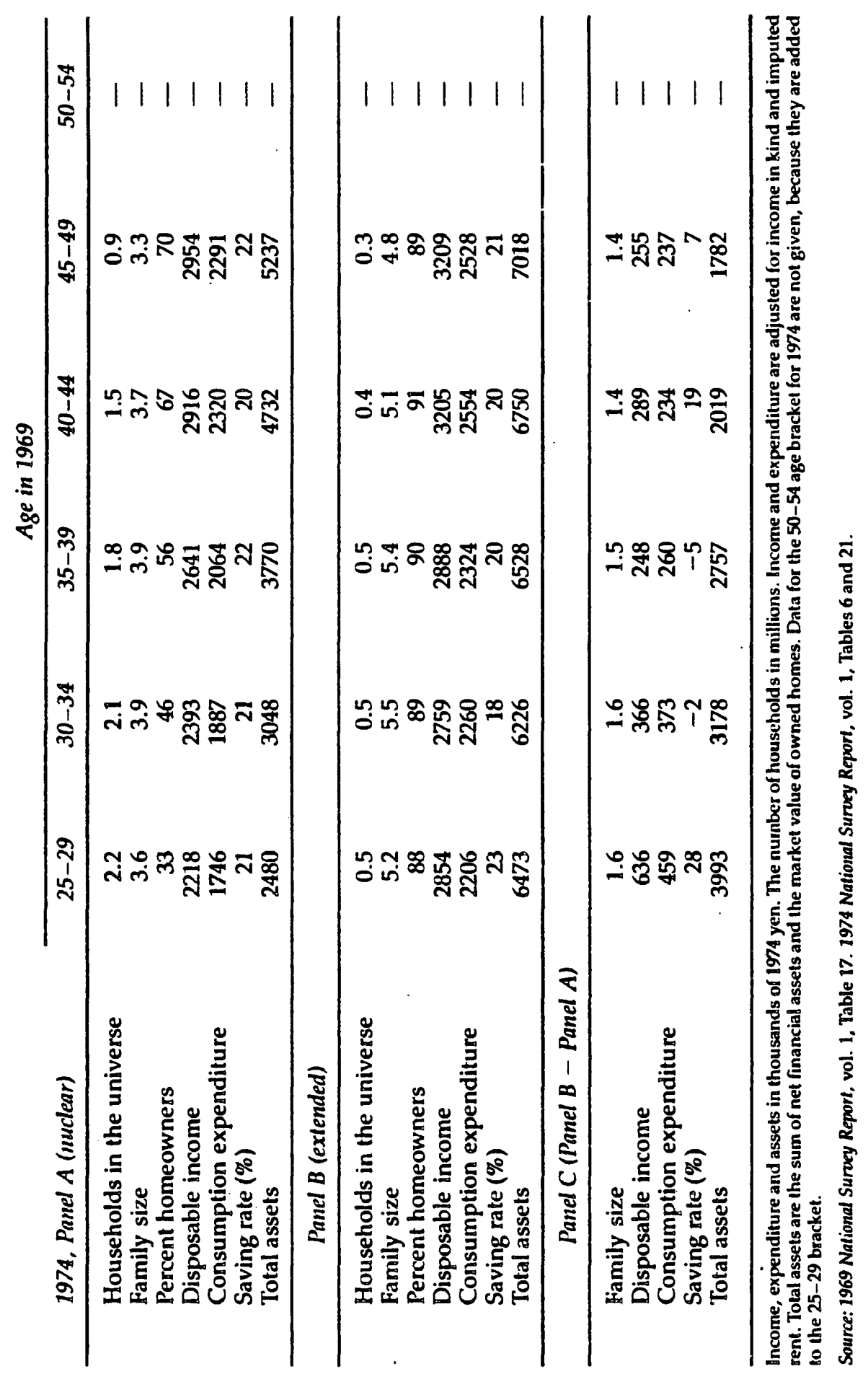


$(i=a, b)$ in age group $j(j=1$ for the $25-29$ group, $j=2$ for the $30-34$, and so forth) in year $t$. Let $N(i, j, t)$ be the number of such households. If $p(i, k ; j)$ is the fraction of households in the $(i, j)$ cell in year $t(=1969)$ moving into the $(k, j+1)$ cell in $t+1(=1974)$, we have, for each age band $j$,

$N(a, j+1, t+1)=N(a, j, t) p(a, a ; j)+N(b, j, t) p(b, a ; j)$.

where we assume that young households never disappear. We assume that the flow of saving in real terms is constant over the five-year period for each type of household. If $L(i, j, t)$ is the predicted wealth (stated at 1974 prices) of a typical household in the $(i, j)$ cell in year $t$ that can be accounted for by accumulated saving on top of initial assets in year $t$, it can be written as ${ }^{22}$

$L(i, j, t)=5.0 * S(i, j, t)+W(i, j, t)$.

Thus the aggregate flow of intergenerational transfers is

$$
\begin{aligned}
T R= & \sum_{j} N(a, j+1,1974) W(a, j+1,1974) \\
& -\sum_{j} N(a, j, 1969) p(a, a, j) L(a, j, 1969) \\
& -\sum_{j} N(b, j, 1969) p(b, a ; j) L(b, j, 1969),
\end{aligned}
$$

where all the wealth variables $W(a, j+1,1974), L(a, j, 1969)$ and $L(b, j, 1969)$ are stated in 1974 prices. The first sum is actual aggregate wealth held in year $t+1(=1974)$ by all households of type (a). The second sum is the wealth accumulated through saving by households that stayed in (a), and the third sum represents the wealth of households which moved from (b) to (a) during the 1969-74 period. Here $S(b, j, t)$ and $W(b, j, t)$ are those that are attributable to the younger generation in the extended family. Note that intergenerational transfers occur only from (c) to (a) or from (b) to (a).

22. In equation $(7)$ it is not necessary to multiply $S(i, j, t)$ or $W(i, j, t)$ by $(1+r)$, where $r$ is the real rate of return, because $S(i, j, t)$ already incorporates the return from assets as it is defined as disposable income less consumption. If $S(i, j, t)$ were defined as after-tax labor income less consumption, then the interest rate adjustment would have been necessary. During the early 1970 s revaluation of assets was substantial (see table 1 ). In the actual calculation of $L(i, j, t)$, we multiplied $S(i, j, t)$ by a factor of 2.13 . This factor translates net saving to saving inclusive of net revaluation. To calculate this factor, we first calculate annual personal net saving and net revaluation at 1974 prices, and then take the averages over the $1970-74$ period. The factor is the ratio of the sum of average real net saving (14.5 trillion in 1974 yen) and average real net revaluation (16.4 trillion) to the average real net saving. 
Table 9 gives data on: $N(i, j, t)(i=a, b ; t=1969,1974), S(a, j, 1969)$ and $W(a, j, t)(t=1969,1974)$ for each $j$. To estimate $S(b, j, 1969)$ and $W(b, j, 1969)$, we have to divide the saving and wealth of the extended family between the younger generation and the older generation. We assume the elderly neither accumulate nor decumulate. Thus their saving is zero (so that $S(b, j, 1969)=S(a, j, 1969)$ for all $j$ ). For the 25-29 age group $W(b, j, 1969)$ equals $W(a, j, 1969)$, so that from Panel $C$ for 1969 we see the asset holdings by the elderly in the 25-29 group to be 3,282 thousand yen (in 1974 prices). Assuming a productivity growth rate of 5 percent, asset holdings by the elderly in the 30-34 group are then this 3,282 thousand multiplied by $(1-.05)^{* *} 5$, which enables us to calculate $W(b, j, t)$ for this age group, and so forth. Finally, the values for $S$ and $W$ are blown up to agree with the implied aggregate averages to account for the underreporting noted in table 5B. Data on $p(b, a ; j)$ can be obtained from the 1969 mortality table assuming that parents are thirty years older than their children. (If there are two parents in the extended family, $p(b, a, j)$ should be the probability that both parents die within five years.) We are thus assuming that an extended family becomes a nuclear family only when the dependent elderly die. Using equation (6), $p(a, a ; j)$ can be calculated from $p(b, a ; j)$. This completes the description of the calculation procedure.

There is one problem of head counting: the number of nuclear families in the 30-39 age group in 1974 is too large to be accounted for by the number of extended and nuclear families in the 25-34 group in 1969. (We see from table 8 that the same phenomenon happened between 1979 and 1984.) Without further information, it is impossible to resolve the question of where those extra nuclear families came from. We decided to ignore this 1969 25-34 group in the summation in equation (8). We have already discarded the 1969 50-54 age group. This leaves only three age groups for 1969: 35-39, 40-44 and 45-49. Thus our aggregation captures only a part of aggregate flow of transfers.

The result is that aggregate wealth held by worker nuclear households in 1974 in the $40-54$ age group stood at 78.0 trillion yen. ${ }^{23}$ Of that, the amount that was accumulated by saving by those households since 1969 in addition to their 1969 wealth holdings was 70.0 trillion yen. The flow

23. From Panel A for 1974 in table 9 the stock of aggregate total assets for the 197440 54 age group (i.e., the $196935-49$ group) is: $1.8 * 3.770+1.5 * 4.732+0.9 * 5.237$ $=18.6$. If this is multiplied by a factor of 3.55, we arrive at 66 trillion yen. The factor of 3.55 is to adjust for the underreporting already mentioned. If we compare this factor with the information given in the last two columns of table $5 \mathrm{~B}$, the factor seems a bit too large. The factor one can calculate from table $5 B$ for financial assets is $3.3 / 1.7=1.9$ and for houses it is $9.8 / 2.9=3.4$. But table $5 \mathrm{~B}$ is for all households. If the similar calculation is done for worker households and the asset-weighted average over financial assets and houses is taken, one comes out with the factor of 3.55. 
of transfers was thus 8 trillion yen. If this is adjusted by the fraction of worker households in the universe, we arrive at an annual flow of 11.5 trillion. Compared with the 1974 year-end aggregate private wealth of 598 trillion, it looks small. Our calculation thus captures only a part of the total flow of intergenerational transfers. Moreover, looking at the tabulation for 1969 in table 9, we note from Panel C negative savings and notso-rapidly declining total assets. Thus the year 1969 might have been a poor (though inevitable) choice. Our calculations also rely on the average total asset holdings for the 25-29 age group in 1969. But that average may be unreliable, since the estimated number of households in that cell is small. Thus, our estimate should be taken as a very loose lower bound for the true aggregate flow of intergenerational transfers.

\section{Intergenerational Transfers}

The evidence already presented points to the importance of intergenerational transfers. Their implication for the aggregate saving rate, however, depends critically on whether or not they are based on intergenerational altruism. Even if parents are not altruistic toward their cinildren, they still leave bequests if they die prematurely (accidental bequests); bequests are used as payments to children for their service rendered to care for older parents; or parents hold wealth in bequeathable form to influence their children's action. In any of the three models the implications of the standard life-cycle model for the saving rate would still hold. Although it is difficult to draw a firm conclusion from the data at our disposal about the nature of bequests, the following pieces of evidence seem largely consistent with intergenerational altruism.

Saving by Retirees Japan's social security system was greatly expanded in 1973. It is now essentially a pay-as-you-go system. Quite likely, this large-scale transfer of resources from the young to the old engineered by the government was not anticipated. The average annual old age benefit per person covered by the annuity benefit program for those employed in the private sector (Kosei Nenkin, the largest public annuity program) is 538 thousand yen in 1974 and 1,360 thousand in 1983, an increase in real terms of 53 percent. The model of dynastic altruism predicts that this increase will be entirely saved by the old to offset the governmentengineered transfer. It is supported by the fact observable from a comparison of income and consumption in Panel C of table 9 with Panel C of table 8 that the saving attributable to the elderly in extended families appears to have increased in several recent years. This is inconsistent with 
the selfish life-cycle models, which predict that the increase in annuities will be consumed.

Does this conclusion favorable to dynastic altruism also apply to older persons maintaining independent households? Since 1969 the National Survey Reports have data on pretax annual income, consumption expenditure, and assets of retired couples where the husband is 65 or over and the wife is 60 or over. They are shown in table 10. The personal saving rate shows no tendency to increase, which appears inconsistent with dynastic altruism. But for older households revaluation of assets may be an important component of income. For 1974 and 1979, there is a great deal of uncertainty in estimating net revaluation (revaluation excluding change in value attributable to general inflation) that might have been perceived by the households over the three-month period of September through November, because as reported in the table (and also in table 2) price changes were so large. The real price of housing was more or less

Table 10 SAVING BEHAVIOR OF RETIRED OLDER COUPLES

\begin{tabular}{|c|c|c|c|c|}
\hline & 1969 & 1974 & 1979 & 1984 \\
\hline Sample size & 242 & 407 & 653 & 951 \\
\hline Percent homeowners & 80 & 81 & 81 & 86 \\
\hline \multicolumn{5}{|l|}{ Percent of pension } \\
\hline recipients & n.a. & n.a. & n.a. & 94 \\
\hline Pretax income & 1494 & 1907 & 2278 & 2457 \\
\hline Consumption expenditure & 1082 & 1468 & 1872 & 1899 \\
\hline \multicolumn{5}{|l|}{ Income in kind } \\
\hline (ind. imputed rent) & 285 & 302 & n.a. & n.a. \\
\hline Value of owned home & 4581 & 5059 & n.a. & n.a. \\
\hline Net financial assets & 4934 & 5566 & 6934 & 8684 \\
\hline General inflation rate (\%) & 5.1 & 22.9 & 4.7 & 2.4 \\
\hline \\
\hline for the stock of houses & n.a. & 7.7 & 13.7 & 2.2 \\
\hline \multicolumn{5}{|l|}{ Rate of change of deflator } \\
\hline for housing investment & 4.1 & 19.8 & 12.8 & 2.3 \\
\hline Saving rate $(\%)$ & 28 & 23 & 18 & 23 \\
\hline \multicolumn{5}{|l|}{ Saving rate with } \\
\hline revaluation & 13 & $?$ & $?$ & 16 \\
\hline
\end{tabular}

Income, expenditure and assets in thousands of 1984 yen. Income and expenditure are not adjusted for income in kind. Pension recipients are defined as couples whose main source of income is a public or private pension. The saving rate does not take taxes into account. The saving rate with revaluation includes in income net revaluation of net financial assets. It is not calculated for 1974 and 1979 because of the uncertainty about the size of net revaluation of owned homes.

Source: 1969 National Survey Report, vol. 1, Table 24. 1974 National Suroey Report, vol. 1, Table 27. 1979 National Survey Report, vol. 7. Table 16. 1984 National Suroey Report. 1986 Report on National Accounts. 


\section{$192 \cdot$ HAYASHI}

constant in 1969 and 1984, so that net revaluation of an owned home can be ignored. If only the net revaluation of financial assets is taken into account, the saving rate is 13 percent in 1969 and 16 percent in 1984. Still, the sharp increase in saving predicted by dynastic altruism is absent.

It may be that, as conjectured in Ando (1985), the saving behavior of older persons who maintain independent households is different from that of older persons living with their children. This is perhaps not surprising. It is hard to imagine that social security has any big impact on the consumption behavior of the elderly in the extended family, because there must be some in-house sense of proportion regarding consumption within the extended family. If social security benefits for older parents are raised with a simultaneous increase in the social security tax on their children living under the same roof, older parents, even without a strong sense of altruism toward their children, would find it morally hard to raise their spending at their children's expense.

Euler Equation There is another way to examine the impact of social security on the consumption behavior by the aged. Every five years since 1959 the National Survey Reports have tabulations by age where the age groups are also five years. As we did in table 9, we can track from year $t$ to $t+1$ a cohort in the $j$ th 5 -year age group in year $t$ by looking at the $(j+1)$ th age group in year $t+1$. For example, a cohort in the 20-24 age group in 1969 was in the 25-29 age group in 1974. If $C(j, t)$ and $Y(j, t)$ are consumption and disposable income of a representative cohort in age group $j$ in year $t$, we can get from the National Survey Reports data on $C(j, t)$ and $Y(j, t)$ for $j=1$ (20-24-year-olds), 2 (25-29-year-olds), . . , 9 (60-64-year-olds) (nine age groups) and for $t=1959, \ldots, 1984$ (six time points). Thus the synthetic cohort analysis as done by Browning, Deaton and Irish (1985) is feasible here. For each cohort, we assume that the Euler equation applies:

$$
\ln C(j+1, t+1)-\ln C(j, t)=a+b r_{t}+e(j, t) .
$$

Here, the left-hand side is the growth rate of consumption from year $t$ to $t+1$. When interest rates are high, it pays to reduce consumption now relative to future consumption. Thus the consumption growth rate should increase with the expected real rate $r_{t}$. This $r_{t}$ is the expectation as of year $t$ of $\ln \left[\left(1+R_{t}\right) P_{t} / P_{t+1}\right]$, where $R_{t}$ is the nominal rate on a 5 -year bond and $P$ is the price index. The sum of the first two terms on the right-hand side, $a+b r_{1}$, is the planned rate of consumption growth. But actual growth can differ from the planned rate, perhaps because the interest rate forecast proved to be wrong, or because earnings change un- 
expectedly over the period $t$ through $t+1$. The last term $e(j, t)$ represents those unexpected developments happening to cohort $j$. As the 1973 expansion of Japan's social security system was an unexpected development that transferred resources from younger generations to older generations, the selfish life-cycle hypothesis predicts that consumption growth from year 1969 to 1974 for older cohorts should be greater than $a+b r_{t}$ and their $e(j, t)$ positive.

As we have data on $C(j, t)$ for six time points $(1959,1964,1969,1974$, 1979 , and 1984), the consumption growth rate can be calculated for five consecutive periods. Thus the sample size for estimating equation (9) is 45 (five times nine age groups). Growth rates and interest rates are stated at annual rates. Because the Euler equation presupposes that expenditure is perishable, we use food expenditure for consumption. Table 11 reports various regression results. In all regressions, AGE (1 for 2024-year-olds, 2 for 25-29-year-olds, and so forth) and AGE squared are included to account for possible age differences in the intercept term $a$ in equation (9). Equation (9) is estimated in Regression 1. The actual real rate is used in place of $r_{t}$. It picked a wrong sign. In Regression 2, to

Table 11 ESTIMATION OF EULER EQUATION ON SYNTHETIC COHORT DATA

\begin{tabular}{|c|c|c|c|c|c|}
\hline $\begin{array}{c}\text { Regression } \\
\#\end{array}$ & $\begin{array}{l}\text { Real } \\
\text { rate of } \\
\text { interest }\end{array}$ & $\begin{array}{c}\text { Social } \\
\text { security } \\
\text { dummy }\end{array}$ & $\begin{array}{c}\text { Log of real } \\
\text { disposable } \\
\text { income }\end{array}$ & $R^{2}$ & $\begin{array}{l}\text { Other } \\
\text { included } \\
\text { variables }\end{array}$ \\
\hline 1 & $\begin{array}{c}-0.14 \\
(1.8)\end{array}$ & - & 一 & 0.55 & AGE, AGE $^{2}$ \\
\hline 2 & $\begin{array}{r}-0.29 \\
(3.0)\end{array}$ & $\begin{array}{c}-0.024 \\
(2.4)\end{array}$ & - & 0.61 & AGE, $\mathrm{AGE}^{2}$ \\
\hline 3 & $\begin{array}{c}-0.027 \\
(0.5)\end{array}$ & - & $\begin{array}{c}-0.043 \\
(6.8)\end{array}$ & 0.79 & $A G E, A^{2} E^{2}$ \\
\hline 4 & $\begin{array}{c}-0.098 \\
(1.3)\end{array}$ & $\begin{array}{l}-0.011 \\
(1.4)\end{array}$ & $\begin{array}{l}-0.041 \\
(6.2)\end{array}$ & 0.80 & $\mathrm{AGE}, \mathrm{AGE}^{2}$ \\
\hline 5 & 一 & $\begin{array}{c}-0.013 \\
(1.9)\end{array}$ & - & 0.84 & $\begin{array}{l}\mathrm{AGE}, \mathrm{AGE}^{2} \\
\text { time dummies }\end{array}$ \\
\hline 6 & - & - & $\begin{array}{c}-0.13 \\
(4.9)\end{array}$ & 0.89 & $\begin{array}{l}\mathrm{AGE}, \mathrm{AGE}^{2} \\
\text { time dummies }\end{array}$ \\
\hline 7 & 一 & $\begin{array}{l}-0.010 \\
(1.8)\end{array}$ & $\begin{array}{c}-0.12 \\
(4.7)\end{array}$ & 0.90 & $\begin{array}{l}\text { AGE, } A_{G E^{2}} \\
\text { time dummies }\end{array}$ \\
\hline
\end{tabular}

All variables are stated at annual rates. The dependent variable is the growth rate of real food expenditure over five-year periods. Real disposable income is the ratio of nominal disposable income to the food component of the CPI. The nominal rate used to construct the real rate is the rate on 5-year discount bonds issued by financial institutions. The price index used to calculate the real interest rate is the food component of the CPI. See the text for the definition of the social security dummy. Numbers in parentheses are the $t$ values. The data source is the National Survey Reports. 
examine the impact of the unexpected 1973 expansion of the social security system, a dummy variable which takes a value of unity for cohorts over 44 years of age for the 1969-74 period is added to the equation. It also has a negative coefficient, which means, contrary to the lifecycle prediction, that the 1973 change reduced consumption by older generations.

In regressions 3 and 4 , the $\log$ of disposable income, $\ln Y(j, t)$, is included to test for liquidity constraints with or without the social security dummy. If people wish to borrow to finance current consumption but are prevented from doing so, a higher level of disposable income leads to an increase in current consumption, thereby reducing the consumption growth over the following five years. Thus if there are liquidity constraints, the disposable income variable should pick up a negative coefficient, which is what is happening in regressions 3 and 4 . The social security dummy still picks up negative coefficients.

For the expected real rate $r_{t}$, we have used the actual real rate. This amounts to conferring on consumers perfect foresight about future prices and thus may be unrealistic. Regressions 5-7 use time dummies in place of the actual real rate. Thus the $a+b r$ term in equation (9) can change its value over the five periods, reflecting changes in the expected real rate and possibly economywide shocks that affect all generations uniformly. Again, the disposable income coefficients are significantly negative and the social security dummy picks up the "wrong" sign.

The Extended Family and Bequests Finally, the fact that most older parents invite their children to move in has two further implications for theories of bequests. First, because if older parents get sick or incapacitated children would feel obliged to take care of them, accidental bequests are clearly less important. Second, the merging of older and younger households means that long before older parents' death there is a de facto transfer from older parents to the children of housing - by far the most important component of wealth. ${ }^{24}$ The strategic aspect of bequests looks less significant for Japan.

24. The actual transfer of ownership does not usually occur until the death of the parents. In 1983 taxable bequests were valued at 5.0 trillion yen, while taxable gifts were 0.6 trillion (see Annual Statistical Report of the Tax Bureau, the only official source of data on taxes in Japan). A standard guidebook on Japanese bequest and gift taxes indicates that bequests are taxed slightly less heavily. The effective bequests tax rate is much lower on houses than on financial assets, because the assessed value of real estate is often less than half the market value. This may explain why the Japanese prefer owning a house to renting. 


\section{The Role of Taxes}

To examine the only remaining major issue, the effect of taxes on saving, we need to address two issues. One is the effective marginal tax rate on income from saving, and the other is the so-called (after-tax) interest elasticity of saving. A good deal of work has been done on the first issue. A comprehensive official description of Japan's tax system can be found in An Outline of Japanese Taxes (various years) by the Ministry of Finance. A good economist's description is in Horioka (1985b, section 4), Shoven and Tachibanaki (1985) and Makin (1985). The treatment of personal interest and dividend income in the Japanese tax system differs considerably from that in the United States. The notorious Maruyu system implies that interest income from a principal of up to 6 million yen (about $\$ 30$ thousand) for "nonsalaried" workers and 12 million yen for "salaried" workers is nontaxable. Because abuse of this system is so common, it is difficult to estimate the marginal tax rate on interest income. Capital gains on stocks are not taxed if the gain is less than a certain amount and if the number of transactions is not large (less than fifty transactions a year). But this provision, too, can be avoided by trading stocks through several different brokers. The tax rate on dividend income is at most 35 percent, as high-income taxpayers can elect to have interest and dividends taxed separately at that rate, and for many middle- and low-income earners it is substantially less. Since the retum from Japanese stocks has been mainly in the form of capital gains, the average tax rate on income from equity capital is very low. These facts led Shoven and Tachibanaki (1985) to assume very low marginal personal tax rates on interest income and income from equity ( 9.6 percent and 18.1 percent respectively). The very generous tax treatment of income from capital at the personal level is in sharp contrast to taxes on labor income whose top combined national and local statutory marginal rate is close to 80 percent.

At the corporate level, it appears that income is more heavily taxed in Japan than in the United States. ${ }^{25}$ Although there is not much difference in the statutory corporate tax rate, the U.S. treatment of depreciation allowances and investment tax credits is more generous, at least in the 1980s. So the marginal tax rate on income from new capital at the corporate level in Japan is higher. The generous tax treatment at the personal level coupled with a relatively heavy tax burden at the corporate level must at least in part be responsible for the recent capital outflow from Japan to the United States.

25. See Ando and Auerbach (1985) for a comparison of the cost of capital in Japan and the United States. 
The present Japanese tax system is thus geared to encourage saving. The other issue is whether it has been effective in promoting saving. The conventional approach to analyzing the response of saving to changes in the after-tax rate of return to saving is the saving function, which relates aggregate saving to the after-tax interest rate. Because of many serious problems, including the Lucas critique, the saving function approach seems to have been discredited by now. The modern approach that replaces it is the Euler equation approach, discussed in the previous section, which looks at the relation between consumption growth and the real interest rate. If saving is elastic to the interest rate, it should show up as a positive relation of the real interest rate with the growth rate of consumption from one period to the next, because increased current saving makes the level of current consumption relative to future consumption lower. The evidence presented in table 11, however, shows no such relation; in fact the sign of the real rate coefficient is the opposite of the theoretical prediction. Saving does not seem sensitive to the interest rate.

To check the robustness of this conclusion, the same form of the Euler equation (9) is estimated on monthly aggregate data on food expen-

Table 12 ESTIMATION OF EULER EQUATION ON MONTHLY AGGREGATE DATA

\begin{tabular}{|c|c|c|c|c|}
\hline $\begin{array}{c}\text { Equation } \\
\#\end{array}$ & $\begin{array}{c}\text { Real } \\
\text { rate of } \\
\text { interest }\end{array}$ & $\begin{array}{c}\text { Log of real } \\
\text { disposable } \\
\text { income }\end{array}$ & $\begin{array}{l}\text { Estimation } \\
\text { technique }\end{array}$ & $\begin{array}{l}\text { Durbin- } \\
\text { Watson } \\
\text { statistic }\end{array}$ \\
\hline la & $\begin{array}{c}0.10 \\
(1.1)\end{array}$ & - & $\begin{array}{l}\text { forward } \\
\text { filtering }\end{array}$ & - \\
\hline $1 b$ & $\begin{array}{l}0.11 \\
(4.3)\end{array}$ & - & OLS & 1.3 \\
\hline $2 a$ & $\begin{array}{c}0.08 \\
(0.96)\end{array}$ & $\begin{array}{c}-0.003 \\
(1.3)\end{array}$ & $\begin{array}{l}\text { forward } \\
\text { filtering }\end{array}$ & - \\
\hline $2 b$ & $\begin{array}{l}0.12 \\
(4.5)\end{array}$ & $\begin{array}{c}-0.014 \\
(3.6)\end{array}$ & OLS & 1.4 \\
\hline
\end{tabular}

The dependent variable is the growth rate of real food expenditure from the month to the month one year ahead, namely, $\ln \left(c_{1+12}\right)-\ln \left(c_{1}\right)$. The nominal rate used for constructing the real rate is the rate on one-year time deposits. The food component of the CPI is used to calculate the real rate. The log of real disposable income is $\ell n\left(y_{t}\right)$ where $y_{f}$ is disposable income of month $t$ divided by the food component of the CPI. Because the consumption growth rate is over one-year periods while the sampling interval is a month, the error term will be a moving average of order 11. The forward filtering technique proposed in Hayashi and Sims (1983) is used for equations $1 \mathrm{a}$ and $2 \mathrm{a}$. Because the ex-post real rate is potentially correlated with the error term, it is instrumented in equations 19 and $2 a$ by the current one-year nomi$\mathrm{nal}$ rate, current and 12 lags of the monthly food inflation rate, and current and 12 lags of the log of monthly disposable income. They explain about 39 percent of monthly variations in the real rate. The data period is from January 1963 through October 1985. Numbers in parentheses are the $t$ values. The data on monthly food expenditure and disposable income for worker households are taken from the Annual Reports of the Family Income and Expenditure Suroey. 
diture. The Annual Reports of the Family Income and Expenditure Survey contain data since 1963 on average monthly expenditure and disposable income for worker households. For reasons explained in the previous section, food expenditure is used for the estimation. (For details of the estimation see the note to table 12.) The real rate coefficient is now positive (the right sign), but still insignificantly different from zero. The negative effect of disposable income suggests the presence of liquidity constraints, but it too is insignificant. The wrong sign of the real rate coefficient found in table 11 may be explainable by the correlation between the ex-post real rate (used for the expected real rate) and the error term that represents unexpected developments (over the five-year periods). On the other hand, the real rate coefficients in table 12, while corrected for the correlation with the error term, suffer from the possible aggregation bias. The Euler equation holds for each individual. Since each year the oldest generations are replaced by new younger generations, it is not necessarily true that the Euler equation holds for aggregate consumption. On the whole, then, there is no strong evidence for a high interest elasticity of saving or for the effectiveness of the tax incentives for saving.

\section{Concluding Comments}

If one subscribes to the dynastic view of Barro (1974) and Becker (1981), it seems that all the evidence presented in this article-the insensitivity of the aggregate saving rate to demographics, saving rates that are independent of age, the possibly significant flow of intergenerational transfers, the insignificance of the social security dummy, and certainly the prevalence of the extended family-are parsimoniously explainable, although we must hasten to add that no direct and formal test of the dynastic model against other theories of bequests was given in the article. ${ }^{26}$ A large flow of bequests by itself does not lead to high saving rates. One can easily construct a stationary economy with a zero saving rate in which assets are passed on from one generation to the next and in which each generation consumes all of its income. The existence of a significant flow of bequests does, however, imply that the infinite horizon assumption may be a good approximation. Add to this the fact that Japan had to

26. The existence of liquidity constraints is not inconsistent with the dynastic model. Suppose that people do not come to realize the linearity of the family until they reach middle age: Until then the only limits on their consumption are liquidity constraints. Their parents do think about the family. Because of liquidity constraints they can determine their impatient son's consumption through transfers. Thus family consumption is effectively controlled by the parents. Also, liquidity constraints do not necessarily invalidate the Ricardian doctrine of the equivalence of taxes and deficits. See Hayashi (1985b). 


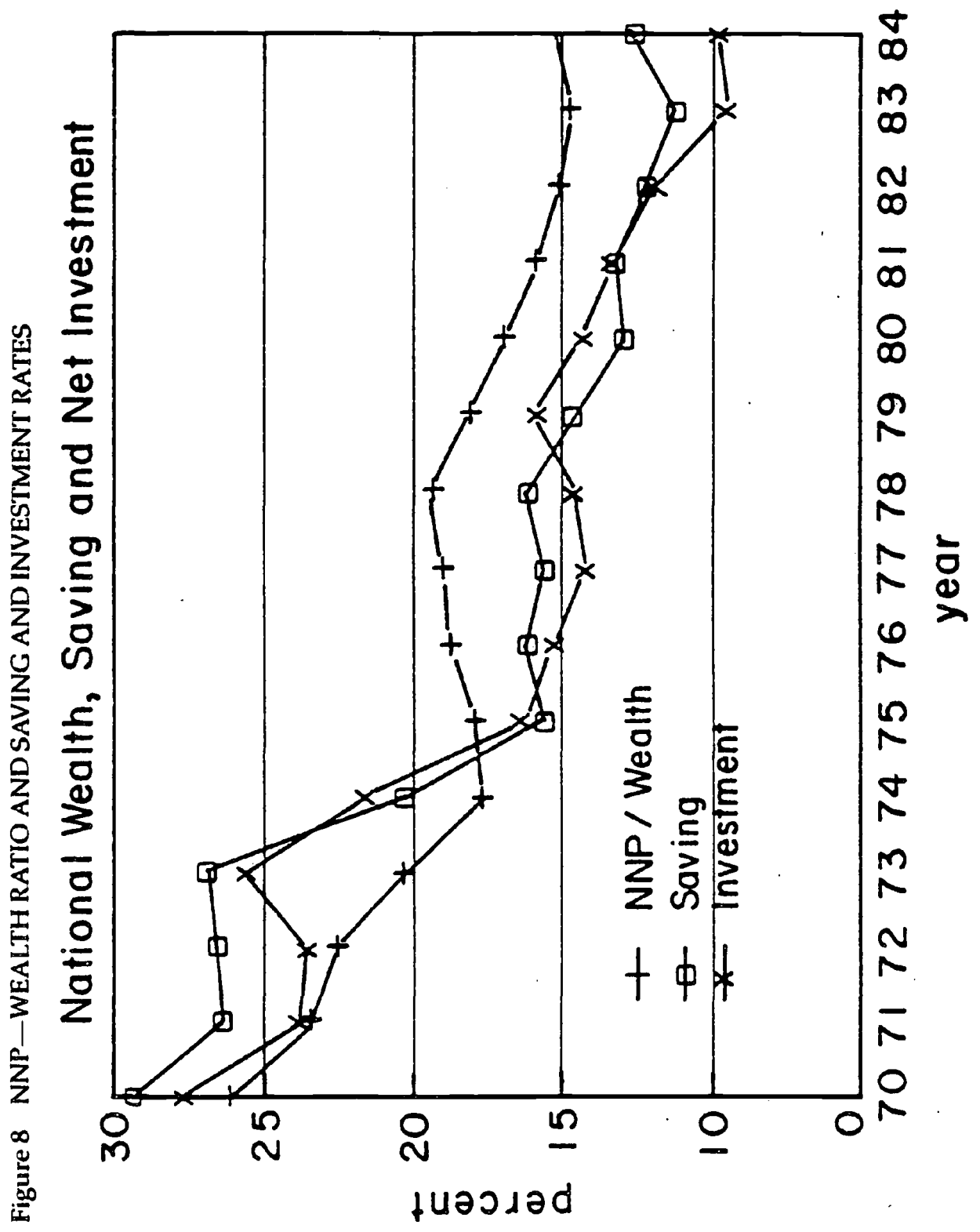


start with a low level of wealth. The infinite horizon optimal growth model implies that the economy's response to the low initial wealth is a high saving rate that gradually stabilizes to a lower level as wealth approaches its steady-state value. Japan's saving rate has been high because the Japanese desire to accumulate wealth in order for their children to live as well as Americans do.

That this simplistic view is consistent with Japan's experience in the last fifteen years (though not in the 1960s, which are not included in the figure) can be seen from figure 8 , which includes a plot of the national saving rate and the (reciprocal of) the national wealth-NNP ratio. (If private saving and private wealth are used one gets a similar picture.) Japan has come a long way toward the steady state. She still has some room to accumulate faster than the United States because her per capita income at a current yen/dollar exchange rate is about 85 percent of the U.S. level. Given Japan's track record, it will not take long to fill the gap. If the infinite horizon view is correct, the rise in the national saving rate that occurred in 1984 is not likely to persist. The plot in the figure of net national investment in tangible assets indicates that Japan's large trade surplus in the 1980s is due more to slumping investment than to saving, which is not high by historical standards.

The author is grateful to Isuneo Ishikawa, Takatoshi Ito, Paul Romer, and other conference participants for discussions and comments on earlier drafts, and especially to Albert Ando, whose detailed written comments helped to improve the final version of the paper.

\section{REFERENCES}

Ando, A. 1985. The savings of Japanese households: A micro study based on data from the National Survey of Family Income and Expenditure. University of Pennsylvania. Mimeo.

Ando, A., and A. Auerbach. 1985. The corporate cost of capital in Japan and the U.S.: A comparison. NBER Working Paper 1762.

Ando, A., and F. Modigliani. 1963. The life cycle hypothesis of saving: Aggregate implications and tests. American Economic Review 53:55-84.

Barro, R. 1974. Are government bonds net wealth? Journal of Political Economy 82:1095-1117.

Barro, R., and J. Friedman. 1977. On uncertain lifetimes. Journal of Political Economy $85: 843-49$.

Becker, G. 1981. A treatise on the family. Cambridge: Harvard University Press.

Boskin, M., M. Robinson, and J. Roberts. 1985. New estimates of federal government tangible capital and net investment. NBER Working Paper 1774.

Browning, M., A. Deaton, and M. Irish. 1985. A profitable approach to labor supply and commodity demands over the life-cycle. Econometrica 53:503-44.

Burnheim, D., A. Shleifer, and L. Summers. 1985. The strategic bequest motive. Jourmal of Political Economy 93:1045-76.

Eisner, R. 1985. The total incomes system of accounts. Survey of Current Business $55: 24-48$. 
Hashimoto, M., and J. Raisian. 1985. Employment tenure and eamings profiles in Japan and the United States. American Economic Review 75:721-35.

Hayashi, F. 1985a. The permanent income hypothesis and consumption durability: Analysis based on Japanese panel data. Quarterly Journal of Economics $100: 1083-1113$.

- 1985b. Tests for liquidity constraints: A critical survey. NBER Working Paper 1720.

Hayashi, F., and C. Sims. 1983. Efficient estimation of time-series models with predetermined, but not exogenous, instruments. Econometrica 51:783-98.

Hayashi, F., T. Ito, and J. Slemrod. 1985. Housing finance imperfection: A simulation analysis for a comparison of the U.S. and Japan. University of Minnesota. Incomplete mimeo.

Horioka, C. 1984. The applicability of the life-cycle hypothesis to Japan. Kyoto University Economic Review 54 (2): 31-56.

. 1985a. Household saving in Japan: The importance of target saving for education and housing. Kyoto University. Mimeo.

. 1985b. A survey of the literature on household saving in Japan: Why is the household saving rate so high in Japan? Kyoto University. Mimeo.

Hulten, C., and F. Wykoff. 1981. The measurement of economic depreciation. In Depreciation, inflation and the taxation of income from capital, ed. C. Hulten, 81-125. Washington, D.C.: Urban Institute.

Ishikawa, T., and K. Ueda. 1984. The bonus payment system and Japanese personal savings. In The economic analysis of the Japanese firm, ed. M. Aoki, 133-92. (Contributions to Eionomic Analysis Series no. 151). Amsterdam: NorthHolland.

Komiya, R. 1966. The supply of personal savings. In Postwar economic growth in Japan, ed. R. Komiya, 157-86. (trans. Robert Ozaki). Berkeley: University of Califormia Press.

Kotlikoff, L., and A. Spivak. 1981. The family as an incomplete annuities market. Journal of Political Economy 89:372-91.

Kurosaka, Y., and K. Hamada. 1984. Why is the personal saving rate so high? In Macro Keizaigaku to Nihon Keizai [Macroeconomics and the Japanese economy]. Tokyo: Nihon Hyoronsha.

Makin, J. 1985. Saving rates in Japan and the United States: The roles of tax policy and other factors. Washington, D.C.: American Enterprise Institute. Mimeo.

Modigliani, F. 1980. The life cycle hypothesis of saving twenty years later. In Contemporary Issues in Economics, ed. M. Parkin, 2-36. Manchester: Manchester University Press.

Modigliani, F., and R. Brumberg. 1954. Utility analysis and the consumption function: An interpretation of cross-section data. In Post-Keynesian economics, ed. K. Kurihara, 388-436. New Brunswick, N.J.: Rutgers University Press.

Ruggles, R., and N. Ruggles. 1982. Integrated economic accounts for the United States, 1947-80. Survey of Current Business 52 (5): 1-53.

Shinohara, M. 1983. The determinants of post-war savings behaviour in Japan. In The Determinants of National Saving and Wealth, ed. F. Modigliani and R. Hemming, 143-80. London: Macmillan.

Shoven, J., and T. Tachibanaki. 1985. The taxation of income from capital in Japan. Stanford University. Mimeo. 
Tobin, J. 1967. Life cycle saving and balanced growth. In Ten economic studies in the tradition of Irving Fisher, ed. W. Fellner, 231-56. New York: Wiley.

\section{DATA APPENDIX}

This appendix describes and presents the Japanese aggregate time-series data used in the text. All the raw data come from the 1986 Annual Report on National Accounts and the Report on Revised National Accounts on the Basis of 1980. The former includes the most recent (1985) benchmark revision with the base year of 1980 . The latter is a companion volume that extends the benchmark revision back to either 1965 or 1970 depending on the series. The series in the capital transactions (saving/investment) accounts and the capital accounts (balance sheets and reconciliations) currently starts in 1970. The variable labels and their values are displayed in tables A1 through A5. They are stated in trillions of current yen. As a general rule, variable labels with "_H" are for the household sector (including private nonprofit institutions serving households), "_C" for the corporate sector (nonfinancial corporations and financial institutions), and "_G" for government. The value of the stock of assets is at the beginning of the year. Revaluations are gross (that is, without adjustments for general inflation). As mentioned in the text, the Japanese national accounts report depreciation in the capital transactions accounts at historical costs, do not adjust after-tax income for capital transfers (wealth taxes and lump-sum transfers), and do not depreciate government depreciable assets either in the capital transactions accounts or in the capital accounts (except for buildings). Data necessary for correcting these are available only for the period after 1969. The data presented in this appendix for 1970-84 are all corrected values unless otherwise noted. The variables listed in the tables can therefore be grouped into four categories: (1) those that are directly available from the National Accounts Reports, (2) those that require capital consumption adjustments, (3) those that also require adjustments for capital transfers, and (4) those that are influenced by our estimate of government depreciable tangible assets.

(1) The following variables are available directly from the Reports after consolidating five sectors into the three sectors (household, corporate and government.)

GNP $=$ gross national product.

CON = personal consumption expenditure.

PCON = deflator for CON.

SVG_BEA = government budget surplus, or net investment in government net financial assets. "_ $B E A$ " is placed in the label because if we 
take the U.S. Bureau of Economic Analysis (BEA) convention of ignoring government tangible assets it should equal government net saving. This is available directly from the government capital transactions accounts after 1969. For $1965-69$ it is defined as: government net saving + depreciation - gross government capital formation. This should equal net investment in financial assets up to statistical discrepancy. DEPH_ $x=$ reported depreciation in the capital transactions accounts of sector $x(x=H, C, G)$.

DFA_ $x=$ net investment in financial assets in the capital accounts of sector $x(x=\mathrm{H}, \mathrm{C}, \mathrm{G})$. After $1969 \mathrm{DFA} \_\mathrm{G}$ equals SVG_BEA.

FA_ $x=$ stock (at the beginning of the year) of net financial assets for sector $x(x=\mathrm{H}, \mathrm{C}, \mathrm{G})$.

RFA_ $x=$ gross revaluation of net financial assets $(x=H, C, G)$.

$\mathrm{GCD}=$ expenditure on consumer durables.

$C D=$ stock of consumer durables at the beginning of the year.

$\mathrm{KD} \_\mathrm{B} \_\mathrm{G}=$ reported value of government depreciable tangible assets.

As the Japanese national accounts has data on the stock of depreciable tangible assets at replacement costs in the capital accounts of the corporate and household sector (but not for the government sector), the following stock variables are also directly arailable from the Reports:

TA_ $x$ = stock of tangible assets (depreciable tangible assets, nonreproducible tangible assets, and inventories) for sector $x(x=H, C)$. $\mathrm{KD} \_x=$ stock of depreciable tangible assets $(x=\mathrm{H}, \mathrm{C})$.

(2) As assets are valued at replacement cost in the capital accounts, depreciation at replacement cost implicit in the Japanese National Accounts can be estimated as follows. Because depreciation in the capital transactions accounts are at historical cost, reconciliations in the capital accounts consist of: revaluation, capital consumption adjustments (i.e., the excess of depreciation at replacement cost over depreciation at historical cost), and some other minor items (e.g., accidental loss/gain of assets). If $K D(t)$ is the nominal stock of depreciable assets at the beginning of the year, $P(t)$ its associated deflator, and $N(t)$ nominal net investment, then revaluation in the National Accounts is calculated as:

revaluation $=\frac{P(t+1)-P(t)}{P(t)} K D(t)+\frac{P A(t)-P(t)}{P(t)} N(t)$,

where $P A(t)$ is an average of the deflator over the year (see $A$ Guide to the Use of the National Economic Accounting, p. 233, Economic Planning 
Agency, 1978). Thus capital gains/losses are conferred on assets acquired during the year. In our calculation $P A(t)$ is taken to be the simple average of $P(t)$ and $P(t+1)$. It is unclear whether nominal net investment $N(t)$ is before or after capital consumption adjustments. We use reported net investment (before capital consumption adjustments) for $N(t)$.

$C C A J_{\text {_ }} x$, our estimate of capital consumption adjustments for the household and the corporate sector $(x=H, C)$, is calculated from the relationship that should hold if the other minor items in reconciliation are ignored:

$C C A I_{-} x=(\mathrm{A} 1)$ for sector $x$ - reconciliation on depreciable assets for sector $x$.

For 1965-69, CCAJ_ $x$ is set at zero (for lack of data on the capital accounts). With this estimate of capital consumption adjustments, the following variables can be calculated for the household and the corporate sector $(x=H, C)$.

$D T A_{\_} x=$ net investment in tangible assets, equals the reported value less $C C A J \_x$.

$D K D \_x=$ net investment in depreciable tangible assets similarly calculated.

$R T A_{-} x=$ gross revaluation of tangible assets, equals the reported value of reconciliation plus $C C A I_{\_} x$.

$R K D_{\_} x=$ gross revaluation of depreciable tangible assets similarly calculated.

For consumer durables, a different procedure is used because depreciation is not reported at all. We first calculate using data on the nominal stock $(C D)$ and nominal gross investment $(G C D)$, the depreciation rate $\delta(t)$ for each year implicit in the perpetual inventory method:

$(P(t) / P(t+1)) * C D(t+1)=C D(t)+G C D(t)-\delta(t) * C D(t),(\mathrm{A} 2)$

where $P(t)$ here is the deflator for the stock of consumer durables available from the Reports. The implicit depreciation rate for 1970-84 turned out to be stable over years with a mean of 19.0 percent. Depreciation at replacement costs on consumer durables is thus calculated as 0.19 times $C D$. Gross revaluation of consumer durables is:

$R C D=(\mathrm{A} 1)$ with $K D$ replaced by $C D, N$ by $G C D-0.19 * C D$, and $P$ by the deflator for $C D$. 
(3) To arrive at net saving, we have to subtract from reported net saving capital consumption adjustments and then add capital transfers. The variables

SVG_ $x=$ net saving by the household sector $(x=H)$ and by the corporate sector $(x=C)$

are thus calculated. Capital transfers are positive for the corporate sector and negative for the household sector for all years since 1970.

(4) As shown in table 2, the average physical rate of depreciation implicit in the capital accounts for buildings is 6.5 percent. Using the beginning of 1970 value of government depreciable assets as the benchmark and using reported government gross investment series and the reported value of deflator for the stock of government depreciable tangible assets, we generate the stock of depreciable assets by the perpetual inventory method (A2). Namely,

$\begin{aligned} K D \_G= & \begin{array}{l}\text { government depreciable tangible assets generated by } \\ \text { perpetual inventory with a depreciation rate of } 6.5 \text { percent. }\end{array}\end{aligned}$

The benchmark 1970 value in the National Accounts is based on the 1970 National Wealth Survey which is a sampling survey on the replacement value of assets by type, industry and institutional sector.

The remaining variables for the government sector are now easy to calculate:

$T A \_G=$ stock of government tangible assets, equals $K D \_G$ plus reported value of the stock of inventories and nonreproducible assets.

$C C A I_{\_} G=$ capital consumption adjustments, equals $0.065 * K D \_G$ minus reported depreciation.

$D K D \_G=$ net investment in depreciable tangible assets as reported in the capital accounts of the government minus $C C A J \ldots G$.

$D T A_{-} G=$ net investment in tangible assets, equals $D K D \_G$ plus reported net investment in inventories and nonreproducible assets.

$R K D_{-} G=$ gross revaluation of depreciable assets calculated by (A1) with $K D$ replaced by $K D \_G, N$ by $D K D \_G$ and $P$ by reported deflator for government depreciable tangible assets.

$R T A \_G=$ gross revaluation of government tangible assets, equals $R K D_{-} G$ plus reported reconciliation on inventories and nonreproducible assets. 
SVG_G = government net saving, equals reported net saving minus $C C A J \_G$ minus capital transfers to other sectors.

This leaves $G N P \_A, N N P \_A, G N P \_B E A$ and $N N P \_B E A$. Since in the National Accounts the value of government output is taken to be equal to the costs of producing it, GNP must be adjusted for the discrepancy between the reported value $\left(K D_{-}{ }^{B} \_G\right.$ above) and our estimate of the government depreciable assets $\left(K D_{-} G\right)$ and depreciation. NNP (net national product) then is this adjusted GNP less national depreciation at replacement costs. We use a rate of return of 4 percent to impute net service flows from government tangible assets. Thus:

$$
\begin{aligned}
& G N P \_A=\text { reported } \mathrm{GNP}+0.04 *\left(K D_{-} G-K D_{-}{ }_{-} \_G\right) \\
& +C C A J_{-} G \text {. } \\
& N N P \_A=G N P \_A-\left(D E P H_{-} H_{-}+D E P H_{-} C+D E P H_{-} G\right) \\
& -\left(C C A J_{\_} H+C C A J_{\_} C+C C A J_{-} G\right) \text {. }
\end{aligned}
$$

Neither $C C A J$ nor $K D \_G$ is available for 1965-69. Thus for this period GNP_A and NNP_ $A$ are equal to respective reported values. The definition of GNP and NNP should be altered if government tangible assets are to be ignored. The BEA definition of Japan's NNP would be:

$$
\begin{aligned}
& G N P \_B E A=G N P \_A-0.04 * T A_{-} G-D E P H_{-} G-C C A J_{-} G . \\
& N N P \_B E A=N N P_{-} A-0.04 * T A \_G .
\end{aligned}
$$

For 1965-69 data on TA_G and CCAJ_G are not available. We use the 1970 ratio of $G N P \_A$ to $G N P \_B E A$ to extrapolate $G N P \_B E A$ for 1965-69. The same extrapolation method is used for NNP. 


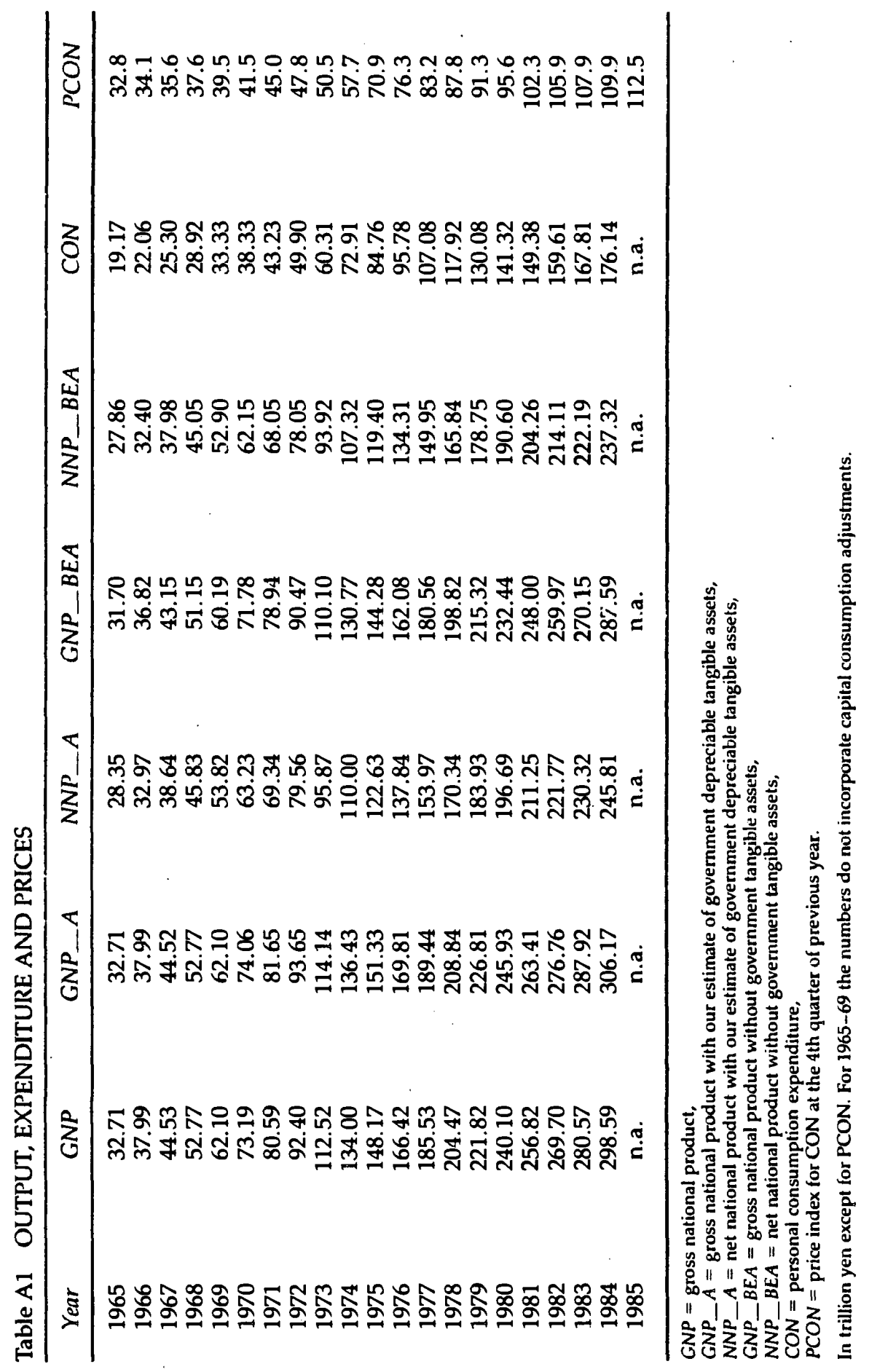




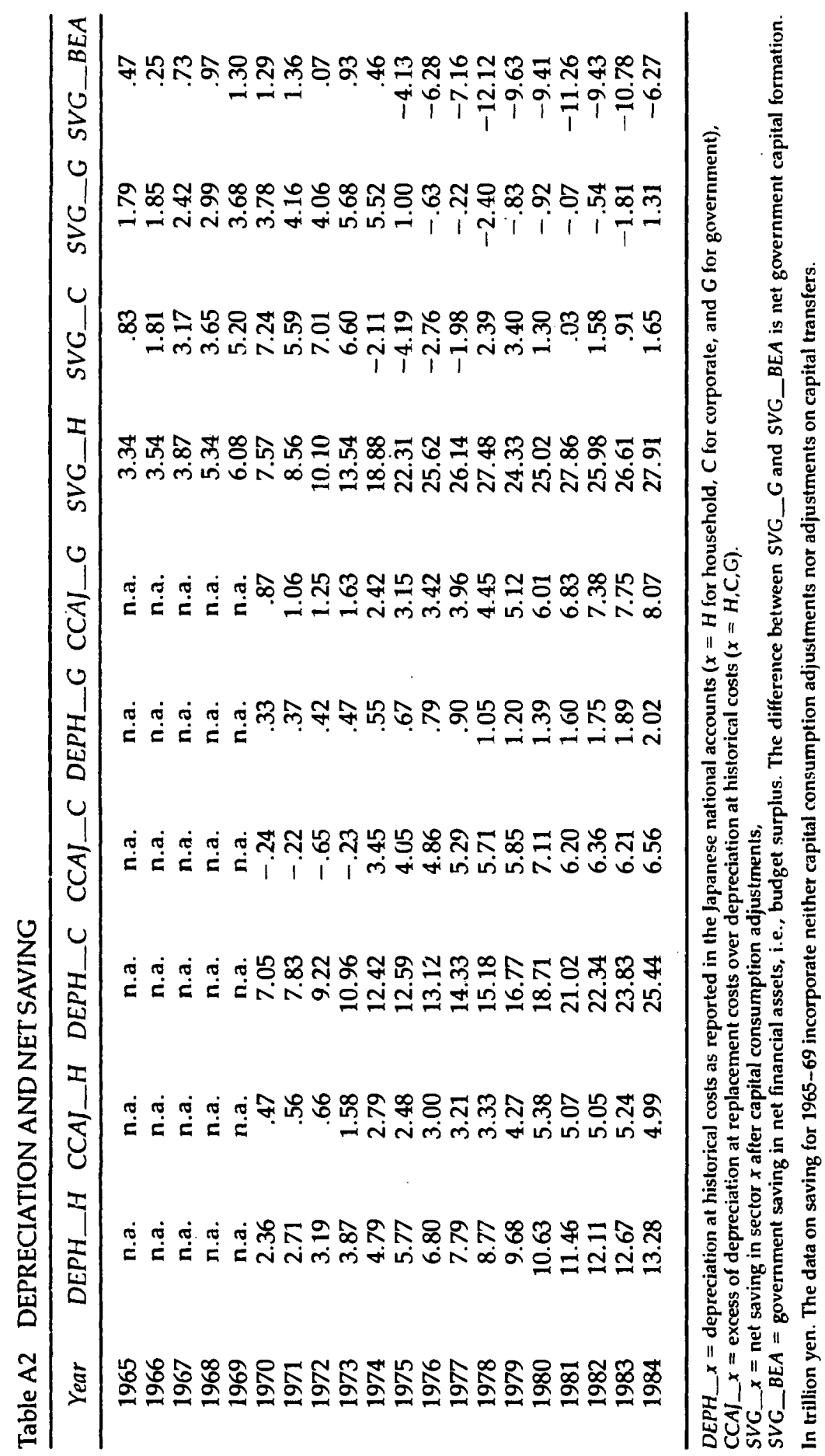




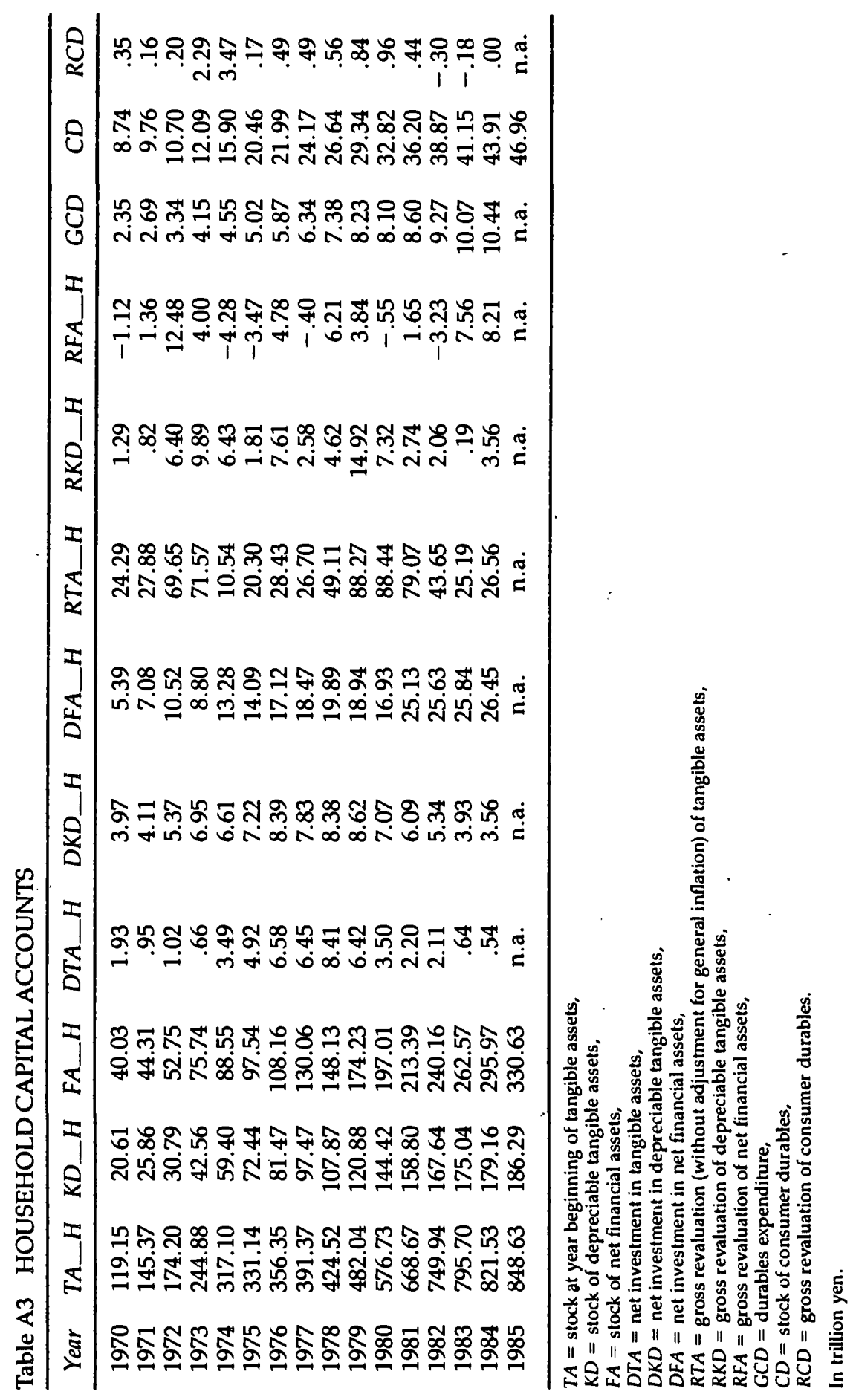




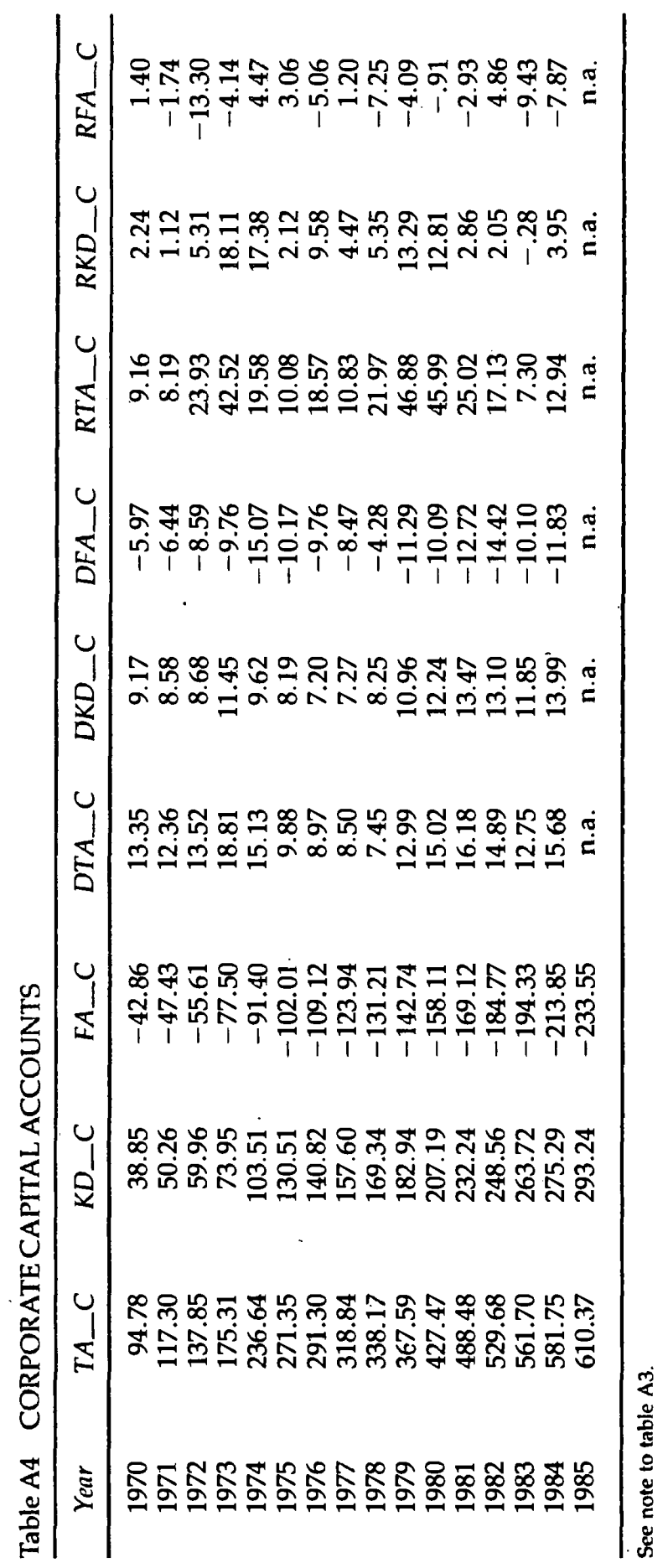




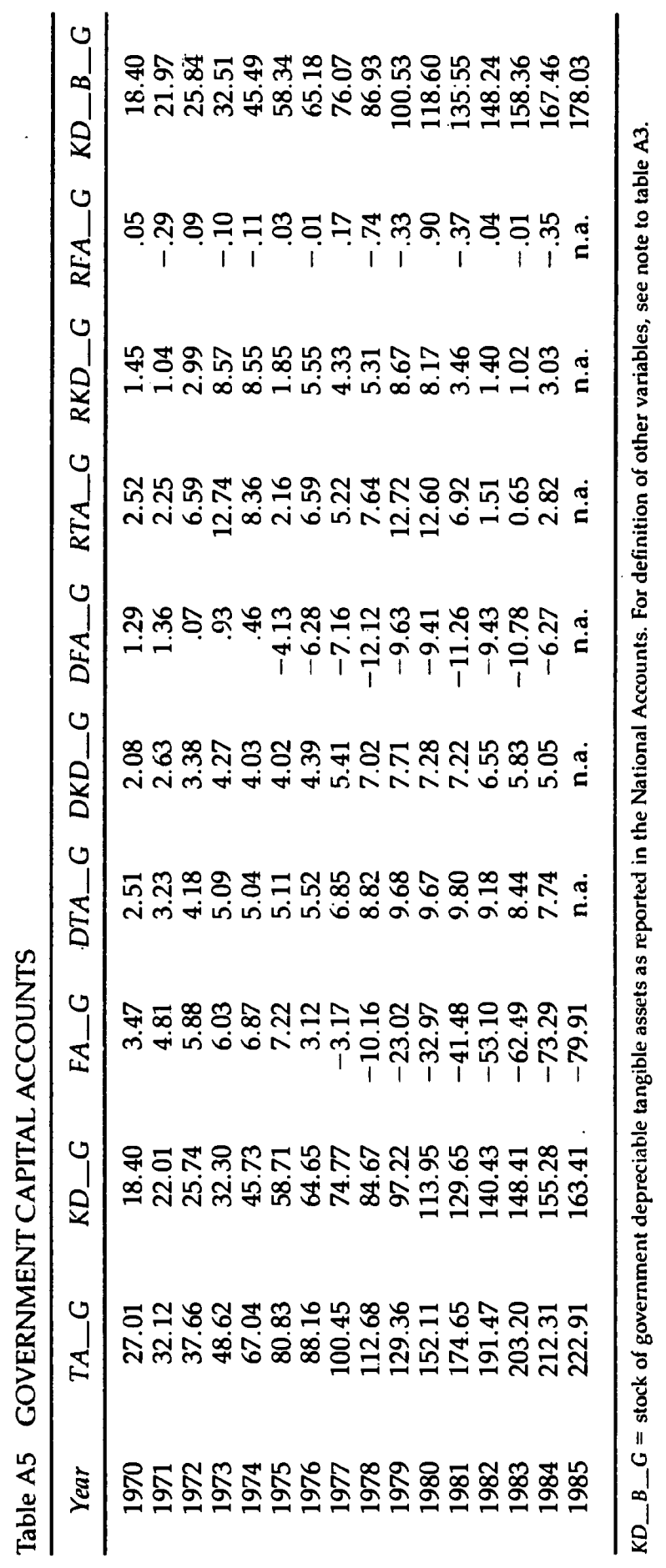




\title{
Comment
}

\author{
ALBERT ANDO \\ University of Pennsylvania
}

Fumio Hayashi has produced a very large article which deals with a number of complex issues including data problems that arise in the course of attempting to understand whether or not the Japanese savings rate is indeed unusually high, and if so, what may be the reasons for it. Since his discussion is so wide-ranging, I comment on only a few of these issues.

\section{How High Is the Japanese Savings Rate?}

It is a curious fact that, as Hayashi demonstrates, there is substantial uncertainty on the magnitude of the Japanese saving rate. I believe, for example, that the saving rate based on the national income and product accounts of Japan is more subject to doubt than, say, the corresponding United States figures. I have no serious disagreement with Hayashi on the selection of adjustments undertaken to make Japanese figures comparable to those of the United States. I would be inclined, however, to rely mostly on the concept of private saving rather than on national saving for the purposes of characterizing Japanese savings and for comparing it with the U.S. case. We can always add net government saving to private saving to obtain national saving if the latter concept is needed for some specific purpose, but I believe that private saving is the more behaviorally meaningful concept than national saving, especially after recent U.S. history indicated that sudden and very large changes in government saving were not in any way compensated by changes in private saving.

It is also helpful to keep in mind the order of magnitude of the aggregate net worth-income ratio of the private sector. In table 1, I present the adjusted net worth of the household and its ratio to disposable income of the household sector in Japan for selected years between 1970 and 1983. The net worth reported in Japanese national income and product accounts was adjusted for two reasons. First, an extraordinarily large proportion of the total net worth is the value of land, which is, of course, nonreproducible and hence does not at the aggregate level result from accumulation of savings. For our purposes, it seems better to exclude the value of land from consideration. Second, for reasons that are too complex to go into here, the value of corporate shares owned by the household sector is grossly understated. Since I know of no reliable estimate of the market value of shares owned by households, I have replaced figures 
reported in the national income and product accounts by the net reproduction value of capital owned by nonfinancial corporations less the value of shares owned by financial institutions.

The ratio of adjusted net worth to disposable income rises dramatically from 2.5 in 1970 to 4.0 in 1983 . Unfortunately, we do not have data to compute the same ratio for earlier years, but I offer a conjecture that this ratio declined during the 1960 s, at least partly because even the high rate of saving of Japan was not quite enough to generate sufficient accumulation of net worth to keep pace with the high rate of growth of income in the 1960s. The comparable figure for the United States is a little higher than 4, so that Japan has just caught up with the United States in terms of this ratio. So long as adjustments for the value of land and the value of corporate shares are made, this result qualitatively remains for a wide variation in choices of the definition for ratios of this type. This immediately establishes two points. First, the high saving rate in Japan is not due to the very high asset-income ratio maintained by the Japanese household sector. Second, during the 1970 s at least, the high saving rate assisted the recovery of the net worth-disposable income ratio of the household sector from a very low level to the level comparable to that in the United States, and indications are that the increase of the net worth-disposable income ratio has now stopped.

This fact and Hayashi's adjustments to figures in Japanese national income and product accounts which lowers the private savings rate noticeably from those reported in official data should place the whole problem in better perspective. The Japanese savings rate is still significantly higher

Table 1 ADJUSTED NET WORTH OF THE HOUSEHOLD SECTOR AND ITS RATIO TO DISPOSABLE PERSONAL INCOME IN JAPAN, SELECTED YEARS (Beginning of the year)

\begin{tabular}{|c|c|c|c|c|c|}
\hline & $\begin{array}{l}\text { Reported } \\
\text { net worth }\end{array}$ & $\begin{array}{c}\text { Less value } \\
\text { of land }\end{array}$ & $\begin{array}{l}\text { Plus adj. } \\
\text { for value of } \\
\text { corp. shares }\end{array}$ & $\begin{array}{l}\text { Adjusted } \\
\text { net worth }\end{array}$ & $\begin{array}{l}\text { Ratio of } \\
\text { adjusted } \\
\text { net worth to } \\
\text { disposable } \\
\text { income }\end{array}$ \\
\hline 1970 & 167.3 & 104.0 & 52.3 & 115.6 & 2.5 \\
\hline 1975 & 411.0 & 235.6 & 162.7 & 338.1 & 3.1 \\
\hline 1980 & 744.0 & 394.3 & 249.1 & 598.8 & 3.5 \\
\hline 1981 & 849.7 & 466.7 & 283.9 & 666.9 & 3.7 \\
\hline 1982 & 954.4 & 535.5 & 306.3 & 752.2 & 3.9 \\
\hline 1983 & $1031: 6$ & 577.3 & 321.1 & 775.4 & 4.0 \\
\hline 1984 & 1082.0 & 600.5 & 312.0 & 793.5 & \\
\hline
\end{tabular}

Source: Annual Report on National Accounts, 1985, Economic Planning Agency of the Government of Japan, 
than that for the United States, but it does not appear to be very much higher than comparable ratios for at least some European countries, although figures for European countries, too, must be carefully reviewed before our comparisons are meaningful. Even Hayashi's figures may be subject to further adjustments, and I mention here one item that immediately comes to mind: In the nonfinancial corporate sector, where most of investment takes place, it should be the case that total gross investment less depreciation and retained earnings after taxes should equal the excess of borrowing over acquisition of financial assets, with a few well-defined adjustments. It turns out, however, that in the Japanese national income accounts the former has been substantially larger than the latter since 1970, and the discrepancy is quite often larger than the total of retained earnings plus dividends. I have never been able to resolve this puzzle, but it is possible that there is substantial underestimation of savings by the corporate sector in Japan.

I believe that there is an urgent need for the Japanese national income and product accounts to be thoroughly examined, and most importantly, much closer communication and exchange of information between officials in charge of these statistics and outside economists.

\section{Hayashi's Theses}

After reviewing a number of suggested causes of the high saving rate in Japan, Hayashi analyzes two of them seriously. First, he notes that the life-cycle theory with its hump-shaped asset accumulation pattern over life for families would make the saving rate dependent on the rate of growth of average productivity per manhour and the population structure; it is conceivable that the high saving rate in Japan can be explained by the high growth rate and an unusual demographic structure. The second hypothesis is the possibility that Japanese families tend to leave very large bequests relative to their lifetime earnings. Hayashi arrives at a tentative conclusion that the life-cycle hypothesis does not apply to Japan, and that bequests are the dominant motive for saving in Japanese families.

Based on his evidence as well as on my own research on this subject, I am sympathetic to the view that the life-cycle theory appears to be on shaky empirical ground in Japan, although I am inclined to say that it probably has somewhat stronger support in Japan than in other countries. I would agree with Hayashi in recognizing strong indications from various data sources for a substantial portion of accumulated assets by households being passed along to the next generation, either as intervivos gifts or as bequests. I find it hard to interpret the evidence as indicating that Japanese families are consciously motivated by the desire to leave bequests, any more than families in the United States or in Europe. 
In any case, I believe the high rate of growth of real income in Japan since 1950 was an important factor contributing to the high saving rate, independent of the validity of the life-cycle hypothesis.

Hayashi bases his first conclusion on the result of his micro simulation analysis, reported in table 4 of his article. In particular, he observes that the aggregate savings-income ratio and the wealth-income ratiogenerated by his simulations have little relation to observed values of these ratios.

In the "steady state", if such a state exists, one would expeci that the rate of growth of aggregate income and of aggregate wealth would be the same, and the aggregate wealth-income ratio, $a$, and the aggregate savingincome ratio, $s$, would satisfy the relationship $s=g a$, where $g$ is the rate of growth of aggregate real income. From Hayashi's discussion of his "steady state" simulations given in footnote 14 of his paper, we can see that he is not requiring results of his simulations to satisfy a condition such as above. It is still somewhat surprising, however, that the pattern of his result is so far from this condition, and understanding the reasons for this divergence is a key to interpreting the result of his simulation analysis correctly.

Most of the results reported in table 4, especially some of the more startling values, are consequences of combining the observed age profile of earnings with the pattern of consumption assumed to grow at a constant rate for the entire life of the household. Given the age profile of earnings presented in table 3 of Hayashi's paper, when the optimal consumption growth rate is fairly low, there would be large dissavings by younger households, substantial savings by the middle-aged households, and dissavings by the elderly. Also the higher productivity growth means that younger persons have much larger lifetime earnings than their older counterparts, so that their dissavings would be greater and savings of the middle-aged would be smaller, thus reducing the level of aggregate savings. This mechanism explains the curious result that the savings rate in table 4 appears to decline when the growth rate of productivity increases, contrary to my proposition in the preceding paragraph. The dissaving by the oldest group matters relatively little, both because there are relatively few older persons and because their lifetime earnings are smaller than those of younger persons.

The above consideration hints that the problem might be alleviated if the dissaving by younger households is eliminated. Hayashi recognizes this possibility, and reports at the end of the section 4 of his paper that he repeated the simulation experiments with the constraint on consumption not to exceed the algebraic sum of income in the same period and the initial value of wealth. He further reports briefly a surprising result that even with such a constraint, the simulation fails to generate the value of 
the wealth-income and saving-income ratios that are even remotely close to observed aggregate ratios, and that the negative relationship between the rate of growth of productivity and the savings-income ratio persists. This is surprising since others have found it fairly easy to generate the wealth-income and saving-income ratios close to observed values through similar simulation experiments once dissavings by younger families are eliminated.

To gain some insights into what is going on, consider an extreme case in which the rate of real interest is zero and the optimal consumption path is to consume the same amount throughout the life of a household. Let us suppose also that the rate of growth of productivity is quite high, say between $5 \%$ and $10 \%$ per year as it has been in Japan since 1950 . The crosssection earnings profile given in table 3 of Hayashi's paper would add another $5 \%$ to $10 \%$ to the growth rate of income, so that the family's li.ngitudinal growth rate of income is between $10 \%$ to $20 \%$ per year. If such a growth rate of income is matched against the zero growth rate of consumption; in the absence of the liquidity constraint, the family would make very large dissaving at the beginning of its life, expecting to eliminate debts through later savings. When it is subject to the liquidity constraint, however, it begins its life consuming all its income, maintaining net wealth position of zero. When it reaches the age at which unconstrained families would have switched from dissaving to saving, it will continue to consume all its income since it has no debts to eliminate.

The liquidity constrained family, under these assumptions, would therefore go through most of its life with zero net wealth, and only shortly before the retirement, would save a very large part of its income in order to acquire wealth to cover consumption after retirement. It is also clear from this description that the greater the rate of growth of productivity, the shorter the period in which such a family would maintain a positive net wealth position. Hence, the size of net worth held by families averaged over the entire population is very small because only those families just before retirement hold any assets, and most families hold zero assets. Furthermore, the greater the rate of growth of productivity, the fewer families there will be with any positive assets, and the smaller the size of net wealth averaged over the entire population. Consequently, provided that the rate of longitudinal growth of income is quite high to begin with (which is insured by the Japanese age-earnings profile), the negative relationship between the aggregate wealth and the rate of growth of productivity can be strong enough to make the relationship between the rate of growth of productivity and the saving rate negative.

These are interesting implications of the model that Hayashi simulates, but it is not at all surprising that the wealth-income and saving-income 
ratios generated by his model do not correspond to those observed in Japan. In Japan, contrary to the implication of this model, we observe that virtually all young families save, and the age profile of savings is quite even throughout the working life of the family. This does not necessarily mean that the savings behavior of Japanese households is contrary to the life-cycle theory, as I am not at all sure how much his simulation and its constantly rising consumption at a fixed rate (and others like it used by other authors in recent years) have to do with the life-cycle model visualized by those who originally formulated the model. Modigliani, for example, in his earlier works often used a utility function which is also separable but cornered like a Leontief production function, so that the allocation of total resources to each period in life is predetermined, reflecting what is considered to be a normal pattern of consumption needs by most families. Logically, I do not see that one is superior to another, and if the utility function used by Hayashi is so clearly contradicted by the data, then perhaps we should consider alternatives.

Hayashi seems to conclude from the simulations not only that the lifecycle theory does not apply to Japan, but also that the growth rate of productivity has little to do with the savings-income ratio. As I have indicated before, the relationship between the growth rate of productivity and the aggregate savings-income ratio is by no means unique to the lifecycle theory. Consider, for example, a society in which all households always aim to leave a fixed proportion of total resources available to them during their lives as bequests to the next generation, and save a fixed proportion of their income throughout their lives to do so, so that there is no dissaving at any point in their lives. In such a society, the aggregate savings-income ratio must be strongly and positively correlated with the sum of the rate of growth of productivity and the rate of growth of population. Indeed, provided that the growth rates are substantial, that is, the sum of the growth rate of productivity and that of population is 3 percent or more, the behavior of older persons, whether they dissave their wealth or leave it to the next generation, makes only a minor difference in the aggregate savings-income ratio and the aggregate wealth-income ratio.

I nevertheless accept the proposition that a critical test of the life-cycle theory is the presence or absence of some dissaving after retirement, although the life-cycle theory can certainly coexist with the presence of some bequests, and that the apparent total lack of dissaving by older households in Japan is clearly inconsistent with the life-cycle theory unless this observation is due to some serious biases of sampling or measurement. Much of the rest of the Hayashi article deals with this question, and since he contrasts his analysis with some earlier results I 
reported elsewhere, I would also like to make a few comments on this rather technical question.

There is no dispute between Hayashi and me that the majority of those older persons maintaining independent households continue to save, and therefore, they leave most of their accumulated wealth as bequests or gifts. (The exception is the small group of some elderly single-person families, mostly women, who are very poor and have virtually no wealth, and appear to subsist on welfare payments and gifts from others.) The behavior of this group is, therefore, not consistent with the life-cycle theory. The problem in Japan is that a larger and larger proportion of older persons become dependent members of younger households as they age. Hayashi reports that in 1983 some 67 percent of persons 65 and over lived with their children. It is generally supposed, and fairly easy to demonstrate, that those older persons remaining independent are likely to be more active economically as well as wealthier. The critical question therefore is what the wealth holdings of those older persons merged into younger households look like, but this is a very difficult question to answer because we do not have any direct observations on them. The only way to infer anything about their wealth-holding behavior is to compare features of those younger households which contain older persons with those of other younger households which do not contain older persons, and try to get at net contributions of older persons indirectly. This is what Hayashi tries to do in his tables 8 and 9.

He draws several conclusions. First, the net contribution of the presence of older persons in the younger family to the total finaricial assets of the extended family appears to decline as the age of the younger head of the household increases. One needs to be careful about this proposition. Net financial assets is not total net worth, and in Japan by far the most important item in a family's net worth is the value of the residence, and the incidence of house-ownership increases very significantly with the age of the head of household. Furthermore, the probability of a family owning a house is very strongly and significantly affected by the presence of older persons when the head of the family is very young, but is almost unaffected when the head of the family is over 50 .

Second, Hayashi observes that the net contribution of the presence of older persons to a measure of savings available in his table 8 is always positive, for all age groups. Hayashi further infers from these two observations that the only possible way in which the positive savings by older persons and the decline in their net financial assets can be reconciled is to suppose that older persons are giving substantial amounts of their assets as bequests and gifts.

I have carried out a somewhat similar analysis in an earlier paper, but 
since I had access to individual observations with fairly extensive demographic information for the same survey, I tried to work with my own estimate of total net worth of families rather than financial assets, estimated lifetime earned income after taxes rather than current pretax income, and attempted to control for both the age of the younger head of household and the age of the older dependent member of the family. I observed a much clearer decline in total net worth than Hayashi does, which may be due to the differences in definitions used and the explicit control for the age of older persons. The size of the increase in consumption expenditure indicated by Hayashi due to the presence of older persons is considerably smaller than mine, but the difference will not make their positive contribution to saving into a negative one. I did not attempt to estimate income or savings of dependent older persons. The surprising feature of his table 8 , it seems to me, is the large net contribution to the income of the family by the presence of retired, older persons, from 10 percent to as much as 30 percent of the income of younger households. Hayashi suggests that I did not take account of the possibility that a part of the net worth of a younger household without an older person living in it may have been contributed by older persons who once lived with them but are now deceased, and that this process is what he is observing. I must confess my skepticism on this very subtle point. I hope that a projected future project using additional data will help Hayashi and me to clarify this.

Hayashi then attempts, through an extremely ingenious scheme, to compute the size of intergenerational transfers implied by data at his disposal, as shown in table 9 . He finds it surprising that the size of implied intergenerational transfers appears to him to be very small in the light of the size of total net worth held by all households in the economy.

I am not very surprised. I have found in my own analysis of the U.S. case that of the total existing assets held by the household at any given time, the part contributed by bequests from the previous generation is quite small, say less than a third or a quarter of the total, even when one works through a model in which all accumulated savings by households are left as bequests to the next generation, provided that the economy has a respectable rate of growth of total real income, say 3 percent per year or more. This is because, given the rate of growth, assets accumulated by the currently living generation at their higher level of income are much larger than the assets accumulated by the deceased generation at their much lower level of income. Given that the rate of growth of output for Japan has been extraordinarily high for the past thirty years, Hayashi's result is clearly in line with what I would have expected. 


\section{Some Final Observations}

This brings me to the point that I find basic to the understanding of the differences in the aggregate savings rate among countries and also its secular (not cyclical) changes in a single country. As I have suggested, the aggregate savings rate does not depend all that critically on the savings behavior of the older, retired persons, simply because the amount of wealth these older persons control as a proportion of the total wealth of the society is not large, provided that the economy is growing at a respectable rate. It depends more critically on the standard pattern of asset accumulation by individual households while they are still income earners, on whether or not this pattern is fairly stable among individuals and over time, and also on the rate of growth of income.

The dependence of the saving rate on the rate of growth of income is not a unique feature of the life-cycle theory, certainly not of a very restrictive version of it. Even when all households in the economy intend to leave all their accumulated savings to the next generation as bequests and succeed in doing so, the saving rate must be positively related to the growth rate. If the bequest motive is to explain variations in the aggregate savings rate among countries independent of the growth rate of income, then couritries with high bequest motives must have not only high saving rates but also a high wealth-income ratio. I do not believe that we observe a very strong relationship between the savings-income ratio and the wealth-income ratio among countries. For the explanation of the aggregate savings-income ratio, my view therefore is that we must first pay attention to the pattern of accumulation during the earning period of individuals and to the rate of growth of income, and only secondarily to the behavior of older, retired persons, independent of whether the life-cycle theory or the bequest model is used as the basic descriptive vehicle. This does not mean that the distinction between the life-cycle model and the bequest model is never important. For example, it still seems critical in analyzing the effects of a substantial expansion in social security programs on household behavior.

I still have difficulty in understanding a bequest model that leads to substantial intergenerational transfers in the context of continually rising productivity. Individuals in a particular generation know that their children will have very much larger resources. For example, if the rate of productivity growth is 2 percent per year, a generation thirty years younger would on average have roughly twice the income of the older generation. If the older generation has a utility function that is separable in time and treats consumption of current and future generations symmetrically, then the maximization of expected utility subject to the budget 
constraint with an infinite horizon must lead to the transfer of resources from the younger to the older generation, not the other way around. Introduction of a very large subjective rate of discount to alleviate the situation will not do, because it is, in effect, introducing the result as an assumption of the analysis. It seems to me, therefore, that we need to have a much better-formulated model of the bequest before we can take it seriously. I am personally more attracted to a model in which individuals' wealth-holding behavior near the end of their lives is strongly affected by the uncertainty of the timing of death, and by the possibility that they might face a catastrophic situation, and who, as a result, end up leaving a substantial portion of their wealth at the time of their death, although their interest in leaving a bequest to the younger generation is limited. In this context, we may also remember the well-known proposition that the behavior of individuals may substantially deviate from that predicted by expected utility theory when the probability of events involved is extremely small.

In the case of Japan, I also believe that the role of home ownership plays an important role in the asset accumulation process, because the value of land is so extraordinarily high, but I think we have only scratched the surface of this complex question.

I have disagreed with a number of analyses and propositions offered by Hayashi in his article. Especially because of this fact, I must stress here that his is a remarkable effort, assembling a vast body of information in a reasonably well-organized manner, and I have learned a great deal from it. Even when I did not like his analysis, it forced me to think through the problem a little more deeply than I would have done otherwise. Problems that I raised in my comments reflect serious difficulties faced by all of us trying to press on with empirical analysis beyond very general observations, and I look forward to learning more about the characteristics of the Japanese economy solidly based on empirical research from Hayashi's future work.

\section{Comment}

PAUL M. ROMER

University of Rochester

Fumio Hayashi's article on Japanese savings, (Hayashi 1986), starts with a detailed examination of data from the United States and Japan. Before moving on to possible explanations for the behavior of savings in Japan, he tries to gauge the accuracy of the widespread perception that the Japanese saving rate has been, and continues to be, two to three times higher 
than the U.S. rate. He concludes that a simple comparison of personal saving rates overstates the difference in true savings behavior and masks a steady decline in the Japanese saving rate since 1970 . He then proceeds to examine possible explanations for the remaining difference between the U.S. and Japanese experience and the behavior of Japanese savings over time.

The first part of the article is valuable because it suggests caution about how one measures savings and raises questions about the reliability of the available data. I heartily agree, and conclude that these difficulties make any comparison of the saving rate in the two countries uninformative about the key questions of interest: What is the nature of intergenerational transfers? Does a budget deficit or a social security system reduce national savings? However, the time-series behavior of savings in Japan does raise interesting issues of its own, especially when compared to the growth of GDP. The period of high savings seems to coincide with an unprecedented period of high GDP growth rates, and this coincidence may deserve more attention than Hayashi gives it.

The conventional way to approach the definition of savings is through national income accounting. Following the usual notation, let $Y$ represent gross domestic product, $C$ private consumption, $G$ government expenditure, and $X$ net exports. We can also define government transfer payments $R$, taxes $T$, and the budget surplus, $B=T-G-R$. Let $F$ denote the value of net foreign assets and let $r$ denote the (domestic consumption good) coupon rate on foreign bonds. Finally, recall that the current account surplus $C A$ is net receipts from foreigners, $C A=X+r F$.

The conventional definition of savings as given in a macroeconomics textbook is the difference between net private disposable income and private consumption. For simplicity, let $K$ denote the aggregate capital stock and let $\delta$ denote the depreciation rate. Then

$$
S=[Y-\delta K+r F+R-T]-C \text {. }
$$

Using the usual income identity and the definitions given above, private savings can be written as the sum of net investment and the current account, minus the budget surplus:

$$
S=(I-\delta K)+C A-B \text {. }
$$

The level of savings can be converted into a saving rate by dividing by net national income.

This kind of measure of savings is the focus of standard open-economy macroeconomics, but it is cnly one of many possible measures of ac- 
cumulation and may not be the one relevant for a given theory. One alternative measure is dismissed early in the article. Savings given in equation (2) is total private-sector savings, but data for the private sector is collected separately in the personal and corporate sectors. The personal saving rate in Japan is indeed two to three times as high as personal savings in the United States, but the difference between private-sector savings is smaller and has been steadily diminishing since 1970. A simple Modigliani-Miller argument suggests that the division of private-sector savings into corporate and personal savings is only a matter of accounting and should have no theoretical significance.

Having made this observation, it is natural to pursue this line one step further and consider net national savings, $S+B$. Adding the budget surplus to private savings reinforces the effects caused by the addition of corporate savings to personal savings. The net national saving rate in Japan is closer still to the rate in the United States, and the downward trend is more pronounced. However, the theoretical justification for choosing national savings over private savings is more controversial. The choice of the measure of savings now depends on the theoretical stand one takes on the nature of intergenerational altruism and transfers. As is now well understood, a Modigliani-Miller argument applies to an increase in government debt caused by a shift in tax liabilities from the present to the future only if the agents who receive the current tax reductions must also pay the increased future taxes. If one believes in a life-cycle theory of savings, a comparison of national saving rates will understate the true divergence between the actions of agents in the United States and in Japan. From this point of view, the question becomes not only why private individuals in Japan save more than those in the United States, but also why government fiscal policy is set to partially offset this difference.

As Hayashi goes on to point out, the measure of the budget surplus in the United States is misleading because it does not distinguish between expenditures on capital goods and consumption goods. Using estimates by private economists of government capital formation for the United States, the article offers an additional measure of savings which adds back net capital formation in the government sector. Comparable figures for Japan are available from the national accounts. At a theoretical level, it is not clear how to take account of the substantial differences in the nature of government expenditures in the two countries, especially with regard to the military. But at this point, problems with the data appear to overwhelm the theoretical issues. The official Japanese accounts do not attempt to measure depreciation on most forms of government capital, presumably because of the difficulty of doing so. The data for the United 
States do include depreciation on the entire capital stock. The net result of the correction for government capital formation is to suggest that net capital formation by the government in the United States is around 1 percent of NNP, but is roughly 5 or 6 percent of NNP in Japan. In the absence of some other systematic difference between the activities of the two governments-and I am aware of no such difference-military expenditure alone should cause net capital formation in the United States to be higher. I suspect, and Hayashi seems to agree, that the apparent difference results from differences in the accounting conventions used to generate the estimates for the two countries. If my prior belief that the U.S. government has the higher rate of net capital accumulation is correct, this suggests that differences in accounting conventions concerning issues like the treatment of depreciation, or simple errors in the system of accounts, can lead to differences in reported rates of accumulation on the order of 5 percent of NNP.

There is direct evidence that issues of measurement extend beyond the government sector. Hayashi notes that the published savings numbers from Japan are derived from a measure of net national product that uses historical cost data to estimate depreciation. Using other data, he can construct a replacement cost estimate of depreciation and reduce the estimate of net national product accordingly. Since the level of savings is calculated as a residual, this causes a one-for-one fall in savings and a reduction of the savings rates by 2 percentage points during the 1970 s.

The U.S. data should also give reason for concern. The national income accounts estimate of personal savings constructed by the BEA has for some time differed substantially from the estimate constructed by the Federal Reserve Board using balance sheet data. For example, for the years 1980 through 1983, the FRB measure of savings by individuals is more than twice the BEA measure of personal savings, at a level of roughly 10 percent of NNP versus 5 percent of NNP. (Data taken from Tables B19, B25, and B26 of the 1985 Economic Report of the President.) The influence of depreciation on the measured rate of savings in Japan is suggestive of general difficulties. Since the national income accounts measure of savings is a residual, small percentage errors in net income or consumption can cause large changes in estimated saving rates. One explanation that has been offered for the most recent decline in the personal saving rate in the United States is that the proliferation of deferred compensation plans (e.g. $401 \mathrm{k}$ or $403 \mathrm{~b}$ plans) may have artificially reduced income reported to the government without affecting measured consumption.

In the case of capital accumulation by the government, skepticism about the data overwhelms any conceptual issues, and emphasis is placed on measures that do not contain any estimate of this effect. The treatment 
of the government is of course not the only source of suspicious data or theoretical ambiguity. Even in the absence of any government capital formation, a national income account measure of savings does not capture all changes in wealth, yet wealth is presumably what matters to individuals. This is true whether or not they are inclined to leave bequests. The article refers explicitly to changes in wealth associated with depreciation in the real value of outstanding U.S. government debt, but the issues here go far beyond this case. To make this point, consider a simple model that is capable of allowing for general gains and losses.

Let $k_{s}(t)$ denote the amount of capital of vintage $s$-that is, capital produced at date $s$-still in service at date $t$. Using the notation from above, $k_{t}(t)$ can be expressed as gross domestic product minus private consumption, government consumption, and net exports:

$k_{\ell}(t)=Y-C-G-X$.

Let $p_{s}(t)$ denote the price at time $t$ of vintage $s$ capital. By the nature of the technology, $p_{t}(t)$ must be equal to 1 , but $p_{s}(t)$ can differ from 1 . Using these prices as weights, define a measure of the aggregate capital stock $K$ as:

$K(t)=\int_{-\infty}^{t} p_{s}(t) k_{s}(t) d s$.

Finally, suppose that all vintages suffer the same exponential rate of physical depreciation, $\delta$. Differentiating $K$ with respect to time yields

$\dot{K}(t)=k_{t}(t)+\int_{-\infty}^{t} p_{s}(t) \dot{k}_{s}(t) d s+\int_{-\infty}^{t} \dot{p}_{s}(t) k_{s}(t) d s$.

Because of the exponential depreciation, the second term is equal to $-\delta K(t)$. The last term represents capital gains on capital, and will be denoted as $\Gamma_{K}$. Thus, we can write

$\dot{K}=k_{t}(t)-\delta K+\Gamma_{K}$.

Measured private sector wealth is the value of all traded assets. Let $L$ denote the stock of land (or of any other input in fixed supply), let $F$ denote the net quantity of foreign bonds, and let $q$ and $m$ denote corresponding prices. Then marketable wealth is

$W(t)=K(t)+q(t) L+m(t) F(t)$,

and the rate of change of wealth is

$\dot{W}(t)=\dot{K}(t)+\dot{q}(t) L+\dot{m}(t) F(t)+m(t) \dot{F}(t)$. 
Following the notation from above, let $\Gamma_{N}$ denote capital gains on land, $\dot{q}(t) L$, and let $\Gamma_{F}$ denote increases in the market value of foreign bonds, $\dot{m}(t) F(t)$. Using equation (4) and the fact that $m(t) \dot{F}(t)$ equals the current account surplus, equation (6) becomes

$\dot{W}=k_{l}(t)-\delta K+C A+\Gamma_{K}+\Gamma_{L}+\Gamma_{F}$.

Finally, using the expression from equation (2) for national savings $S+B$ and from equation (3) for $k_{t}(t)$, we have

$W=(S+B)+\Gamma_{K}+\Gamma_{L}+\Gamma_{F}$.

Thus, national savings differs from the rate of accumulation of wealth because it neglects capital gains on marketable wealth.

Whether the rate of change of wealth should be used in place of a national income account measure of savings for normative or positive purposes is not clear. Even if the capital gains terms in equation (8) could be measured accurately, it is not necessarily the case that they should be included. The article motivates consideration of changes in wealth based on the observation that the fall in the real value of outstanding U.S. government debt represents a true increase in future national consumption possibilities. For economic purposes, the division of the returns from bond holding into coupon income and appreciation is irrelevant; yet under the accounting arrangements described here, if the U.S. government were to refinance the outstanding debt held by foreigners with zero coupon bonds, the budget surplus and the current account surplus would increase immediately. Thus gains such as $\Gamma_{f}$ should surely be included.

An opposing accounting argument arises because the coverage of this measure of wealth is incomplete. Recent increases in, say, the value of land or of corporate assets in the United States may simply reflect changes in taxation like the reduction in the average effective tax rate for corporations or the introduction of the exemption from taxation of gains from the sale of owner-occupied housing. If the resulting reduction in tax revenue from these sources was recovered by an increase in the tax on labor income, the increase in the value of marketable assets. will have been largely offset by a fall in the value of human capital. Since there are no market prices for human capital, it can not be included in $W$ and $\dot{W}$ will show a net increase in wealth.

This is not to argue that all or most measured capital gains arise purely from accounting conventions. Simple arguments suggest that real gains may be quite important. Consider a production function for GDP that 
can be written as a stationary function $f$ multiplied by a term $e^{g t}$ which captures exogenous technological change. The function $f$ will depend on land $L$, labor $N$, and all vintages of capital:

$Y=e^{g t} f\left(k_{s}\right.$ for $\left.s \in(-\infty, t], L, N\right)$.

If all arguments of $f$ stayed constant over time, the term $e^{8^{t}}$ would cause the marginal products, and hence the rental prices, of all inputs to increase, leading to capital gains that represent real increases in welfare. Of course, one would not expect all inputs to stay constant. New capital $k_{t}(t)$ would continue to be added over time. If different vintages of capital are sufficiently good substitutes, this will lead to a compensating decrease in the marginal product and price of older capital. Technological change that leads to the introduction of a new megabyte computer memory chip does not in and of itself reduce the marginal product of existing chips; but if the cost of the new chip is low, the total number of bytes of memory in use will increase and the old chips will indeed suffer a capital loss. In the classical case where all vintages are perfect substitutes, these effects will cancel, the price of all capital goods is always 1 , and no capital gains on capital take place. But if $f(K, L, N)$ is homogeneous of degree one, the marginal product $D_{K} f(K, L, N)$ is homogeneous of degree zero and

$$
-K D_{K K} f=L D_{K L} f+N D_{K N} f
$$

Thus, the decrease in the rental price of capital, caused by an increase in the stock of capital, is offset by an increase in the rental price of some other input. To the extent that this increases the marginal productivity of land (or of any other marketable factor in fixed supply), technical change will still be captured in changes in wealth. If different types of capital are not perfect substitutes, gains on capital could still be observed; think for example of the effect of cheaper computer memory chips on the value of all of the patents and proprietary software held by IBM. To the extent that the gains accrue to labor, they will not be captured in a measure of increases in wealth. If the size of the work force were truly fixed at some level $N$, increases in the value of human capital would show up in high rates of growth of productivity; but in the United States, for example, employment has increased dramatically in the last fifteen years, so this effect must be estimated as part of a larger simultaneous system.

A national income accounting measure of accumulation captures that part of growth in income that is explained by growth in the stock of inputs in a growth accounting exercise. Capital gains correspond to the 
unexplained residual. Most growth accounting type exercises suggest that the technology residual is relatively large. For example, Kendrick (1976) estimates that a large fraction of the increase in per capita growth of output over the period 1929 to 1969 can not be accounted for by growth in a broadly defined set of tangible and intangible inputs to production. If technological change occurred at a uniform rate across countries, this would be of little import for the kind of cross-country comparative analysis undertaken here, but given our level of ignorance about this residual, this kind of argument should not offer much comfort.

This exercise may partially help explain why the estimates like the FRB measure of private savings that are based on balance sheet data differ from national income account estimates. Balance sheet data will pick up capital gains; national income account estimates do not. The problem is that the discrepancy seems too large to be explained entirely by the influence of capital gains. The FRB measure of savings in 1982 is \$296 billion, equal to 11 percent of NNP in that year. The personal saving rate from the BEA is only 5 percent, and the private saving rate is 6 percent (Hayashi, table 1). Even if all corporate savings in the BEA sense (e.g., undistributed profits) show up as capital gains for individuals and hence are captured in the FRB measure of savings by individuals, this leaves 5 percent attributable to true capital gains on tangible assets in a year that was not noted for the robust performance of asset markets.

Ultimately, the article focuses primarily on the behavior of national savings $S+B$ without making any correction for government capital accumulation. The choice seems to be based on a mixture of simple theory and the degree of confidence in the data. Personal savings is not used because it neglects the substantial differences between corporate savings behavior in the two countries. National savings is chosen over private savings on less clear grounds, but the qualitative behavior of these two series is similar. Government capital accumulation and capital gains are neglected, apparently because they cannot be measured with any accuracy.

There is clearly a limit to how much can be done in a study of this size to reconcile, evaluate, and correct official data. Hayashi's article does quite a lot, especially given that its main focus is on explaining the data, not uncovering them. Nonetheless, it is perhaps worth emphasizing how much room there is for improvement in the data and how much work remains to be done before we can confidently take them as given and use them to refine our theories. Reliable data on national income account savings and on the rate of accumulation of wealth that are internally consistent and consistent across countries would offer a far more complete picture of how rapidly different countries are accumulating, of 
how rapidly future consumption possibilities are expanding. Whether this kind of data would alter our perspective on relative rates of growth across different countries is an open question. In the comparison between the United States and Japan, it seems quite unlikely that such data would alter the perception that the Japanese are saving more and growing rich faster, although it could change our estimate of the magnitude of the difference. In a comparison between Western Europe and the United States, such a reversal could indeed take place. At the present time, policy discussions focus on the low rate of savings in the United States relative to Western Europe, with its ominous implications for low relative rates of growth and accumulation of wealth in the United States; and focus simultaneously on the contrast between robust employment growth in the United States and persistent stagnation in Europe. In the absence of better data, it seems highly unlikely that we will be able to use cross-country comparisons to learn anything useful about the major outstanding questions concerning the extent to which the government budgetary policies and transfer programs affect rates of accumulation and growth. The number of data points is too small and the amount of noise in the data too large.

Presumably there is some consistency to the way savings is calculated in each country, so that the time-series properties of official savings data are likely to contain useful information about the true behavior of accumulation. Thus, one can still ask why the private and national saving rates in Japan have fallen since 1970 . Given that there is fragmentary evidence that the saving rate in Japan during the 1950s and 1960s was also high relative to historical levels, one can also ask why it rose as it did.

The one piece of evidence about which there seems to be little room for dispute is that growth rates in postwar Japan have been astonishingly high. As is illustrated in Figure 1, the postwar growth rates are unprecedented in the prewar era. The figure plots the logarithm of an index of the level of real GDP for Japan and the United States, with the logarithm of each index equal to zero in 1885 . To give information about the levels, Figure 2 plots the ratio of total and per capita GDP in the two countries. Whether one uses total GDP or per capita GDP, growth in the two countries prior to World War II is very similar. If anything, growth in the United States is higher. Income in the two countries increases by virtually the same factor in the fifty years from 1885 to 1935; even then, Japanese growth catches up with growth in the United States only because Japan was not significantly affected by the slowdown in the first half of the 1930s. In the postwar period, Japanese growth is uniformly higher than U.S. growth, which continues at approximately its prewar rate. By 1960 , Japanese GDP had returned to the level that one would predict 
from an extrapolation of prewar levels using the prewar growth rate, but rapid growth continues for the next twenty years, slowing somewhat during the 1970s. From 1960 to 1978, the ratio of Japanese to U.S. per capita GDP doubles from roughly .35 to .70 .

Figure 3 plots the growth rates and the net national saving rate for Japan. The casual impression from this graph is that savings tracks the broad movements in GDP growth. Although the data in the article go back only to 1965, Albert Ando reports that a study done for the Bank of Japan (cited in Ando (1985)) indicates that savings in prewar Japan did not occur at the high postwar levels, and was not notably different from savings in other countries.

Taken together, this evidence suggests that the problem for theory is to explain why savings and growth are simultaneously high. One of the key contributions of Hayashi's article is to emphasize that in the context of the standard life-cycle model, the rapid growth rate cannot explain the

Figure 1 REAL GDP GROWTH, US AND JAPAN

Log of GDP index set to 0 for 1885

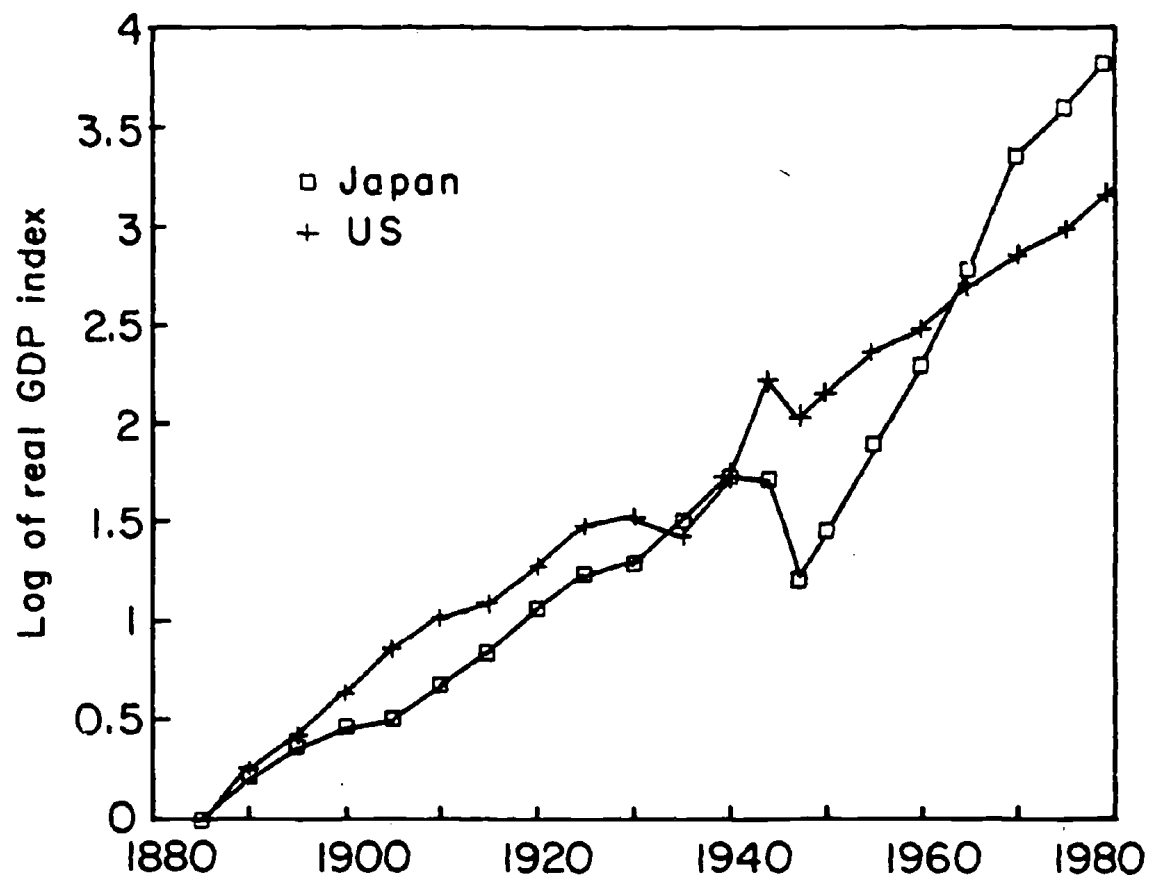

Raw data on GDP and prices for GDP comparisons are taken from Maddison (1982). Observations are taken every five years with two exceptions: observations for 1944 and 1947 are used in place of a 1945 data point, and 1979 is the last data point. 
saving rate. His simulations show that the late peak in the age-earnings profile in Japan should cause the life-cycle saving rate to decrease with the productivity growth rate. (Moreover, it should cause the saving rate to be lower than the rate in the United States.) Demographic changes also suggest that in contrast to the observed downward trend, savings in Japan should be higher in 1980 than in 1970.

The article takes an ambivalent attitude toward one possible explanation for the coincidence of high growth and high savings. Under the standard optimizing growth model, the positive response of the saving rate to interest rates causes a country with low capital, hence high interest rates, to grow faster. This is the basis for the usual convergence to a steady-state level or to a steady-state growth rate driven by exogenous technological change. This argument can not offer a complete explana-

Figure 2 RATIO OF JAPANESE TO US GDP Levels and Per Capita

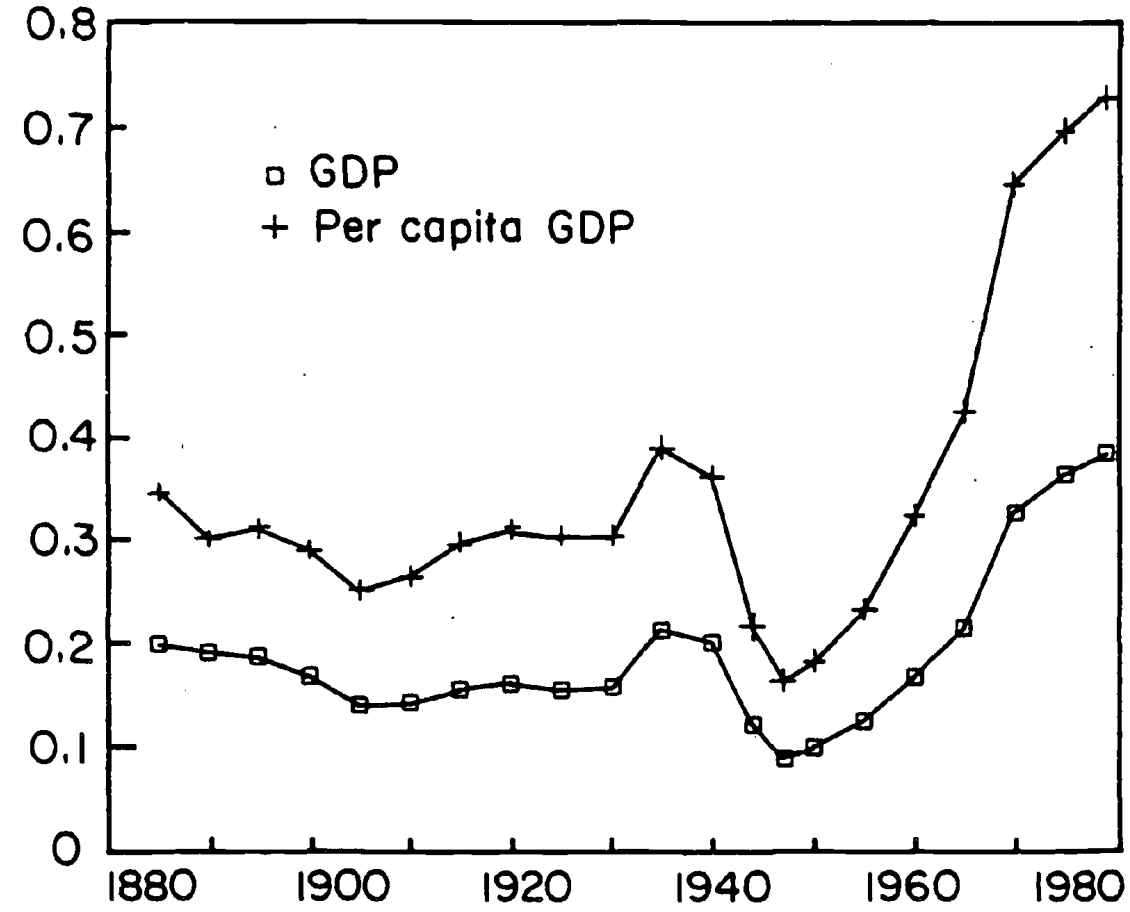

Raw data on GDP and prices for GDP comparisons are taken from Maddison (1982). Observations are taken every five years with two exceptions: observations for 1944 and 1947 are used in place of a 1945 data point, and 1979 is the last data point. 
tion for the rapid growth after the war because it should apply with even more force to prewar Japan, and for that matter to all other countries starting from low levels of per capita capital. Something else is needed to explain the postwar acceleration in growth. But given that it took place, it must be true that ex post returns to investment were quite high during the 1950s and 1960s, falling somewhat since then. Assuming that these returns were foreseen and that the degree of intertemporal substitution of consumption was sufficiently large, growth and savings would have moved together. Given enough intertemporal substitution, this should be true in a model with either dynastic families or with life-cycle individuals. Note that the entire postwar era is roughly the time in the labor force for a single individual.

Hayashi suggests the classical theory of diminishing marginal productivity as an explanation for the recent slowdown, but also notes that his Euler equation estimates imply a very low degree of intertemporal substitution. Since these estimates are based only on consumption of food,

Figure 3 GROWTH AND SAVINGS IN JAPAN 1965 to 1979

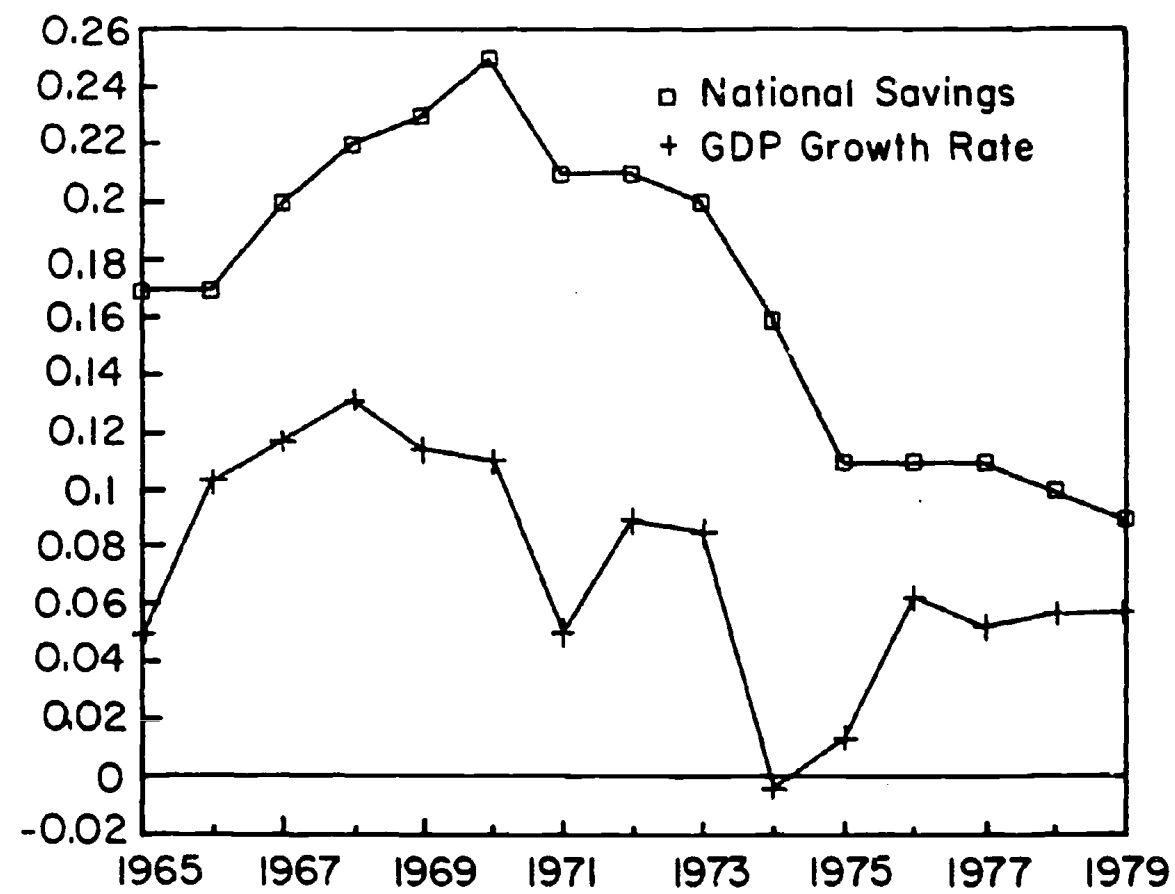

GDP data are from Maddison (1982). The saving rate is the national saving rate under the BEA conventions for government expenditure from table 1 in Hayashi (1986). 
for which intertemporal subtitution may indeed be quite small, this does not offer decisive evidence about the overall degree of intertemporal substitution in consumption. Moreover, estimates of this kind have to be treated with caution because in any overall test of its implications, the underlying model is typically rejected by the data.

In addition to the qualification that the saving rate must be responsive to the interest rate, this explanation for the behavior of savings requires that the high postwar rates of return and growth were foreseen. (Note that this assumption of foresight is also made in the steady-state simulations given in the article for the life-cycle model.) Given the unprecedented nature of growth during this period, this is a very strong assumption. By 1960, it should have been clear to even the most naive that things were going extremely well, but the relevant question was how long this could be expected to last. An alternative line of attack on this problem might be to consider the effect of a long string of positive surprises in rates of return and in the rate of growth of labor income in either a life-cycle or infinitely lived agent model. Under the usual form of additively separable preferences, the entire consumption profile increases immediately in response to positive wealth shocks. But any added element in preferences or any adjustment cost that causes an agent to want to smooth the rate of change of consumption as well as the level of consumption will imply that the rate of growth of consumption will lag behind the rate of growth of income, especially if current rates of growth are not expected to be sustained indefinitely.

In summary, whether or not one believes in dynastic families or lifecycle individuals, it is possible to argue that high growth rates in Japan were responsible for high saving rates. What seems to be crucial is not the form of intergenerational transfers, but rather the degree of foresight that can be presumed in this extraordinary period, and the nature of intertemporal preferences for an individual-that is, whether the saving rate is responsive to the rate of interest and whether there is any tendency toward smoothing in the rate of growth of consumption as well as in the level.

This conclusion is based on the premise that causality runs from growth to savings rather than vice versa. Given the enormous cultural and social changes that took place in postwar Japan, one cannot completely dismiss the possibility of an exogenous increase in the saving rate, but I find it difficult to offer an explanation for why it might have taken place. It also seems implausible that double-digit rates of growth can be explained simply by an exogenously high rate of saving. From 1950 to 1970, GDP and population in Japan grew at annual average compound rates of 9.5 percent and 1.1 percent per year respectively. Using 
estimates of the relative share of capital in total income ranging from $1 / 3$ to $1 / 4$, these growth rates imply that the net stock of capital in Japan had to grow at an average annual compound rate of between 25 and 30 percent per year; that is, by 1970, the stock of capital would have had to have increased to 150 times its level in 1950 . I suspect that a growth accounting exercise for postwar Japan would find a large residual.

In principle, one must also allow for the possibility that there is no direct causal relationship between the time path for saving and growth rates, each being the result of some third influence; or for the possibility that there is no causal relation at all. But I would find it quite surprising if postwar savings and growth in Japan were not intimately linked.

\section{REFERENCES}

Ando, A. 1985. The savings of Japanese households: A micro study based on data from the National Survey of Family Income and Expenditure. University of Pennsylvania. Mimeo.

Hayashi, F. 1986. Why is Japan's saving rate so apparently high. (this volume)

Kendrick, J. 1976. The formation and stocks of total capital. New York: NBER.

Maddison, A. 1982. Phases of capitalist development. Oxford: Oxford University Press.

\section{Discussion}

Fumio Hayashi, in responding to his discussants, expanded on the difference between intentional and accidental bequests; in his article, he argued that bequests were intentionally large. The rapid expansion of the social security system in 1973 provided some evidence on whether the finite-life life-cycle model holds. If parents are not altruistic, then increased social security benefits would lead them to increase their consumption. If the dynastic view of the family is a good approximation, the elderly should increase their saving. The data show little change in the saving rate of the elderly.

James Poterba suggested that the savings behavior of the elderly received too much attention. The major difference between savings behavior in Japan and the United States appears to be in the behavior of the young, not the old, and it is that difference that should be the focus of the study.

Takatoshi Ito argued that much of Japanese saving may be for catastrophic events, despite the fact that the saving rate changed little after the introduction of the social security system. People may not trust the social security system very much, since many believe it will ultimately 
go bankrupt; they may be saving for the day the social security system breaks down. Ito also commented that Hayashi dismissed the life-cycle hypothesis too quickly. Hayashi tested the steady-state implications of the life-cycle hypothesis, but the Japanese economy may not have been in a steady state. Another possible explanation of the high Japanese saving rate is the target wealth hypothesis. This would explain the high saving rate from 1973 to 1975 , since people have to increase their saving to maintain the target asset-income ratio in the presence of high inflation, which depreciates the assets. Finally, he questioned the validity of the data in the interest elasticity calculation. The nominal rate was regulated during the estimation period.

Lawrence Summers suggested cultural differences between Japanese and Americans as a possible explanation of the high saving rate in Japan. He cited a work based on survey data for Japanese-Americans by one of his students. The research showed that Japanese-Americans' saving rate is 5 percent higher than that of other groups, and that there is no systematic relation between the saving rate and the number of generations the Japanese-American has lived in this country. Albert Ando commented that the cultural difference explanation may not work, since the saving rate was not high in prewar Japan.

Martin Feldstein raised some questions. If the Japanese hide some of their assets for tax purposes using the Maruyu system, how honestly do they report the data in the survey used in Hayashi's article? How does the pattern of growth affect saving in the life-cycle hypothesis? What is the reason for the decline in national saving in Japan? For what purpose do Japanese accumulate bequests on the scale suggested by Hayashi?

Stephen Zeldes commented that the economy may exhibit altruistic characteristics even if not all of each bequest is intentional. He also pointed out that the current account deficit in Japan in the 1960s was consistent with an economy having effectively an infinite horizon: the low capital-output ratio in Japan meant that investment was highly profitable, so that investment may have driven the current account.

Paul Romer asked how one can reconcile the existence of systematic government transfers from the young to the old with the altruistic dynastic family view. 